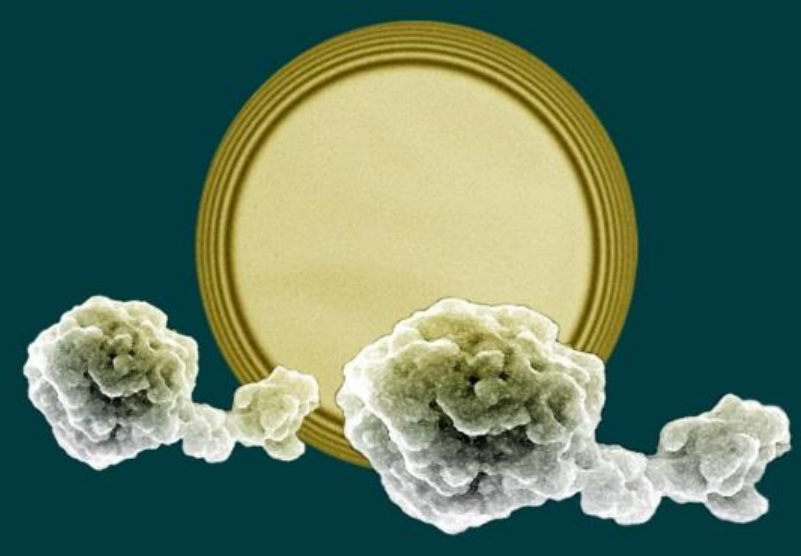

Min Chen

The role of casein micelles and their aggregates in foam stabilization 


\section{The role of casein micelles and their aggregates in foam stabilization}

Min Chen 


\section{Thesis committee}

\section{Promotors}

Prof. Dr E. van der Linden

Professor of Physics and Physical Chemistry of Foods

Wageningen University

Prof. Dr A.C.M. van Hooijdonk

Professor of Dairy Science

Wageningen University

\section{Co-promotors}

Dr M.B.J. Meinders

Senior Researcher

Wageningen Food and Biobased Research

Dr G. Sala

Researcher

Wageningen Food and Biobased Research

\section{Other members}

Prof. Dr J. van der Gucht, Wageningen University

Prof. Dr P. Fischer, ETH Zurich, Switzerland

Prof. Dr A. Kelly, University College Cork, Ireland

Dr P.A. Wierenga, Wageningen University

This research was conducted under the auspices of the Graduate School VLAG (Advanced studies in Food Technology, Agrobiotechnology, Nutrition and Health Sciences). 


\title{
The role of casein micelles and their aggregates in foam stabilization
}

\author{
Min Chen
}

Thesis

submitted in fulfilment of the requirements for the degree of doctor at Wageningen University

by the authority of the Rector Magnificus

Prof. Dr A.P.J. Mol,

in the presence of the

Thesis Committee appointed by the Academic Board

to be defended in public

on Monday $12^{\text {th }}$ of December 2016

at 1:30 p.m. in the Aula. 
Min Chen

The role of casein micelles and their aggregates in foam stabilization 140 pages.

$\mathrm{PhD}$ thesis, Wageningen University, Wageningen, NL (2016)

With references, with summary in English

ISBN 978-94-6257-984-2

DOI $10.18174 / 393613$ 


\begin{abstract}
Many foam products derived from milk or specific dairy ingredients suffer from drainage, coalescence and/or disproportionation. Previous studies indicated that foam properties of milk are strongly influenced by the composition of the milk as well as by the processing conditions during foam production. The aim of this research was to get a better understanding of these two factors. Interestingly, the presence of aggregates of casein micelles was found to result in very stable foams. The interfacial properties (adsorption speed, adsorption energy, dynamical interfacial tension, interfacial dilatational moduli), thin film stability (rupture time) and foam properties (foamability, drainage, coalescence) of casein micelle dispersions were determined. Based on these data, the very stable foams were concluded to result from properties of the thin films in the foam, which were affected drastically by the presence of the large aggregates of casein micelles.
\end{abstract}


Learn \& Grow

致我的父母 


\section{Table of Contents}

Chapter 1

General introduction

Chapter 2

Particle size determines foam stability of casein micelle dispersions

Chapter 3

Interfacial properties, thin film stability and foam stability of casein micelle dispersions

\section{Chapter 4}

Mechanism of ultra-stabilization of foam by casein micelle aggregates

Chapter 5

Foam properties of $\beta$-casein and silica particle mixtures: the influence of particle size and concentration

Chapter 6

General discussion

Summary

Acknowledgements

About the author 



\section{Chapter 1}

General introduction 


\section{Chapter 1}

\subsection{Introduction}

Consumers like aerated foods or foams. A problem of these products is that many are unstable and suffer from drainage, coalescence and/or disproportionation. Despite the enormous research that has been performed on the formation and stability of foams, there are still important issues to be solved. This especially concerns the role of surface and bulk components in complex food systems on the formation and stability of foams. Various studies have been performed on the formation and stability of dairy foams [1-10]. Results indicated that foam properties of milk are strongly influenced by the composition of the milk as well as the processing conditions during foam production [8]. However, the role of the different components in milk on the formation and stability of foams is still not well understood. The aim of this research was to get better understanding of the role of the milk components in milk foam behaviour and to use this understanding to better control dairy aerated products. Hereto, milk was first decomposed into key ingredients that control the formation and stability of milk foam. Special focus was on the influence of proteins, lipids (phospholipid, diglycerides and free fatty acids) in milk. Casein micelles, the main protein reservoir in milk, which is also a natural nanogel particle, stand out. As a preliminary finding we observed that certain processing conditions improved the stability of milk foam to a large extent. In particular, casein micelles dispersions were hypothesised as one of the key factors in this observation. Therefore, casein micelle dispersions were taken as a model system for the study. Research was conducted on casein micelle dispersions regarding interfacial properties (adsorption speed, adsorption energy, dynamical interfacial tension, interfacial dilatational moduli), thin film stability (rupture time) and foaming properties (formability, drainage, coalescence) to uncover the stabilization mechanism. Finally these findings were tested in a model system simulating casein micelle dispersions to get better insights on foam stabilization with particles in complex system. In this chapter, we first shortly address the theory of foam stabilization in general and then give a more detailed review of foams stabilized with complex system of particles mixed with proteins or surfactants. In the final part we present the outline of the thesis. 


\subsection{Foams}

Foams are metastable colloidal systems that consists of two phases, a continuous liquid phase surrounding a disperse gas phase. The thin film separating two bubbles is called lamella or film. The thicker channels where three lamella meet are Plateau borders (Figure 1-1). The basis of foam formation is the insertion of gas bubbles into a liquid phase [11]. Foams do not form spontaneously. Energy is required to disperse the gas in the liquid. Foams can be prepared using various methods like sparging, gas injection, agitation, and super saturation etc. [8]. When new bubbles are formed, energy is needed to create the air/water surface. Foams are therefore instable and tend to coalesce and disproportionate to minimize the air/water surface area [12] [13]. Depending on the liquid fraction, foams can be divided into wet foams and dry foams $\left(\Phi_{l} \leq 0.02\right)[14]$.

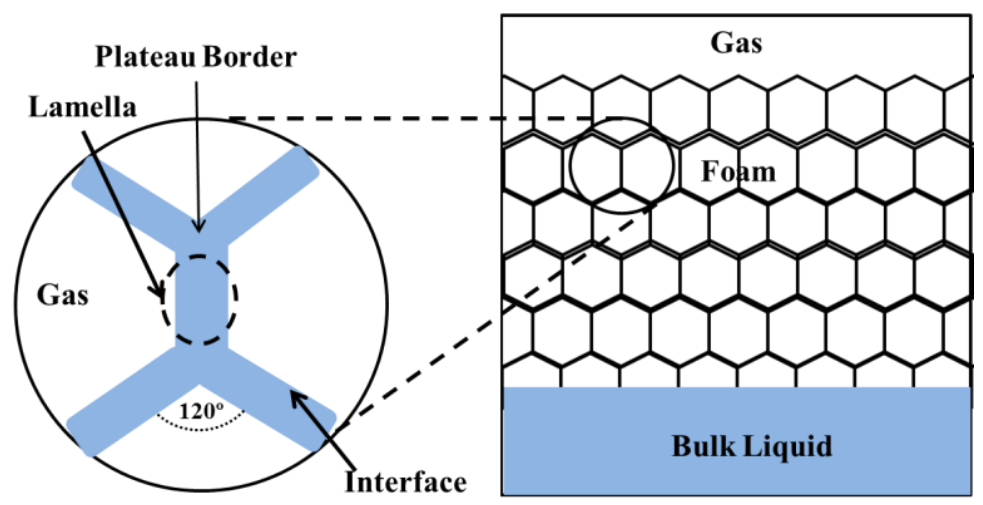

Figure 1-1. Schematic representation of foam structure redrawn after [15].

\subsection{Foam instability}

Foam instability is caused by liquid drainage, bubble coalescence and disproportionation. After foam formation, foam consists of spherical air bubbles that are separated by the continuous phase. Liquid drainage starts immediately due to gravity [2]. After a certain time, sufficient amount of liquid drains out and bubbles come into contact, allowing deformation of bubbles into polyhedral. Liquid will drain out from the lamella into the Plateau borders due to capillary suction. At a certain thickness the film can rupture, leading to bubble coalescence, which results in formation of larger bubbles, smaller total interfacial area and reduction in bubble number [8]. As a matter of fact, bubble coalescence also occurs during foam formation and this process is greatly affected by the adsorption of surface active molecules. Faster adsorption of these molecules leads to the formation of more stable films and thus minimizing coalescence during foam formation, creating foam with smaller bubbles [16]. Together with drainage and coalescence, disproportionation (Oswald ripening) also takes place after foam formation. This is a process of gas transfer 


\section{Chapter 1}

from small to large bubbles (through the lamella) due to differences in Laplace pressure. As a result, small bubbles disappear, while large ones become larger. Disproportionation can be slowed down by minimizing the polydispersity of the bubbles, by using gas with low solubility in the continuous phase (i.e. using $\mathrm{N}_{2}$ instead of $\mathrm{CO}_{2}$ ) [8], or by formation of an elastic protein layer [17].

\subsection{Liquid film rupture and coalescence}

\subsubsection{Interaction between two interfaces}

During foaming, surfactants adsorb at the surface of air bubbles. When two bubbles meet, the forces between the two interfaces are crucial to understand the stability of the thin liquid film. The forces include the London-van der Waals forces and the electrostatic forces, which results repulsion when the interfaces are equally charged. Besides, there may be other forces involved like hydration forces, steric repulsion forces and supramolecular forces due to the presence of organized structures in the film like micelles and their confinement in the films. For proteins, adsorbed polymers and solid particles adsorbed at an interface, steric repulsion is observed at a thickness of several hundreds of nanometers, which could be either homogeneous or non-uniform. These forces are normally expressed per unit area and called the disjoining pressure.

\subsubsection{Film thinning and rupture}

The curvature of the Plateau border is larger than that of the film so that the hydrodynamic pressure in the film is larger than in the Plateau borders. This causes the suction of liquid from the film into the adjacent Plateau borders, which is called capillary suction. Film thinning occurs. In order for a flat film to exist at equilibrium, it is necessary that, in addition to the liquid pressure, $\mathrm{p}$, there is a positive disjoining pressure, $\Pi$, which balances the gas pressures and resists the suction from the Plateau borders. At equilibrium, the disjoining pressure is equal to the capillary pressure $P_{c}, \Pi=P_{c}=\frac{\gamma}{r}$, where $\mathrm{r}$ is the radius of curvature of the Plateau border, which depends on the bubble diameter and the liquid fraction, and $\gamma$, the interfacial tension.

The lamella can be studied using a Scheludko cell [18-20]. The thickness of the film, h, could be measured using interference and calculated as described in equation [21]:

$$
h=\frac{\lambda}{2 \pi n} \sin ^{-1}\left(\sqrt{\frac{I-I_{\min }}{I_{\max }-I_{\min }}}\right)
$$

Where $\lambda$ is the wavelength of the light (we used $\lambda=546 \mathrm{~nm}$ ), $\mathrm{n}$ is the refractive index of the film, $I$ is the intensity of the reflected light, and $I_{\min }$ and $I_{\max }$ are the minimum and maximum intensities, respectively.

A film with thickness in the range 10 to $80 \mathrm{~nm}$ is called a common black film (CBF). A film under a greater capillary pressure may equilibrate in a so called Newton black film 
(NBF). Generally the film is approximated by a circular horizontal film of radius R. Its thinning velocity is expressed as $v_{R e}=-d h / d t$. Besides film thinning, oscillations of the interfaces of a film generated by mechanical or thermal perturbations sometimes cause film rupture. Ivanov [22] and Vrij et al.[23] have shown that there is a critical film thickness for film rupture.

\subsubsection{Coalescence of foam}

Foam can disappear via a succession of film ruptures: coalescence. The bubble films at the top of foam are most susceptible to rupture: they are the thinnest due to drainage, the most curved and they evaporated the most quickly and subject to external perturbations. Thus foam often collapses from the top. The liquid fraction of foam depends on the height.

\subsection{Foaming agents}

Foaming agents includes all kinds of low molecular weight surfactants, proteins, colloidal particles. Milk proteins are widely used in aerated products. Milk mainly contains caseins (four kinds of phosphoproteins: $\alpha_{\mathrm{S} 1}, \alpha_{\mathrm{S} 2}, \beta, \kappa$ ), organized in casein micelles (colloidal particles), and whey proteins. Amphiphilic surfactants like caseins [24], sodium caseinates [25] and $\beta$-lactoglobulin [26] can adsorb fast and stabilize the air/water interface by forming a relatively strong elastic interfacial layer. Casein micelles, natural food nano-gel particles, function as the main emulsion stabilizing component of homogenized milk.

\subsubsection{Physicochemical properties of casein micelles}

Casein micelles is natural nanoparticles present in milk with a diameter of 50 to $500 \mathrm{~nm}$ and average size of $150 \mathrm{~nm}$, which account for about $2.8 \%$ of the dry matter content take up $10 \%$ of volume of milk. The dry matter of casein micelles contain up to $94 \%$ of protein and the remaining $6 \%$ is composed of low molecular mass compounds, mainly inorganic salts of calcium phosphates called colloidal calcium phosphate (CCP). Casein micelles are highly hydrated and have a voluminosity of $4.4 \mathrm{~cm}^{3} / \mathrm{g}$ protein $[27,28]$. The morphology of casein micelles is shown in Figure 1-2. The structure of casein micelle have been extensively studied and still under debate, and several models have been proposed for it: (i) sub micelle model, (ii) nanocluster model, and (iii) dual binding model [29]. In a review [30], it is proposed that casein micelles can be seen as large spherical complexes with a sponge-like structure. The interior part consists of linked $\mathrm{CCP} /$ calcium nanocluster, while the surface is covered with the hairy $\kappa$-casein layer, providing a steric stabilization to the micelles and preventing them to approach each other. 


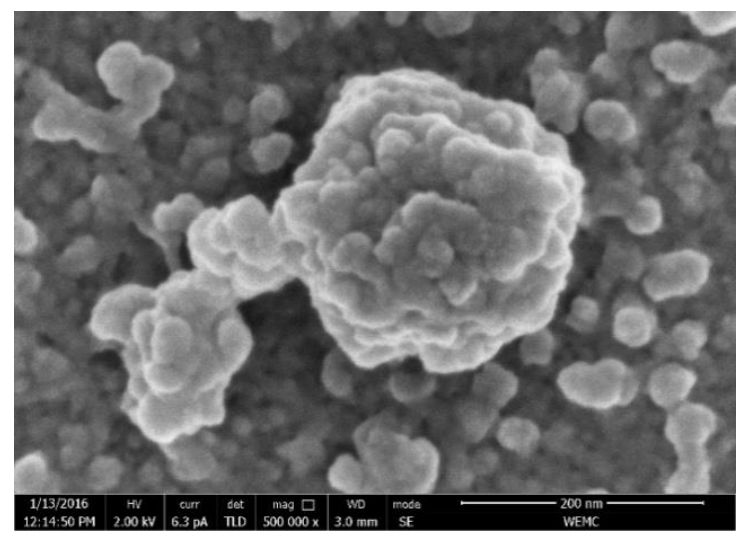

Figure 1-2. SEM image of casein micelles studied in this thesis.

\subsubsection{Role of casein micelles in stabilizing milk foam}

Casein micelles can be prepared from skim milk by ultracentrifugation. Considering the molecular weight (around $10^{8} \mathrm{Da}$ ) of casein micelles, centrifugation is sufficient to sediment most of the casein micelles in milk (90-95\%). The redispersion of casein micelle pellets is temperature dependent [31]. Pellets can be redispersed in a milk permeate without changing the original properties of the micelles [9, 32] or, depending on redispersion conditions like temperatures and times, casein micelle dispersions (CMDs) with different particle properties like size distribution of the casein micelles or their aggregates can be obtained. Previous research studied casein micelles in skim milk samples $[3,4,6]$ and the influence of heat treatment, temperatures [9], $\mathrm{Ca}^{2+}$ chelating agents [33], $\mathrm{pH}$ [34] and ionic strength [4] on their foaming properties. An interesting finding [9] is that micellar casein fraction exhibited higher foam stability compared with low-heated skim milk. Casein micelles seem to play an important role in the dairy foam stabilization. Microscopic images of bubble ghosts of milk foam suggested that casein micelles can be adsorbed at the air/water interface [35], possibly in a reversible way [1]. However, Borcherding et al. [6] indicated that casein micelles are not likely to be present at the air/water interface. Due to the complex composition of CMDs, which contain individual caseins, casein micelles, possibly small amount of casein-derived peptides, it remains unclear whether the casein micelles actually lead to changes in interfacial properties that result in better foaming properties. Further research needs to be performed in order to establish a quantitative correlation between interfacial properties, thin film characteristics and foam stability of CMDs. Since it is reported that the presence of protein aggregates could either improve or decrease the foam stability of protein solutions [36], inducing aggregates into CMDs makes the system even more complex and therefore foaming behaviour more complicated.

\subsection{Foams stabilized by mixed system of protein and aggregates}


Protein aggregates could be made by heat-treatment induced fibrillization, denaturation of proteins and gelation [36] [37-39] [40]. Also, complexes can be formed by electrostatic attraction of two ingredients [41]. Previous research has shown that the presence of aggregates can have a large influence on foam stability of protein solutions [42]. Whey protein aggregates $[36,37,43]$, soy protein aggregates $[44,45]$ whey protein fibrils $[38,46]$ and whey protein microgel $[47,48]$ were shown to be advantageous for foam stabilization, while other studies indicated that protein aggregates can also decrease foam stability [41, 43]. The aggregate size resulting in higher foam stability varied for different aggregated materials and their structure [41, 43]. There seems to be an optimal particle size for aggregates to stabilize foam and this optimal size is system-related, ranging from tens of nanometers to a few micrometers. A recent review reported improved foam stability in the presence of protein aggregates without causing significant differences in the interfacial properties of the air/water interface [49]. However, the dilatational properties were determined only at small deformations and constant frequency, and no large amplitude dilatations, which are more sensitive to subtle changes in the microstructure of the interface, were performed. Ultrastabilization of foams with particles or protein aggregates is mostly ascribed to a final jamming or gelled network formed in the lamella and/or plateau borders [41, 42, 50-52]. A correlation between thin film stability and the foam stability has been reported [50, 51]. According to Rullier et al. [53] [43, 50], the thin film stability is dependent on the aggregate size and on the ratio between non-aggregated proteins and protein aggregates. The mobility of aggregates at the film surface was found to be crucial for film stability. A gel-like network formed within the foam film was interpreted from the immobility of aggregates on the film surface. Saint-Jalmes et al. (2005) [51] investigated a CMD with a particle size range between $50 \mathrm{~nm}$ and $300 \mathrm{~nm}$. These casein aggregates appeared as thick spot-regions of a few microns within the thin film. The mentioned group also indicated that an increase in concentration of the casein aggregates yielded higher film stability. However, the reason why casein micelle aggregates get trapped in the film remains unknown. No explanation was given on formation of these casein aggregates with normal casein micelles within size range of $300 \mathrm{~nm}$ in the initial sample. The effective concentration of aggregates accounted for improved foam stability is not well quantified. For large casein micelle aggregates, there is still no direct proof on the gel network formation by these aggregates in the foam lamella. Besides, the optimum size of casein aggregates for foam stabilization, the location of these aggregates regarding different particle size and particle concentration is unknown and need further research. Table 1-1 give an overview of recent research on foams of systems containing aggregates.

\subsection{Foams stabilized by particles}

Besides protein aggregates, foams stabilized by food particles [41, 42, 46, 54-58] have received considerable attention recently. Foam stabilization by solid particles is an extensively studied topic $[42,59]$. Compared to irregular protein aggregates, particles are 


\section{Chapter 1}

often better designed and can be used as elements of complex systems for foam study. The important physical properties of particles for foam stabilization include contact angle, size, shape, and concentration [59]. Depending on surface properties, particles can be divided into adsorbing particles and non-adsorbing particles. Completely hydrophilic particles do not adsorb at air/water interface neither stabilize the foam [60]. Partially hydrophobic particles with contact angle, $\theta$, close to $90^{\circ}$ can act as a foam stabiliser, whereas very hydrophobic particles $\left(\theta>90^{\circ}\right)$ act in the opposite way and are used as antifoams through a bridging de-wetting mechanism [59]. The particle hydrophobicity could be modified by appropriate chemical synthesis [61, 62] or after dispersing them in the aqueous phase and adjusting the salt concentration [63]. Hydrophobic particles can be accomplished through the adsorption of appropriate amphiphilic compounds on the surface of hydrophilic particles [57]. The surface roughness of the particle could also influence their contact angle since it could lead to a 'non-equilibrium' wetting characteristic of the particles. Kaptay (2003) indicated that there is a maximum regarding particle size for foam stabilization with particles [64] and explained the importance of particle size on film and foam stabilization.

The role of particles in thinning and stability of the aqueous films separating the bubbles is crucial for the coalescence and foam collapse. Depending on the contact angle of particles, two cases for particle location can be considered: (i) the particles are attached to the film surfaces; (ii) the particles are present only inside the film but not at its surfaces [59].

In the first case, it is reported that the mobility of particles at the film surfaces plays a very important role in the film stabilisation by solid particles. According to Vinaldini et al. (2013), the interfacial stability of foam stabilized by particles is defined as:

$$
\text { Interfacial Stabiliy }=\frac{\Delta G_{a d s}}{k_{B} T}=\frac{\text { Adsorption Energy }}{\text { Thermal Energy }}
$$

Where $\Delta G_{a d s}$ is the adsorption energy of the particles, which could be calculated according to equation:

$$
\Delta G_{a d s}=\pi R^{2} \gamma_{A W}(1 \pm \cos \theta)^{2}
$$

Where $\gamma_{A W}$ is the air/water interfacial tension $(\mathrm{mN} / \mathrm{m})$ and $\mathrm{R}$ is the particle radius $(\mathrm{m}), \theta$ is the contact angle of the particles on the air/water interface. When the adsorption energy of particles $\left(\Delta G_{a d s}\right)$ is lower or just above the thermal energy $\left(k_{B} T\right)$, foam of particles cannot be formed because of an unstable air/water interface. Other research also indicate that surface irregularities (for instance the aggregation patterns of particles at the interface) can also influence the stability of air/water interface depending on the surface coverage of the particles [65] and the interaction between them [66-68]. For films with diluted particle at the surfaces, there is a hydrodynamic liquid flow inside the film due to drainage. Particles in dilute monolayers cannot resist the flow and are dragged away from the film centre, 
leaving the centre and thinnest part of the film unprotected and vulnerable to rupture [69]. However, films with close-packed particle monolayers at their surfaces behave differently from those with dilute monolayers. Close packed particle monolayers at the film surfaces can oppose the drag, thus slowing down the film thinning and preventing the film rupture. The films of partially hydrophobic particles with contact angles around $65^{\circ}$ and smaller than $90^{\circ}$ were found to be optimal for foam stabilization [70-72]. This is the so called Pickering stabilization of foams by particles, which has been reported in several recent studies [73-77].

In the second case, when the particles are present only inside the film, a stable bilayer of particles or a bridging monolayer is formed at the final stage of thinning. Stratification of particles in the films could be visualized in this case [78, 79]. Further suction of liquid out of the meniscus becomes impossible. Alternatively, as shown in Figure 1-3, if the particle rearrangement during bilayer-monolayer transition is difficult due to strong cohesion, a void (crack) could be formed inside the bilayer, then the film breaks due to the rupture of the unprotected region [80].

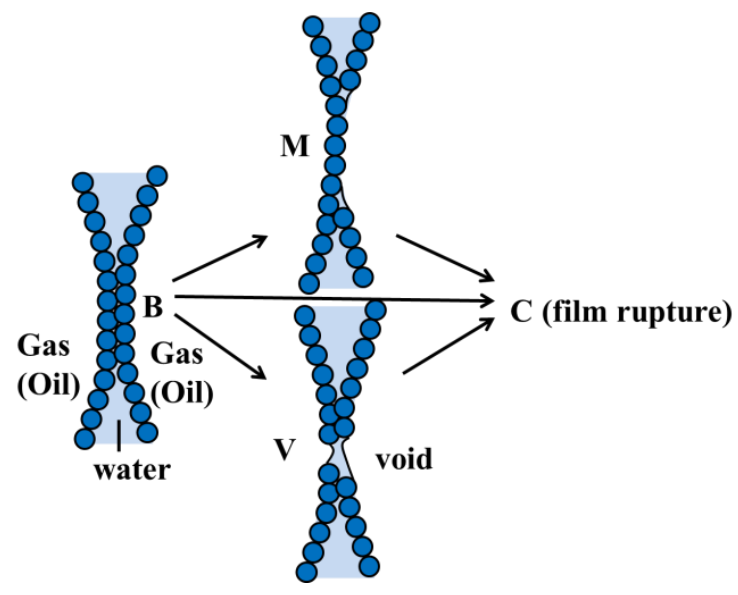

Figure 1-3. Possible mechanisms of rupture of a water film stabilized by a bilayer of particles: (B-C) direct rupture without rearrangement of the particles, (B-M-C) via bilayerto monolayer transition and $(\mathrm{B}-\mathrm{V}-\mathrm{C})$ via void formation redrawn after [59].

Besides the two cases described above, another mechanism of foam film stabilisation is due to the presence of particle aggregates inside the films. It occurs either when the excess particles in the bulk aqueous phase are flocculated and form three dimensional networks (gel) or if a sufficient amount of particle aggregates with an appropriate size get trapped and confined in the thin liquid films. This mechanism has been used to explain the high stability of particle-stabilised foams and bubbles reported recently [52, 61, 81-85]. In summary, the mechanism of foam stabilization by particles is different depending on the 


\section{Chapter 1}

physical properties of studied particles and the interaction between particles and other coexisting components in the system.

Silica $\left(\mathrm{SiO}_{2}\right)$ is one of the widely used spherical inorganic particles [61]. Silica particles are negatively charged at $\mathrm{pH}$ above isoelectric point ( 2 to 3 ) due to the dissociation of surface silanol groups $(\mathrm{Si}-\mathrm{OH})$ [86]. At neutral $\mathrm{pH}$, unmodified silica particles are completely hydrophilic and cannot go to the air/water interface to stabilize foam [61]. Foaming behaviour of silica can be controlled by surface modification of particles, i.e. with different amount of $\mathrm{SiOH}$ on the particle surface. Table 1-2 gives an overview of foam studies of modified silica particles. Foams of chemically modified silica particles have been intensively studied. For pure particles, modified particles with intermediate hydrophobicity exhibited the best foam stabilization. More recently research has been focussed on foams of silica modified by adsorption of amphiphiles on particle surface, for instance silica particles modified by SDS [87] and hexylamine [88]. In these particle-amphiphile systems, the foaming behaviour becomes more complicated depending on the ratio between particles and amphiphiles. Below a certain concentration of amphiphiles, bulk aggregation of particles occurred [89]. It is reported that $\beta-\mathrm{CN}$ could attach to the surface of silica [90]. In this project, three hydrophilic silica with three seizes were used, $200 \mathrm{~nm}, 1 \mu \mathrm{m}$ (both nonporous and well spherical) and $3 \mu \mathrm{m}$ (porous and roughly spherical with some irregularities). Particles modified with $\beta-\mathrm{CN}$ were expected to have a similar surface charge and hydrophobicity compared to that of casein micelles. This is also why the foaming behaviour of $\beta-\mathrm{CN} /$ silica system was investigated and compared to that of CMDs in this project. 
Table 1-1. An overview of studies on foams of systems containing aggregates.

\begin{tabular}{|c|c|c|c|c|c|c|c|c|c|}
\hline System & $\begin{array}{l}\text { Formation of } \\
\text { aggregates }\end{array}$ & $\begin{array}{l}\text { Aggregates } \\
\text { size }\left(\mathbf{R}_{A}\right)\end{array}$ & $\begin{array}{l}\text { Concentration } \\
\text { of aggregates } \\
\left(\mathrm{C}_{\mathrm{A}}\right)\end{array}$ & Charge & $\begin{array}{l}\text { Foam } \\
\text { stability }\end{array}$ & $\begin{array}{l}\text { Bulk } \\
\text { properties }\end{array}$ & $\begin{array}{l}\text { Interfacial } \\
\text { properties }\end{array}$ & $\begin{array}{l}\text { Thin film } \\
\text { stability }\end{array}$ & Ref \\
\hline $\begin{array}{l}\beta-\mathrm{Lg} \\
\text { with/without } \\
\text { aggregates }\end{array}$ & $\begin{array}{l}\text { Heat } \\
\text { treatment }\end{array}$ & $30-200 \mathrm{~nm}$ & $1-10 \mathrm{~g} / \mathrm{L}$ & $\mathrm{pH} 7.0$ & $\begin{array}{l}\mathrm{R}_{\mathrm{A}}<100 \mathrm{~nm}(+) \\
\text { When } \mathrm{R}_{\mathrm{A}}>100 \mathrm{~nm}, \\
\mathrm{C}_{\mathrm{A}}: \leq 90 \%(+)\end{array}$ & & $\begin{array}{l}\mathrm{R}_{\mathrm{A}}=197 \mathrm{~nm} \\
(\Pi=0 \mathrm{mN} / \mathrm{m})\end{array}$ & $\begin{array}{l}\text { Size } \mathrm{R}_{\mathrm{A}}, \\
\text { ratio } \\
\text { between } \\
\mathrm{A} / \mathrm{NA}\end{array}$ & $\begin{array}{l}{[43,} \\
53, \\
91]\end{array}$ \\
\hline $\begin{array}{l}\text { Aggregated } \beta- \\
\text { lactoglobulin }\end{array}$ & $\begin{array}{l}\text { Heat } \\
\text { treatment }\end{array}$ & $3-1000 \mathrm{~nm}$ & $10 \mathrm{~g} / \mathrm{L}$ & $\begin{array}{l}\mathrm{pH} 6.8- \\
8.0 \\
\mathrm{I}=0-130 \\
\mathrm{mM}\end{array}$ & $\begin{array}{l}(+) R_{A}=1000 \mathrm{~nm} \\
\text { No link to } \\
\text { Interfacial } \\
\text { properties }\end{array}$ & Dynamic $\eta$ & $\begin{array}{l}\text { П, E'\&E'” } \\
\text { Slower } \\
\text { protein } \\
\text { adsorption } \\
\text { with larger } \\
\mathrm{R}_{\mathrm{A}}\end{array}$ & & [37] \\
\hline $\begin{array}{l}\text { Whey protein } \\
\text { Aggregates }\end{array}$ & $\begin{array}{l}\text { Heat } \\
\text { Treatment }\end{array}$ & $50-330 \mathrm{~nm}$ & $1 \mathrm{~g} / \mathrm{L}$ & $\begin{array}{l}\mathrm{pH} 6.0- \\
7.0 \\
\mathrm{I}=0-120 \\
\mathrm{mM}\end{array}$ & $\begin{array}{l}(+) \mathrm{pH}>6.6, \mathrm{I}>70 \\
\mathrm{mM}\end{array}$ & & П, Е'\&Е'” & & [36] \\
\hline Casein & & $50-300 \mathrm{~nm}$ & $0.03-1 \mathrm{~g} / \mathrm{L}$ & pH 5.6 & & & $\begin{array}{l}\Pi(\mathrm{t}=3 \mathrm{~s}) \leq 20 \\
\mathrm{mN} / \mathrm{m}\end{array}$ & $\begin{array}{l}+(+) \mathrm{C}_{\mathrm{A}} \\
\text { dependent }\end{array}$ & [51] \\
\hline Casein micelles & $\begin{array}{l}\text { Redispersion } \\
\text { of } \\
\text { casein pellet }\end{array}$ & $\begin{array}{l}500-5000 \\
\mathrm{~nm}\end{array}$ & $0.6-50 \mathrm{~g} / \mathrm{L}$ & $\mathrm{pH} 6.7$ & $\begin{array}{l}\text { (+) } \mathrm{C}_{\mathrm{A}} \text { dependent, } \\
\text { no link to Interfacial } \\
\text { properties }\end{array}$ & $\begin{array}{l}\eta \text { slightly } \\
\text { increased with } \\
C_{A}\end{array}$ & $\begin{array}{l}\Pi(\mathrm{t}=1 \mathrm{~s} \& 60 \\
\mathrm{s}) \leq 25 \mathrm{mN} / \mathrm{m}, \\
\mathrm{E}^{\prime} \& \mathrm{E}^{\prime},\end{array}$ & & [92] \\
\hline $\begin{array}{l}\text { Soy (11S) } \\
\text { fibril-peptide } \\
\text { system }\end{array}$ & $\begin{array}{l}\text { Heat-induced } \\
\text { fibrillar } \\
\text { aggregates }\end{array}$ & $\begin{array}{l}\text { Height: a } \\
\text { few } \\
\text { nanometers } \\
\text { Length: } 2.3 \\
\mu \mathrm{m}\end{array}$ & $1.0 \mathrm{~g} / \mathrm{L}$ & $\mathrm{pH} 7.0$ & $\begin{array}{l}(+) \text { no link to } \\
\text { Interfacial } \\
\text { properties }\end{array}$ & & $\begin{array}{l}\text { Nonlinear } \\
\text { Surface } \\
\text { Dilatational } \\
\text { Rheology }\end{array}$ & & [38] \\
\hline $\begin{array}{l}\text { Whey proteins } \\
\text { (globular } \\
\text { aggregates and } \\
\text { fibre) }\end{array}$ & $\begin{array}{l}\text { Heat-induced } \\
\text { denaturation } \\
\text { and } \\
\text { fibrillization }\end{array}$ & $\begin{array}{l}\text { Height: } 2-3 \\
\text { nm } \\
\text { Length: } 15 \\
\mu \mathrm{m}\end{array}$ & $20 \mathrm{~g} / \mathrm{L}$ & $\begin{array}{l}\mathrm{pH} 7.0 \\
\mathrm{pH} 2.0\end{array}$ & (+) Slower drainage & & & & [39] \\
\hline $\begin{array}{l}\text { Protein/pectin } \\
\text { complexes }\end{array}$ & $\begin{array}{l}\text { Electrostatic } \\
\text { attraction }\end{array}$ & $\begin{array}{l}200-500 \mathrm{~nm} \\
\text { or }>1500 \\
\mathrm{~nm}\end{array}$ & $0.1-5 \mathrm{~g} / \mathrm{L}$ & $\begin{array}{l}\mathrm{pH} 7.0 \\
\mathrm{I}=25 \mathrm{mM} \\
\& 148 \\
\mathrm{mM}\end{array}$ & $\begin{array}{l}\mathrm{C}_{\mathrm{A}} \text {, ionic strength, } \\
\mathrm{R}_{\mathrm{A}} \\
200-500 \mathrm{~nm}(+) ; \\
1500 \mathrm{~nm}(-)\end{array}$ & $\begin{array}{l}\text { Free proteins } \\
\text { or } \mathrm{R}_{\mathrm{A}}\end{array}$ & $\Pi$ & & [41] \\
\hline $\begin{array}{l}\text { Whey protein } \\
\text { micro gels }\end{array}$ & $\begin{array}{l}\text { Heat } \\
\text { treatment }\end{array}$ & $\begin{array}{l}270-6000 \\
\mathrm{~nm}\end{array}$ & $50 \mathrm{~g} / \mathrm{L}$ & pH 5.0 & $\begin{array}{l}\text { (+) Slower drainage } \\
\& \text { less } \\
\text { disproportionation }\end{array}$ & $\begin{array}{l}\text { Intrinsic } \eta(10 \\
\mathrm{mL} / \mathrm{g}) \\
\text { Self- } \\
\text { aggregation at } \\
\text { IEP }\end{array}$ & & & [40] \\
\hline $\begin{array}{l}\text { Whey protein } \\
\text { fluid gels }\end{array}$ & $\begin{array}{l}\text { Heat induced } \\
\text { gelation }\end{array}$ & $10^{3}-10^{6} \mathrm{~nm}$ & $50 \mathrm{~g} / \mathrm{L}$ & $\begin{array}{l}\mathrm{pH} 5.0 \& \\
8.0\end{array}$ & $\begin{array}{l}(+) \text { larger } R_{A}, \\
\text { link to bulk an } \\
\text { interfacial properties }\end{array}$ & $\begin{array}{l}\mathrm{pH} 5.0 \rightarrow 8.0, \\
\text { higher local } \\
\text { bulk viscosity }\end{array}$ & $\begin{array}{l}\text { pH5.0 } \rightarrow 8.0, \\
\text { higher E'\&E", }\end{array}$ & & [47] \\
\hline
\end{tabular}

- A: aggregates;

- NAP: non-aggregated protein

- I: Ionic strength;

- IEP: isoelectronic $\mathrm{pH}$ 


\section{Chapter 1}

Table 1-2. An overview of studies on foams of hydrophilic/hydrophobic particles.

\begin{tabular}{|c|c|c|c|c|c|c|c|c|c|c|}
\hline System & $\begin{array}{l}\text { Surface } \\
\text { Modification }\end{array}$ & \multicolumn{2}{|c|}{$\begin{array}{l}\text { Particle } \\
\text { Size }\left(\mathbf{R}_{\mathbf{p}}\right)\end{array}$} & $\mathrm{C}_{\mathrm{p}}$ & $\begin{array}{l}\theta \text { (Surface } \\
\text { Charge) }\end{array}$ & $\begin{array}{l}\text { Foam } \\
\text { ability }\end{array}$ & $\begin{array}{l}\text { Foam } \\
\text { stability }\end{array}$ & $\begin{array}{l}\text { Interfacial } \\
\text { properties }\end{array}$ & $\begin{array}{l}\text { Bulk } \\
\text { properties }\end{array}$ & Ref \\
\hline Silica & $\mathrm{pH}$ & \multicolumn{2}{|c|}{$5-40 \mathrm{~nm}$} & $\begin{array}{l}10- \\
150 \\
g / L\end{array}$ & pH 2-12 & $\begin{array}{l}(+) \text { at } \\
\mathrm{pHpzc}, \\
(-) \\
\mathrm{pH} \uparrow, \\
(-) \\
\mathrm{R}_{\mathrm{p}} \uparrow \\
(+) \\
\mathrm{C}_{\mathrm{p}} \uparrow\end{array}$ & $\begin{array}{l}(+) C_{p} \uparrow \text { till } \\
160 \mathrm{~g} / \mathrm{L}\end{array}$ & $\begin{array}{l}\Pi \uparrow \text { Partially } \\
\text { modified, } \\
\text { especially at } \\
\text { pHpzc }\end{array}$ & & {$[93,94]$} \\
\hline Silica & Silanization & \multicolumn{2}{|c|}{$20-50 \mathrm{~nm}$} & $\begin{array}{l}30 \\
g / L\end{array}$ & $\begin{array}{l}\mathrm{SiOH}: \\
14-100 \% \\
\theta: 13^{\circ}-84^{\circ}\end{array}$ & $\begin{array}{l}(+) \\
\text { Max: } \\
32 \% \\
\mathrm{SiOH}, \\
(-) \\
\geq 42 \% \\
\mathrm{SiOH}\end{array}$ & $32 \%, \mathrm{SiOH}$ & $\begin{array}{l}\text { Adsorbed } \\
\text { particle } \\
\text { layer, } \\
\gamma \text { and } \\
\text { E'dependent } \\
\text { on } C_{p}\end{array}$ & & {$[61,74]$} \\
\hline Silica & $\begin{array}{l}\text { Dichloro- } \\
\text { dimethylsilane }\end{array}$ & \multicolumn{2}{|c|}{$20 \mathrm{~nm}$} & $\begin{array}{l}10 \\
g / L\end{array}$ & $\begin{array}{l}\mathrm{SiOR}: \\
30-55 \% \\
\theta: 30-110^{\circ}\end{array}$ & $(-) R_{p} \uparrow$ & $\begin{array}{l}(+) 33 \% \\
\mathrm{SiOR} \\
\mathrm{NaCl}\end{array}$ & & $\begin{array}{l}\text { A weak gel } \\
\text { work with } \\
\text { salts present }\end{array}$ & {$[63,83]$} \\
\hline $\begin{array}{l}\text { Inorganic } \\
\text { colloidal } \\
\text { particles }\end{array}$ & $\begin{array}{l}\text { Adsorption of } \\
\text { amphiphiles } \\
\text { on particle } \\
\text { surface }\end{array}$ & \multicolumn{2}{|c|}{$\begin{array}{l}50-1800 \\
\mathrm{~nm}\end{array}$} & $\begin{array}{l}35 \%, \\
\text { v/v }\end{array}$ & pH 10.6 & $(-) \theta \uparrow$ & $\begin{array}{l}\text { Bubble } \\
\text { size: } 20 \text { to } \\
80 \mu \mathrm{m}, \\
\text { Foam } \\
\text { life }>1 \text { day, } \\
(+) C_{p} \uparrow\end{array}$ & $\begin{array}{l}\text { Adsorbed } \\
\text { particle } \\
\text { layer }\end{array}$ & $\eta<2 \mathrm{Pas}$ & $\begin{array}{l}{[81,82]} \\
{[84]}\end{array}$ \\
\hline Silica & $\begin{array}{l}\text { Adsorption of } \\
\text { Surfactant } \\
\text { CTAB on } \\
\text { particle } \\
\text { surface }\end{array}$ & \multicolumn{2}{|c|}{$20 \mathrm{~nm}$} & $2 \mathrm{~g} / \mathrm{L}$ & pH 6.5-8.0 & $\begin{array}{l}(+) \\
\mathrm{C}_{\mathrm{CTAB}} \\
\uparrow\end{array}$ & $\begin{array}{l}(+) 1.0- \\
3.0 \mathrm{mmol} / \mathrm{L} \\
\text { CTAB }\end{array}$ & $\begin{array}{l}\Pi<45 \\
\mathrm{mN} / \mathrm{m} \\
\text { dependent } \\
\text { on } \mathrm{C}_{\mathrm{CTAB}}\end{array}$ & & [95] \\
\hline Silica & $\begin{array}{l}\text { Adsorption of } \\
\text { Surfactant on } \\
\text { particle } \\
\text { surface }\end{array}$ & & & $\begin{array}{l}25 \\
\mathrm{~g} / \mathrm{L}\end{array}$ & $\mathrm{pH} 10.3$ & $\begin{array}{l}\mathrm{C}_{s} \uparrow \\
\text { first } \\
(+), \\
\text { then } \\
(-)\end{array}$ & $\begin{array}{l}\text { (+) Bulk } \\
\text { aggregation } \\
\text { of particles }\end{array}$ & $\begin{array}{l}\text { Aggregation } \\
\text { of particles, } \\
\text { dependent } \\
\text { on } \mathrm{C}_{\mathrm{s}}\end{array}$ & & [89] \\
\hline $\begin{array}{l}\text { Hydrophobic } \\
\text { silica }\end{array}$ & $\begin{array}{l}\text { SiOH replaced } \\
\mathrm{CH} 3-, \text { then mi } \\
\text { silicone oil }\end{array}$ & with & $\begin{array}{l}20 \\
\mathrm{~nm}\end{array}$ & $\begin{array}{l}42 \\
g / L\end{array}$ & Hydrophobic & & $\begin{array}{l}\text { Defoamer } \\
\text { by bridging } \\
\text { dewetting }\end{array}$ & & & [96] \\
\hline $\begin{array}{l}\text { Catalyst } \\
\text { particles }\end{array}$ & $\begin{array}{l}\text { oxidised with } \\
\text { nitric acid }\end{array}$ & & $\begin{array}{l}20 \\
\mu \mathrm{m}\end{array}$ & $\begin{array}{l}0- \\
6.0 \% \\
\mathrm{v} / \mathrm{v}\end{array}$ & $81.2^{\circ}$ & & $\begin{array}{l}\text { Defoamer } \\
\text { by bridging } \\
\text { dewetting }\end{array}$ & & & [97] \\
\hline
\end{tabular}

pHpzc: the $\mathrm{pH}$ when at point of zero charge of the particles

$\mathrm{C}_{\mathrm{p}}$ c concentration of particles

$\mathrm{C}_{\mathrm{s}}$ : concentration of surfactants 


\subsection{Aim and outline of this thesis}

The aim of this project was to get better insights of the role of milk components in milk foam behaviour and to use these insights to better control milk foams. One of the key components identified in a preliminary study was that of casein micelles. Therefore, we distinguished two main systems

$\checkmark \quad$ System 1: casein micelle dispersions (CMDs)

$\checkmark \quad$ System 2: silica particle $+\beta-\mathrm{CN}(\beta-\mathrm{CN}-$ Silica $)$

The research aim for system 1 was to uncover the mechanism of foam stabilization by dispersions of casein micelle and casein micelle aggregates: interfacial properties (adsorption speed, adsorption energy, dynamical interfacial tension, interfacial dilatational and shear moduli), thin film stability (rupture time, disjoining pressure) and foaming properties (formability, drainage, coalescence) were investigated with this regard. The research aim for system 2 was to determine the mechanisms of foam (de-)stabilisation of the hydrophilic casein micelle aggregates (CMAs) particles using silica particles as a better defined model system and to compare these with those of system 1 .

The outline of this thesis is presented as follows. In the first study which is described in Chapter 2, CMDs with different particle size distributions were obtained by controlling the dispersing temperature of casein micelle pellets. The influence of particle size and protein concertation and composition on the foam stability of casein micelle dispersions (CMDs) was investigated. In addition, the foaming behaviour of CMDs was compared to that of the skim milk. The second study is described Chapter 3, different systems including sodium caseinates, CMDs without and with CMAs were studied. Linear and non-linear surface rheology was conducted to reveal the mechanical properties of the air/water interface stabilized by casein micelles. The stability and morphology of thin films stabilized by CMDs were studied with microscope equipped with a Scheludko cell. The foaming behaviour of all studied samples was characterized and link to their interfacial properties as well as thin film stability. In the third study of this project (Chapter 4), ultra-stable foam was obtained with CMDs which contained large CMAs. The amount of CMAs in the bulk and in the foam lamella were quantified and related to the corresponding foam stability and thin film stability. The mechanism of the ultra-stabilization of foams by CMDs with CMAs present is discussed regarding whether a gel network formed in the foam lamellae. In the last study which is described in Chapter 5, the versatility of foam stabilization mechanism with CMDs was checked particularly on the role of particle size and concentration in foam stabilization. A model system for CMDs was build up by adding hydrophilic silica particles with three sizes $(200 \mathrm{~nm}, 1 \mu \mathrm{m}$ and $3 \mu \mathrm{m})$ into $\beta-\mathrm{CN}$ solution at varying weight ratios. The foaming and interfacial properties of $\beta-\mathrm{CN} /$ silica system as well as its thin film properties were investigated. Finally, a general discussion is given in Chapter 6. The role of casein micelles and CMAs in foams of CMDs was evaluated and compared to that of silica 


\section{Chapter 1}

particle by linking their foaming behaviour to corresponding interfacial structure and thin film morphology. 


\section{References}

1. Brooker, B.E., Observations on the air-serum interface of milk foams. Food Structure, 1985. 4(2): p. 12.

2. Dickinson, E., et al., Adsorption at interfaces in dairy systems. International Journal of Dairy Technology, 1989. 42(1): p. 18-22.

3. Ward, B.R., et al., EDTA-induced dissociation of casein micelles and its effect on foaming properties of milk. Journal of Dairy Research, 1997. 64(4): p. 495-504.

4. Zhang, Z., Dalgleish, D.G. and Goff, H.D., Effect of pH and ionic strength on competitive protein adsorption to air/water interfaces in aqueous foams made with mixed milk proteins. Colloids and Surfaces B: Biointerfaces, 2004. 34(2): p. 113-121.

5. $\quad$ Rouimi, S., et al., Foam stability and interfacial properties of milk protein-surfactant systems. Food Hydrocolloids, 2005. 19(3): p. 467-478.

6. Borcherding, K., et al., Effect of foaming temperature and varying timeltemperature-conditions of preheating on the foaming properties of skimmed milk. International Dairy Journal, 2008. 18(4): p. 349358.

7. Kamath, S., et al., The influence of temperature on the foaming of milk. International Dairy Journal, 2008. 18(10): p. 994-1002.

8. Huppertz, T., Foaming properties of milk: A review of the influence of composition and processing. International Journal of Dairy Technology, 2010. 63(4): p. 477-488.

9. Kamath, S., Webb, R.E. and Deeth,H.C., The composition of interfacial material from skim milk foams. Journal of Dairy Science, 2011. 94(6): p. 2707-2718.

10. Oetjen, K., et al., Temperature effect on foamability, foam stability, and foam structure of milk. Colloids and Surfaces A: Physicochemical and Engineering Aspects, 2014. 460: p. 280-285.

11. Hailing, P.J. and Walstra, P., Protein-stabilized foams and emulsions. CRC Critical Reviews in Food Science and Nutrition, 1981. 15(2): p. 155-203.

12. Kinsella, J.E., Functional properties of proteins: possible relationship between structure and function in foams. Food Chemistry, 1981. 7(4), p. 273-288.

13. Langevin, D., Aqueous foams: a field of investigation at the frontier between chemistry and physics. ChemPhysChem, 2008. 9(4): p. 510-522.

14. Cantat, I., et al., Foams: Structure and Dynamics. 2013: OUP Oxford.

15. Schramm, L.L. and Wassmuth, F., Foams: Fundamentals and Applications in the Petroleum Industry. American Chemical Society, 1994. 242.

16. Marinova, K.G., et al., Physico-chemical factors controlling the foamability and foam stability of milk proteins: Sodium caseinate and whey protein concentrates. Food Hydrocolloids, 2009. 23: p. 18641876.

17. Kloek, W., Vliet,T.v. and Meinders, M., Effect of Bulk and Interfacial Rheological Properties on Bubble Dissolution. Journal of Colloid and Interface Science, 2001. 237(2): p. 158-166.

18. Scheludko, A., Thin liquid films. Advances in Colloid and Interface Science, 1967. 1(4): p. 391-464.

19. Bergeron, V., Waltermo, Å. and Claesson, P.M., Disjoining pressure measurements for foam films stabilized by a nonionic sugar-based surfactant. Langmuir, 1996. 12(5): p. 1336-1342.

20. Lech, F.J., et al., Stability Properties of Surfactant-Free Thin Films at Different Ionic Strengths: Measurements and Modeling. Langmuir, 2015. 31(9): p. 2777-2782.

21. Scheludko, A. and Platikanowa, D., Untersuchung dunner flussiger schichten auf quecksiber.Kolloidzertschrift and zeitschrift fur polymere, 1961. 175(2): p. 150.

22. Ivanov, I., Thin liquid films. Vol. 29. 1988: CRC Press.

23. Vrij, A. and Overbeek, J.T.G., Rupture of thin liquid films due to spontaneous fluctuations in thickness. Journal of the American Chemical Society, 1968. 90(12): p. 3074-3078.

24. Danov, K.D., et al., Surface shear rheology of hydrophobin adsorption layers: laws of viscoelastic behaviour with applications to long-term foam stability. Faraday Discussions, 2012. 158: p. 195-221. 


\section{Chapter 1}

25. Antipova, A.S., Semenova,M.G. and Belyakova, L.E., The effect of sucrose on the thermodynamic properties of ovalbumin and sodium caseinate in bulk solution and at air-water interface. Colloids and Surfaces B: Biointerfaces, 1999. 12(3): p. 261-270.

26. Jiménez-Castaño, L., et al., Study on $\beta$-lactoglobulin glycosylation with dextran: effect on solubility and heat stability. Food Chemistry, 2005. 93(4): p. 689-695.

27. Fox, P.F. and McSweeney, P.L.H., Advanced Dairy Chemistry. New York: kluwer Academic/Plenum Publishers, 2003. 1: p. 1-48.

28. Morris, G., Foster, T. and Harding, S., Further observations on the size, shape, and hydration of casein micelles from novel analytical ultracentrifuge and capillary viscometry approaches. Biomacromolecules, 2000. 1(4): p. 764-767.

29. Horne, D.S., Casien micelle structure and stability, in Milk porteins: from expression to food. Elsevier, Inc.: New York, 2009. p. 133-162.

30. Dalgleish, D.G. and Corredig,M., The Structure of the Casein Micelles of Milk and Its Changes During Processing. Annual Reviews of Food Science and Technology, 2012. 3: p. 449-467.

31. Horne, D.S., Casein interactions: casting light on the black boxes, the structure in dairy products. International Dairy Journal, 1998. 8(3): p. 171-177.

32. Huppertz, T. and de Kruif, C.G., Rennet-induced coagulation of enzymatically cross-linked casein micelles. International dairy journal, 2007. 17(5): p. 442-447.

33. Augustin, M.A. and Clarke, P.T., Skim milk powders with enhanced foaming and steam-frothing properties. Dairy Science and Technology, 2008. 88(1): p. 149-161.

34. Zhang, Z., Goff, H.D. and Tharp, B., Studying the composition of the air interface in aqueous milk protein foam and ice cream. In Ice cream II. Proceedings of the Second IDF International Symposium on Ice Cream, Thessaloniki, Greece. International Dairy Federation. 2004. 209-222.

35. Mulder, H. and P. Walstra, The Milk Fat Globule: Emulsion Science as Applied to Milk Products and Comparable Foods. No. 4. Wageningen, Netherlands, Centre for Agricultural Publishing and Documentation., 1974.

36. Schmitt, C., et al., Whey protein soluble aggregates from heating with NaCl: Physicochemical, interfacial, and foaming properties. Langmuir, 2007. 23(8): p. 4155-4166.

37. Dombrowski, J., et al., Correlation between bulk characteristics of aggregated $\beta$-lactoglobulin and its surface and foaming properties. Food Hydrocolloids, 2016. 61: p. 318-328.

38. Wan, Z., Yang, X. and Sagis, L.M., Nonlinear Surface Dilatational Rheology and Foaming Behavior of Protein and Protein Fibrillar Aggregates in the Presence of Natural Surfactant. Langmuir, 2016. 32(15): p. 3679-3690.

39. Oboroceanu, D., et al., Fibrillization of whey proteins improves foaming capacity and foam stability at low protein concentrations. Journal of Food Engineering, 2014. 121: p. 102-111.

40. Schmitt, C., Bovay,C. and Rouvet,M., Bulk self-aggregation drives foam stabilization properties of whey protein microgels. Food Hydrocolloids, 2014. 42: p. 139-148.

41. Schmidt, I., et al., Foaming properties of protein/pectin electrostatic complexes and foam structure at nanoscale. Journal of Colloid and Interface Science, 2010. 345(2): p. 316-324.

42. Fameau, A.L. and Salonen, A., Effect of particles and aggregated structures on the foam stability and aging. Comptes Rendus Physique, 2014. 15(8-9): p. 748-760.

43. Rullier, B., Novales, B. and Axelos, M.A.V., Effect of protein aggregates on foaming properties of $\beta$ lactoglobulin. Colloids and Surfaces A: Physicochemical and Engineering Aspects, 2008. 330(2-3): p. 96-102.

44. Guo, F., et al., Surface Properties of Heat-Induced Soluble Soy Protein Aggregates of Different Molecular Masses. Journal of food science, 2015. 80(2): p. C279-C287.

45. Morales, R., et al., Modification of foaming properties of soy protein isolate by high ultrasound intensity: particle size effect. Ultrasonics sonochemistry, 2015. 26: p. 48-55.

46. Oboroceanu, D., et al., Fibrillization of whey proteins improves foaming capacity and foam stability at low protein concentrations. Journal of Food Engineering, 2014. 121: p. 102-111. 
47. Lazidis, A., et al., Whey protein fluid gels for the stabilisation of foams. Food Hydrocolloids, 2016. 53: p. 209-217.

48. Nicolai, T., Formation and functionality of self-assembled whey protein microgels. Colloids and Surfaces B: Biointerfaces, 2016. 137: p. 32-38.

49. Wierenga, P.A., van Norél, L. and Basheva, E.S., Reconsidering the importance of interfacial properties in foam stability. Colloids and Surfaces A: Physicochemical and Engineering Aspects, 2009. 344(1-3): p. 72-78.

50. Rullier, B., et al., $\beta$-Lactoglobulin aggregates in foam films: Effect of the concentration and size of the protein aggregates. Journal of colloid and interface science, 2010. 343(1): p. 330-337.

51. Saint-Jalmes, A., et al., Differences between protein and surfactant foams: microscopic properties, stability and coarsening. Colloids and Surfaces A: Physicochemical and Engineering Aspects, 2005. 263(1): p. 219-225.

52. Rio, E., et al., Unusually stable liquid foams. Advances in Colloid and Interface Science, 2014. 205: p. 74-86.

53. Rullier, B., et al., $\beta$-Lactoglobulin aggregates in foam films: Correlation between foam films and foaming properties. Journal of Colloid and Interface Science, 2009. 336(2): p. 750-755.

54. Murray, B.S., et al., Stabilization of foams and emulsions by mixtures of surface active food-grade particles and proteins. Food Hydrocolloids, 2011. 25(4): p. 627-638.

55. Nicolai, T., Britten, M. and Schmitt, C., $\beta$-Lactoglobulin and WPI aggregates: Formation, structure and applications. Food Hydrocolloids, 2011. 25(8): p. 1945-1962.

56. Lazidis, A., et al., Whey protein fluid gels for the stabilisation of foams. Food Hydrocolloids, 2016. 53: p. 209-217.

57. Binks, B.P., et al., Dispersion Behavior and Aqueous Foams in Mixtures of a Vesicle-Forming Surfactant and Edible Nanoparticles. Langmuir, 2015. 31(10): p. 2967-2978.

58. Asghari, A.K., et al., Interfacial and foaming characterisation of mixed protein-starch particle systems for food-foam applications. Food Hydrocolloids, 2016. 53: p. 311-319.

59. Horozov, T.S., Foams and foam films stabilised by solid particles. Current Opinion in Colloid \& Interface Science, 2008. 13(3): p. 134-140.

60. Vivaldini, D.O., et al., Why foams containing colloidal hydrophilic particles are unstable? Ceramics International, 2013. 39(5): p. 6005-6008.

61. Binks, B.P. and Horozov, T.S., Aqueous foams stabilized solely by silica nanoparticles. Angewandte Chemie, 2005. 117(24): p. 3788-3791.

62. Safouane, M., Langevin, D. and Binks, B., Effect of particle hydrophobicity on the properties of silica particle layers at the air-water interface. Langmuir, 2007. 23(23): p. 11546-11553.

63. Dickinson, E., et al., Factors controlling the formation and stability of air bubbles stabilized by partially hydrophobic silica nanoparticles. Langmuir, 2004. 20(20): p. 8517-8525.

64. Kaptay, G., Interfacial criteria for stabilization of liquid foams by solid particles. Colloids and Surfaces A: Physicochemical and Engineering Aspects, 2003. 230(1): p. 67-80.

65. Hunter, T.N., et al., The role of particles in stabilising foams and emulsions. Advances in Colloid and Interface Science, 2008. 137(2): p. 57-81.

66. Stamou, D., Duschl, C. and Johannsmann, D., Long-range attraction between colloidal spheres at the air-water interface: The consequence of an irregular meniscus. Physical Review E, 2000. 62(4): p. 5263.

67. Kralchevsky, P.A., Denkov, N.D. and Danov, K.D. Particles with an undulated contact line at a fluid interface: interaction between capillary quadrupoles and rheology of particulate monolayers. Langmuir, 2001. 17(24): p. 7694-7705.

68. Ghezzi, F., et al., Pattern formation in colloidal monolayers at the air-water interface. Journal of colloid and interface science, 2001. 238(2): p. 433-446.

69. Narsimhan, G., Drainage of particle stabilized foam film. Colloids and Surfaces A: Physicochemical and Engineering Aspects, 2016. 495: p. 20-29. 


\section{Chapter 1}

70. Ata, S., Ahmed, N. and Jameson, G.J., Collection of hydrophobic particles in the froth phase. International Journal of Mineral Processing, 2002. 64(2): p. 101-122.

71. Ata, S., N. Ahmed, and Jameson, G., The effect of hydrophobicity on the drainage of gangue minerals in flotation froths. Minerals engineering, 2004. 17(7): p. 897-901.

72. Schwarz, S. and Grano, S., Effect of particle hydrophobicity on particle and water transport across a flotation froth. Colloids and Surfaces A: Physicochemical and Engineering Aspects, 2005. 256(2): p. 157-164.

73. Alargova, R.G., et al., Foam superstabilization by polymer microrods. Langmuir, 2004. 20(24): p. 10371-10374.

74. Stocco, A., et al., Aqueous foams stabilized solely by particles. Soft Matter, 2011. 7(4): p. 1260-1267.

75. Cervin, N.T., et al., Lightweight and strong cellulose materials made from aqueous foams stabilized by nanofibrillated cellulose. Biomacromolecules, 2013. 14(2): p. 503-511.

76. Guevara, J.S., et al., Stabilization of Pickering foams by high-aspect-ratio nano-sheets. Soft Matter, 2013. 9(4): p. 1327-1336.

77. Wasan, D., Nikolov,A. and Shah, A., Foaming-antifoaming in boiling suspensions. Industrial \& engineering chemistry research, 2004. 43(14): p. 3812-3816.

78. Sethumadhavan, G.N., Nikolov, A.D. and Wasan, D.T., Stability of liquid films containing monodisperse colloidal particles. Journal of colloid and interface science, 2001. 240(1): p. 105-112.

79. Sethumadhavan, G., Nikolov, A. and Wasan, D., Stability of films with nanoparticles. Journal of colloid and interface science, 2004. 272(1): p. 167-171.

80. Nushtaeva, A. and Kruglyakov, P., Investigation of model emulsion films stabilized by solid particles: thickness of films, their stability, and interfacial tension. Colloid Journal, 2004. 66(4): p. 456-465.

81. Gonzenbach, U.T., et al., Ultrastable Particle-Stabilized Foams. Angewandte Chemie International Edition, 2006. 45(21): p. 3526-3530.

82. Gonzenbach, U.T., et al., Stabilization of foams with inorganic colloidal particles. Langmuir, 2006. 22(26): p. 10983-10988.

83. Kostakis, T., Ettelaie, R. and Murray,B.S., Effect of high salt concentrations on the stabilization of bubbles by silica particles. Langmuir, 2006. 22(3): p. 1273-1280.

84. Gonzenbach, U.T., et al., Tailoring the microstructure of particle-stabilized wet foams. Langmuir, 2007. 23(3): p. 1025-1032.

85. Schmitt, C., Bovay, C. and Rouvet, M., Bulk self-aggregation drives foam stabilization properties of whey protein microgels. Food Hydrocolloids, 2014. 42: p. 139-148.

86. Binks, B.P., Kirkland, M. and Rodrigues, J.A., Origin of stabilisation of aqueous foams in nanoparticle-surfactant mixtures. Soft Matter, 2008. 4(12): p. 2373.

87. Karakashev, S.I., et al., Formation and stability of foams stabilized by fine particles with similar size, contact angle and different shapes. Colloids and Surfaces A: Physicochemical and Engineering Aspects, 2011. 382(1-3): p. 132-138.

88. Kruglyakov, P.M., Elaneva, S.I. and Vilkova, N.G., About mechanism of foam stabilization by solid particles. Advances in colloid and interface science, 2011. 165(2): p. 108-116.

89. Carl, A., Bannuscher, A. and von Klitzing, R., Particle stabilized aqueous foams at different length scales: synergy between silica particles and alkylamines. Langmuir, 2015. 31(5): p. 1615-1622.

90. Krisdhasima, Vinaraphong, V., P. and McGuire, J., Adsorption Kinetics and Elutability of $\alpha$ Lactalbumin, $\beta$-Casein, $\beta$-Lactoglobulin, and Bovine Serum Albumin at Hydrophobic and Hydrophilic Interfaces. Journal of Colloid and Interface Science, 1993. 161(2): p. 325-334.

91. Rullier, B., et al., $\beta$-Lactoglobulin aggregates in foam films: Effect of the concentration and size of the protein aggregates. Journal of Colloid and Interface Science, 2010. 343(1): p. 330-337.

92. Chen, M., et al., Particle size determines foam stability of casein micelle dispersions. International Dairy Journal, 2016. 56: p. 151-158.

93. Blute, I., et al., Silica nanoparticle sols: 1. Surface chemical characterization and evaluation of the foam generation (foamability). Journal of colloid and interface science, 2007. 313(2): p. 645-655. 
94. Blute, I., et al., Industrial manufactured silica nanoparticle sols. 2: Surface tension, particle concentration, foam generation and stability. Colloids and Surfaces A: Physicochemical and Engineering Aspects, 2009. 337(1): p. 127-135.

95. Dong, X., et al., Aqueous foam stabilized by hydrophobically modified silica particles and liquid paraffin droplets. Colloids and Surfaces A: Physicochemical and Engineering Aspects, 2010. 353(2): p. 181-188.

96. Marinova, K.G., et al., Optimal hydrophobicity of silica in mixed oil-silica antifoams. Langmuir, 2002. 18(9): p. 3399-3403.

97. Van der Zon, M., et al., Coalescence of freely moving bubbles in water by the action of suspended hydrophobic particles. Chemical engineering science, 2002. 57(22): p. 4845-4853. 


\title{
Chapter 2
}

\section{Particle size determines foam stability of casein micelle dispersions}

\begin{abstract}
This study examined the role of interfacial properties and size of casein micelles aggregates on foam stability of casein micelle dispersions (CMDs). CMDs were prepared by redispersing casein micelles pellets obtained by ultracentrifugation. The size of colloidal particles could be controlled by differences in redispersing temperature. CMD redispersed at $20^{\circ} \mathrm{C}\left(\mathrm{CMD}_{20^{\circ} \mathrm{C}}\right)$ and $4^{\circ} \mathrm{C}\left(\mathrm{CMD}_{4}{ }^{\circ} \mathrm{C}\right)$ had average particle sizes of around $200 \mathrm{~nm}$ (micelles) and $500 \mathrm{~nm}$ (micelles and aggregates), respectively. The foaming properties of $\mathrm{CMD}_{20^{\circ} \mathrm{C}}$ and $\mathrm{CMD}_{4}{ }^{\circ} \mathrm{C}$ with different total protein concentrations, $c_{p}$, were studied. The foam half-life, $t_{1 / 2}$, of $\mathrm{CMD}_{4^{\circ} \mathrm{C}}\left(t_{1 / 2} \approx 1 \mathrm{~d}\right.$ for $\left.c_{p} \geq 3 \%\right)$ was significantly higher than that of $\mathrm{CMD}_{20}{ }^{\circ} \mathrm{C}$ and skim milk $\left(t / / 2 \sim 4 \mathrm{~h}\right.$ for $c_{p} \geq 3 \%$ ). No correlation between foam stability and surface rheological properties or protein composition could be observed. Foam stability was strongly related to the size of colloidal particles present in CMD. This was confirmed by the observation that the foam stability of $\mathrm{CMD}_{4^{\circ} \mathrm{C}}$ decreased to that of $\mathrm{CMD}_{20^{\circ} \mathrm{C}}$ when the aggregates were broken down by homogenization.
\end{abstract}

Published as:

M. Chen, R. Bleeker, G. Sala, M.B.J. Meinders, H.J.F. van Valenberg, A.C.M. vanHooijdonk, E. van der Linden. Particle size determines foam stability of casein micelle dispersions. International Dairy Journal (2016), 56, 151-158. 


\section{Chapter 2}

\subsection{Introduction}

Previous research has shown that the foaming properties of milk are strongly influenced by its composition. However, the foaming properties of milk are still not well understood [1, 2]. Several studies have been conducted on the foaming properties of skim milk [2-4]. These studies indicate that casein micelles, which account for $80 \%$ of milk proteins, play an important role in the stability of milk foams. Kamath et al. (2011)[5] reported that a micellar casein fraction showed far better foam stability than skim milk. The reasons suggested for this higher foam stability were the absence of foam-inhibiting compounds, such as fat, glycerides, free fatty acids and phospholipids, and higher protein coverage at the air/water interface. This would imply that changes in interfacial properties would be the main reason for the higher foam stability. Indeed, foam stabilization is commonly linked to the properties of the adsorbed interfacial layer between the air and liquid phase. For example, an adsorbed protein layer with high surface viscosity and elasticity was claimed to reduce the rate of drainage [6], retard disproportionation [7, 8] and prevent rupture of the film between two adjacent bubbles [9]. Only a few studies have been published on the relationship between interfacial properties of casein micelle dispersions and their foaming properties. Microscopic images of bubble ghosts of milk foam suggested that casein micelles can be adsorbed at the air/water interface [10], possibly in a reversible way [11]. However, Borcherding et al. (2008) [3] indicated that casein micelles are not likely to be present at the air/liquid interface. Whether the casein micelles actually lead to changes in interfacial properties that result in better foaming properties remains unclear. In fact, whether the increased foam stability observed by Kamath et al. (2011) [5] can be attributed at all to interfacial phenomena remains unproven at this point.

A parameter that might also explain the stability of foam prepared with colloidal dispersions is the presence of aggregated proteins, which would affect the stabilisation of the thin films in the foam. Although not much research has been performed on this, it has been reported that the presence of protein aggregates could either increase or decrease the foam stability of protein solutions [12]. Thus, different particle size distributions of casein micelle dispersions (CMDs) might lead to different foaming properties. Indeed, the average diameter of particles in the samples prepared by Kamath et al. [5] ranged from 400 to 600 $\mathrm{nm}$, and foams prepared from dispersions with larger particles were more stable. The size of CMDs used to prepare foams was approximately twice the average diameter of casein micelles in regular milk samples (200 to $250 \mathrm{~nm}$ ). This difference might be caused by the fact that Kamath et al. (2011) prepared the CMDs by first separating casein micelles by ultracentrifugation and then redispersing the casein micelle pellets in milk permeate at $4^{\circ} \mathrm{C}$ for $24 \mathrm{~h}$.

In this paper the key factors for foam stability of CMDs and skimmed milk were addressed. Therefore, to what extend interfacial properties or the presence of large casein micelle aggregates control foam stability was studied. Variation in the size of colloidal particles 
present in the dispersions was obtained by varying the redispersion temperature. Casein micelle pellets obtained by ultracentrifugation were redispersed in milk permeate at $20^{\circ} \mathrm{C}$ and $4^{\circ} \mathrm{C}$. Skim milk was prepared by reconstitution of Nilac powder at $20^{\circ} \mathrm{C}$ and $4{ }^{\circ} \mathrm{C}$. Foaming properties, including foam half-life and mean bubble diameter, were related to interfacial properties, particle size distribution (micelles and/or aggregates), total protein concentration, viscosity, protein and fat content.

\subsection{Material and Methods}

\subsubsection{Materials}

Low-heat skim milk powder NILAC was obtained from NIZO (Ede, The Netherlands). Acetonitrile was bought from Biosolve-Chemicals (HPLC Ultra-Gradient, Eindhoven, Netherlands). Tri-sodium citrate dihydrate and trifluoroacetic acid were purchased from Merck (Haarlem, The Netherlands). Bis-Tris buffer, DL-dithiothreitol (DTT), guanidine hydrochloride $(\mathrm{GdnHCl})$ and sodium azide were purchased from Sigma Aldrich (Zwijndrecht, The Netherlands). Ultra-pure water (MilliQ Purelab Ultra, Darmstadt, Germany), free of surface active contaminants, was used in all experiments (>18.2 M $\Omega$-cm, surface tension of $72.26 \pm 0.4 \mathrm{mN} \mathrm{m}^{-1}$ at $20^{\circ} \mathrm{C}$ ).

\subsubsection{Preparation of casein micelle dispersions (CMD)}

Skim milk was reconstituted $(10 \%, \mathrm{w} / \mathrm{w})$ by dissolving NILAC milk powder in MilliQ water and stirring overnight at room temperature (RT). Sodium azide $(0.02 \%$, w/w) was added as preservative. The reconstituted skim milk was ultracentrifuged (L-60 Beckman Ultracentrifuge, rotor type $70 \mathrm{Ti}$, Krefeld, Germany) at $100,000 \mathrm{~g}$ for $90 \mathrm{~min}$ at $20^{\circ} \mathrm{C}$, as described by Huppertz et al.(2007) [13]. The obtained casein micelle pellets were separated from the serum phase and ground using a Mixer Mill MM 400 (Retsch GmbH, Haan, Germany) at a frequency of $30 \mathrm{~Hz}$ for $10 \mathrm{~min}$ at RT. Subsequently, the obtained casein micelle paste were redispersed in milk permeate either at $20^{\circ} \mathrm{C}$ or at $4{ }^{\circ} \mathrm{C}$ for 60 hours to obtain casein micelle dispersions (CMDs) with $3 \%$ and $5 \%(\mathrm{w} / \mathrm{w})$. CMDs with $0.06 \%$ and

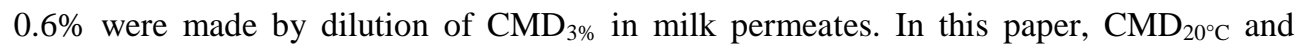
$\mathrm{CMD}_{4}{ }^{\circ} \mathrm{C}$ are used to indicate $\mathrm{CMDs}$ redispersed at $20^{\circ} \mathrm{C}$ and $4^{\circ} \mathrm{C}$, respectively. The milk permeate was prepared by reconstitution of milk permeate powder in MilliQ water for 30 min. Milk permeate powder was prepared by ultrafiltration of the reconstituted skim milk $(10 \%, \mathrm{w} / \mathrm{w})$ using a polysulfone membrane with a pore size of $10 \mathrm{kDa}$ and surface area of $0.48 \mathrm{~m}^{2}$. The length and outer diameter of the membrane were $73.5 \mathrm{~cm}$ and $3.2 \mathrm{~cm}$, respectively. The skim milk was stirred and cooled at $4^{\circ} \mathrm{C}$ for one hour before being poured into the cold trap $\left(8^{\circ} \mathrm{C}\right)$. Subsequently, it was filtered through the membrane under pressure from 0.3 bar to 1.7 bar at maximum. The milk permeate was collected, freeze-dried and stored at $-20^{\circ} \mathrm{C}$. The dry matter content of the milk permeate was $5.76 \%(\mathrm{w} / \mathrm{w})$. The 


\section{Chapter 2}

calcium activity of milk permeates was $4.76 \mathrm{E}-04$ (i.e. comparable to that of skim milk, 4.88E-04).

For a specific experiment, $\mathrm{CMD}_{4}{ }^{\circ} \mathrm{C}$ samples with protein concentration of $3 \%(\mathrm{w} / \mathrm{w})$ were homogenized at 200 bar for 10 min with a homogenizer (Delta Instruments, Drachten, the Netherlands) at RT. $\mathrm{CMD}_{20}{ }^{\circ} \mathrm{C}$ with $0.02 \mathrm{mg} \mathrm{kg}^{-1}$ of the plasmin inhibitor aprotinin (SigmaAldrich, Steinheim, Germany) $\left(\mathrm{CMD}_{20^{\circ} \mathrm{CPI}}\right)$ was prepared to check the effect of the proteolytic activity of plasmin during redispersion on the foaming properties of CMDs.

\subsubsection{Characterization of samples}

\section{Viscosity and $\mathrm{pH}$}

The shear viscosity of the samples was measured with a controlled stress rheometer MCR 301 (Anton Paar, Graz, Austria) equipped with a Double Gap geometry DG 26.7/T1 and a measuring cell C-DG 26.7/T200/Ti. Sample (3.8 mL) was placed into the measuring cell, and shear rate sweep tests from $1 \mathrm{~s}^{-1}$ to $1000 \mathrm{~s}^{-1}$ at $20^{\circ} \mathrm{C}$ were carried out. Each sample was measured in triplicate. The $\mathrm{pH}$ of the samples was measured with Advanced ISE/pH/mV/ORP apparatus (Thermo Electron Corporation, Massachusetts, USA).

\section{Particle size}

The size distribution of the colloidal particles (casein micelles and/or aggregates) present in milk and CMDs was measured using a Malvern Zetasizer Nano-ZS (Malvern Instruments Ltd, Worcestershire, United Kingdom). The samples were diluted to a protein concentration of $0.03 \%(\mathrm{w} / \mathrm{w})$ with milk permeate and subsequently transferred into a cuvette (DTS0012) using a syringe. A single measurement consisted of 11 runs and the duration of each run was $10 \mathrm{~s}$. The refractive indices used for the calculation of the sizes were 1.341 [14] for the milk permeate and 1.57 [15] for the casein micelles, respectively. The measurement angle was set to $173^{\circ}$ backscatter (NBS default) with automatic measurement duration. Three measurements of each sample without pausing were performed at $20^{\circ} \mathrm{C}$.

\section{Supernatant preparation}

CMDs and skim milk samples were ultracentrifuged for a second time according to the procedure described in Section 2.2. The fat content of the supernatant of the studied samples was analysed by MilkoScan FT 120 (FOSS Benelux BV, IJsselstein, the Netherlands). Their protein content and composition were further analysed as described below.

\section{Protein content}


Total nitrogen content was determined using the Dumas method [16]. Samples of $200 \mu \mathrm{L}$ were dried in an oven at $60^{\circ} \mathrm{C}$ overnight. A factor of 6.38 was used for the conversion of the nitrogen content into total protein content.

\section{Protein composition}

The protein composition was measured by Reversed Phase High Pressure Liquid Chromatography (RP-HPLC) according to the method of Bonfatti et al.(2008) [17] with some modifications. This procedure was used for the quantification and identification of the casein fractions ( $\kappa$-caseins; $\alpha_{\mathrm{S} 1}$-casein; $\alpha_{\mathrm{S} 2}$-casein; $\beta$-casein) in the CMDs and their supernatants. Samples were mixed with 0.1 M Bis-Tris buffer ( $\mathrm{pH}$ adjusted to 6.8), $6 \mathrm{M}$ guanidine hydrochloride (GdnHCL), $5.37 \mathrm{mM}$ sodium citrate and $19.5 \mathrm{mM}$ Dithiothreitol (DTT) (pH 7) at a ratio of 1:1. The mixture was kept at RT for one hour and centrifuged for $5 \mathrm{~min}$ at $16000 \mathrm{~g}$ to remove the fat. Subsequently the samples were diluted 1:1 (v/v) with a solution containing $4.5 \mathrm{mM}$ GndHCL in solvent $\mathrm{A}(\mathrm{pH}=2.0)$, which consisted of $0.1 \%$ $(\mathrm{v} / \mathrm{v})$ trifluoroacetic acid in water. Separations were performed on a reversed-phase

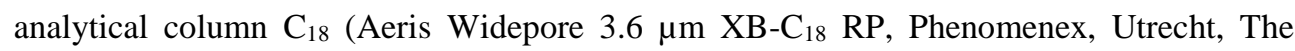
Netherlands) with a silica-based packing (3.6 $\mu \mathrm{m}, 300 \AA$, 250 x 4.6 I.D.). The temperature of the column was set to $45^{\circ} \mathrm{C}$. A Security Guard Ultra Cartridge System (Phenomenex, Utrecht, the Netherlands) was used as pre-column (wide-pore $\mathrm{C}_{18}$ for $4.6 \mathrm{~mm}$ I.D.). The sample vials were kept at constant low temperature $\left(4^{\circ} \mathrm{C}\right)$ inside the auto-sampling unit, and an injection loop of $50 \mu \mathrm{L}$ was used. The UV detection wavelength was $214 \mathrm{~nm}$. And the flow rate was $0.25 \mathrm{~mL} \mathrm{~min}^{-1}$ to $24 \mathrm{~min}$, after which it was increased to $0.4 \mathrm{~mL} \mathrm{~min}^{-1}$ over 3 min, leading to a total analysis time of 41 min per sample.

\subsubsection{Interfacial properties}

Interfacial properties were measured using the SINTERFACE PAT 1-M (SINTERFACE Technologies, Berlin, Germany). Data were obtained using the pendent drop method and SINTERFACE software (Profile Analysis Tensiometer PAT 1-M version 1.4.0.685), according to Wüstneck et al.(2012) [18] with some modifications. The area of the droplet was $25 \mathrm{~mm}^{2}$. Dynamic surface dilatational elastic modulus, E', and surface viscous modulus, E', were determined after $\mathrm{t}=1000 \mathrm{~s}$ from the interfacial pressure response to an oscillatory change of the interfacial area. The frequency and relative amplitude of the oscillations were set to $0.1 \mathrm{~Hz}$ and $6 \%$, respectively. There were 5 oscillations in one sweep, which was repeated 10 times with $10 \mathrm{~s}$ pause in between.

\subsubsection{Foaming properties}

Foaming properties were assessed with a FoamScan (Teclis IT-Concept, Longessaigne, France). Foam was generated by sparging air through a porous frit in $40 \mathrm{~mL}$ solution. The gas flow rate was set at $200 \mathrm{~mL} \mathrm{~min}^{-1}$ until the volume of the foam reached $120 \mathrm{~mL}$. After 


\section{Chapter 2}

reaching this volume, the gas flow rate was set to 0 . All experiments were carried out at $20^{\circ} \mathrm{C}$. All solutions were stirred for one hour prior to foaming at RT. The foam volume was estimated from light intensity of tube images based on calibration of pixels and the black/white coefficient was set to $55 \%$. Foam volume was recorded as a function of time. The measurement stopped when the foam reached half of its initial value. The corresponding time, $t_{1 / 2}$ (foam half-life), was used as a measure for foam stability.

\section{Bubble size distribution}

Two dimensional images of the foam at the wall of the tube were recorded using a chargecoupled device (CCD) camera. The image covers an area of $1.0 \mathrm{~cm}^{2}$. From the images, analysed using Matlab V.2013a (Mathworks) and the Dip Image software (Quantitative Imaging Group, Faculty of Applied Sciences, Delft University of Technology, Delft, The Netherlands), the mean bubble diameter, $D$, was obtained.

\subsubsection{Statistical analysis}

All tests were conducted in triplicate. The results obtained were subjected to a one-way analysis of variance (ANOVA). Duncan's new multiple range test was performed using SPSS 22.0 software (SPSS Inc., Chicago, IL, USA) to determine the significance of difference between samples using a significance level of $p<0.05$.

\subsection{Results}

\subsubsection{Foam properties}

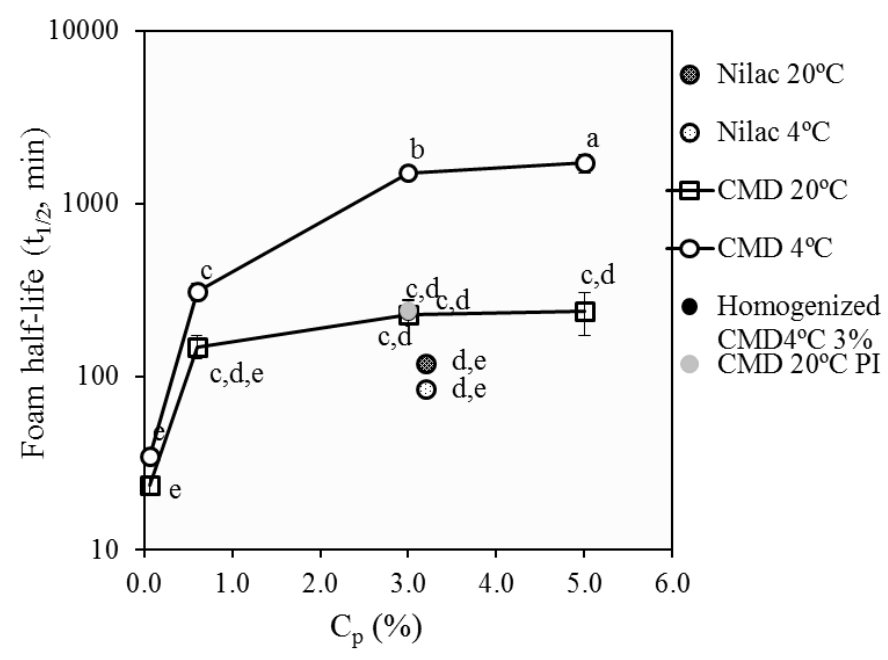


Figure 2-1. Foam half-life, $\mathrm{t}_{1 / 2}$, [min] of foams made with CMD redispersed at $20^{\circ} \mathrm{C}$ and $4{ }^{\circ} \mathrm{C}$ as a function of protein concentration, $\mathrm{C}_{\mathrm{p}}[\%, \mathrm{w} / \mathrm{w}] . \mathrm{t}^{1} / 2$, values of skimmed milk $\left(\mathrm{C}_{\mathrm{p}}\right.$ around $3 \%$ ) redispersed at $20^{\circ} \mathrm{C}$ and $4^{\circ} \mathrm{C}$, homogenised $\mathrm{CMD}_{4}{ }^{\circ} \mathrm{C} 3 \%$ and $\mathrm{CMD}{ }_{20}^{\circ} \mathrm{CPI}\left(\mathrm{CMD}{ }_{20}{ }^{\circ} \mathrm{C}\right.$ with plasmin inhibitor added) are also shown. Data with different letters indicate statistically significant differences.

All measured samples reached the set foam volume of $120 \mathrm{~mL}$ after $36 \mathrm{~s}$, with the set gas flow rate of $200 \mathrm{~mL} \mathrm{~min}^{-1}$. Figure 2-1 shows the foam half-life, $\mathrm{t} 1 \frac{2}{2}$, of CMDs and skimmed milk as a function of total protein concentration. $\mathrm{CMD}_{4}{ }^{\circ} \mathrm{C}$ showed a significantly higher foam half-life than $\mathrm{CMD}_{20^{\circ} \mathrm{C}}$, for all protein concentrations. For both types of $\mathrm{CMD}, \mathrm{t}^{1 / 2}$ increased with protein concentration up to a concentration of $3 \%(w / w)$. Further increases in protein concentration did not improve the foam stability of the CMDs. To rule out the effect of protein concentration, $\mathrm{t}^{1} / 2$ of the skimmed milk was compared to that of CMD with equivalent protein concentration. The total protein concentration of skimmed milk was $3.27 \%(\mathrm{w} / \mathrm{w})$. On comparing $\mathrm{t}^{1 / 2} \mathbf{2}$ values of the samples with a protein concentration of $3 \%$ (w/w) (Fig. 2-1), it can be deduced that the foam stability of $\mathrm{CMD}_{4}{ }^{\circ} \mathrm{C}$ was considerably higher than that of the other samples. $\mathrm{t}^{1} / 2$ of $\mathrm{CMD}_{4}{ }^{\circ} \mathrm{C}$ was higher than $25 \mathrm{~h}$, while that of $\mathrm{CMD}_{20^{\circ} \mathrm{C}}$, was about $230 \mathrm{~min}$, i.e., slightly higher than that of skimmed milk redispersed at $20^{\circ} \mathrm{C}\left(\mathrm{t}_{1 / 2}=120 \mathrm{~min}\right)$ and $4^{\circ} \mathrm{C}\left(\mathrm{t}_{1 / 2}=85 \mathrm{~min}\right)$. After homogenization at $20 \mathrm{MPa}$ for $10 \mathrm{~min}$, the foam stability of $\mathrm{CMD}_{4}{ }^{\circ} \mathrm{C}$ decreased to around $4 \mathrm{~h}$. The effect of the proteolytic activity of plasmin on foam stability of CMD was investigated. There was no significant difference between $\mathrm{t}^{1} / 2$ of $\mathrm{CMD}_{20}{ }^{\circ} \mathrm{C} 3 \%$ with or without plasmin inhibitor added and without. 


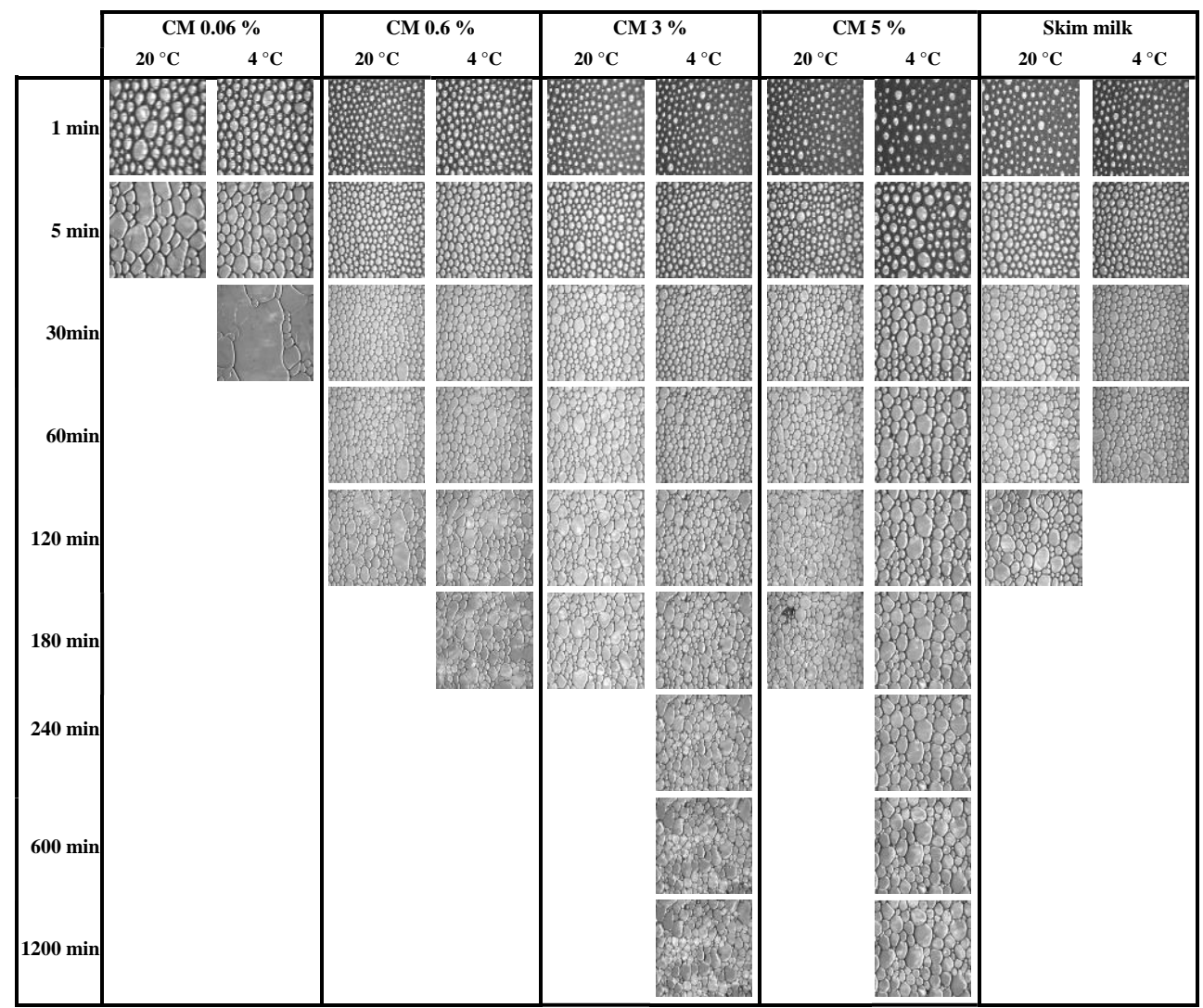

Figure 2-2. Images of bubbles located at the wall of the foaming tube of foams made with CMD and skim milk, for different redispersing temperatures and protein concentrations, at different times.

Bubble images were taken automatically every minute with a CCD camera located at the middle part of the foaming tube (roughly just underneath half of the original foam height). Images taken at 1, 5, 30, 60, 120, 180, 240, 600 and 1200 min after foaming were selected (Figure 2-2). Bubbles were all spherical in the beginning and became polygonal with drainage. Coalescence of bubbles could be clearly visualized already within $30 \mathrm{~min}$ for CMDs with the lowest protein concentration $(0.06 \%$, w/w). For the other samples, bubble coalescence was observed after $30 \mathrm{~min}$. For $\mathrm{CMD}_{4}{ }^{\circ} \mathrm{C}$ with protein concentrations of $3 \%$ and $5 \%(\mathrm{w} / \mathrm{w})$, the images hardly changed after $120 \mathrm{~min}$. The averaged bubble diameter, $D$, determined from the first image after sparging and taken as a measure of the initial mean bubble diameter, was $0.3 \mathrm{~mm}$ for the CMDs with the lowest protein concentration $(0.06 \%$, $\mathrm{w} / \mathrm{w})$ while, for all other samples, with higher protein concentration, it was about $0.15 \mathrm{~mm}$.

\subsubsection{Sample characterization}


Table 2-1 shows the results of the characterisation of the studied samples, including average colloidal particle size (casein micelles and/or aggregates thereof), $\mathrm{pH}$, total protein content and protein and fat content of the supernatants obtained by ultracentrifugation.

Table 2-1. Properties of casein micelle dispersions (CMD) and skim milk redispersed at $20^{\circ} \mathrm{C}$ and $4^{\circ} \mathrm{C}$

\begin{tabular}{|c|c|c|c|c|c|c|}
\hline Samples & $\begin{array}{c}\text { Redispersing } \\
\text { temperature } \\
\left({ }^{\circ} \mathrm{C}\right)\end{array}$ & $\mathrm{pH}$ & $\begin{array}{l}\text { Average } \\
\text { size of } \\
\text { colloidal } \\
\text { particles } \\
(\mathrm{nm})\end{array}$ & $\begin{array}{c}\text { Total protein } \\
\text { concentration } \\
(\%, w / w)\end{array}$ & $\begin{array}{c}\text { Protein } \\
\text { content of } \\
\text { supernatant } \\
(\%, w / w)\end{array}$ & $\begin{array}{c}\text { Fat content of } \\
\text { supernatant } \\
(\%, w / w)\end{array}$ \\
\hline CMD 3\% & 20 & $6.70 \pm 0.01^{\mathrm{b}}$ & $262 \pm 90^{\mathrm{b}}$ & $2.90 \pm 0.21$ & $0.40 \pm 0.03^{\mathrm{c}}$ & $0.02 \pm 0.005^{\mathrm{b}}$ \\
\hline CMD 5\% & 20 & $6.71 \pm 0.01^{\mathrm{b}}$ & $206 \pm 7^{b}$ & $5.02 \pm 0.57$ & $0.66 \pm 0.08^{b}$ & $0.03 \pm 0.01^{\mathrm{b}}$ \\
\hline Nilac & 20 & $6.70 \pm 0.01^{\mathrm{b}}$ & $213 \pm 2^{b}$ & $3.27 \pm 0.02$ & $0.81 \pm 0.00^{\mathrm{a}}$ & $0.07 \pm 0.01^{\mathrm{a}}$ \\
\hline $\begin{array}{l}\text { CMD } \\
3 \% \mathrm{PI}^{*}\end{array}$ & 20 & $6.71 \pm 0.01^{\mathrm{b}}$ & $218 \pm 13^{b}$ & $2.86 \pm 0.01$ & $0.38 \pm 0.00^{c}$ & $0.02 \pm 0.00^{\mathrm{b}}$ \\
\hline CMD 3\% & 4 & $6.78 \pm 0.04^{\mathrm{a}}$ & $555 \pm 143^{a}$ & $3.00 \pm 0.19$ & $0.25 \pm 0.05^{\mathrm{d}}$ & $0.03 \pm 0.01^{\mathrm{b}}$ \\
\hline CMD 5\% & 4 & $6.77 \pm 0.01^{\mathrm{a}}$ & $522 \pm 56^{\mathrm{a}}$ & $5.05 \pm 0.73$ & $0.36 \pm 0.01^{\mathrm{c}}$ & $0.03 \pm 0.00^{\mathrm{b}}$ \\
\hline Nilac & 4 & $6.77 \pm 0.01^{\mathrm{a}}$ & $227 \pm 17^{b}$ & $3.27 \pm 0.03$ & $0.86 \pm 0.01^{\mathrm{a}}$ & $0.07 \pm 0.01^{\mathrm{a}}$ \\
\hline
\end{tabular}

* CMD 3\%PI refers to $\mathrm{CMD}_{20} \mathrm{C} 3 \%$ but with plasmin inhibitor added.

Superscripts with different letters in one column indicate statistical significant differences.

Table 2-2. Particle size distribution of CMDs and skim milk samples in volume fraction $(\%)$

\begin{tabular}{lccccc}
\hline & & Homogenized & & \\
& $\mathrm{CMD}_{20^{\circ} \mathrm{C}}$ & $\mathrm{CMD}_{4}{ }^{\circ} \mathrm{C}$ & $\mathrm{CMD}_{4}{ }^{\circ} \mathrm{C}$ & $9.9 \pm 0.0$ & $99.9 \pm 0.0$ \\
\hline$<500 \mathrm{~nm}$ & $99.9 \pm 0.1$ & $83.7 \pm 8.7$ & $99.7 \pm 0.4$ & $0.1 \pm 0.0$ & 0 \\
$500-2000 \mathrm{~nm}$ & $0.6 \pm 0.3$ & $17.4 \pm 9.8$ & $0.6 \pm 0.3$ & 0 & 0 \\
$2000-5000 \mathrm{~nm}$ & 0 & $2.5 \pm 1.2$ & 0 & 0 & 0 \\
$>5000 \mathrm{~nm}$ & 0 & $1.3 \pm 0.4$ & 0 & 0 & 0 \\
\hline
\end{tabular}




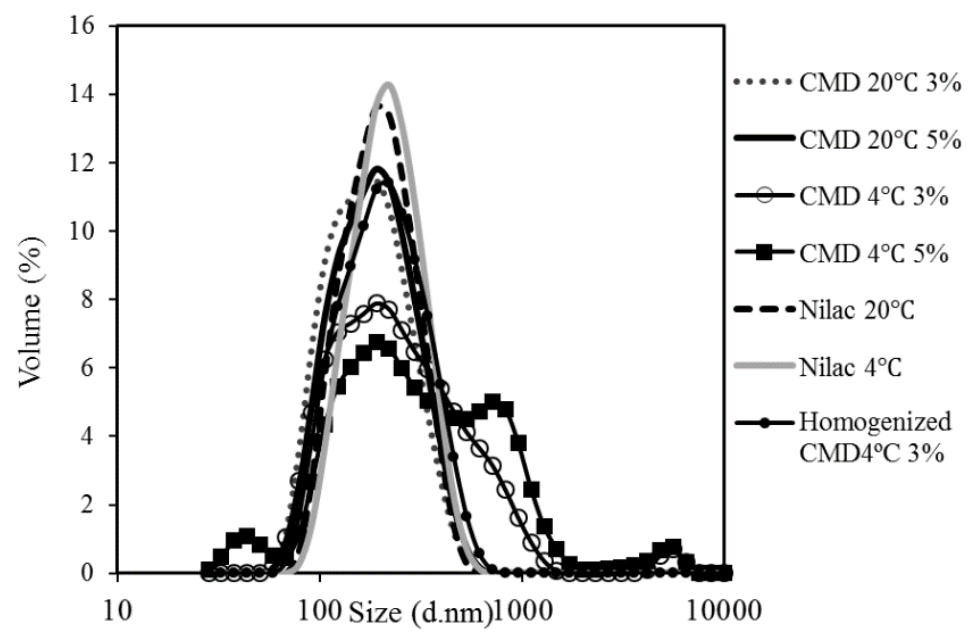

Figure 2-3. Size distribution of colloidal particles in CMD (3\%, w/w) and skim milk (Nilac) redispersed at $20^{\circ} \mathrm{C}$ and $4{ }^{\circ} \mathrm{C}$.

Typical examples of the size distribution of the colloidal particles of the studied samples are shown in Figure 2-3. From these distributions, average particles sizes were calculated and are shown in Table 2-1. The average particle size was around $200 \mathrm{~nm}$ for $\mathrm{CMD}_{20^{\circ} \mathrm{C} \text { and }}$ skim milk samples. It can be deduced that these dispersions contained mainly casein micelles. $\mathrm{CMD}_{4}{ }^{\circ} \mathrm{C}$ had an average particle size of about $500 \mathrm{~nm}$. This means that these dispersions also contained casein micelles aggregates. The aggregates in $\mathrm{CMD}_{4}{ }^{\circ} \mathrm{C}$ accounted for $20 \%$ of the volume fraction, which mostly ranged from $500 \mathrm{~nm}$ to $2 \mu \mathrm{m}$ (Table 2-2). There was less than $0.3 \%$ volume fraction of particles larger than $500 \mathrm{~nm}$ in $\mathrm{CMD}_{20^{\circ} \mathrm{C}}$, skim milk samples and homogenised $\mathrm{CMD}_{4}{ }^{\circ} \mathrm{C}$. The average size distribution of the supernatant of $\mathrm{CMD}_{20^{\circ} \mathrm{C}}$ was also checked, which was around $80 \mathrm{~nm}$. The $\mathrm{pH}$ of the CMDs varied between 6.70 and 6.80, which are normal values for milk [19]. The protein content of Supernatant $4^{\circ} \mathrm{C}$ and Supernatant $20^{\circ} \mathrm{C}$ accounted for 7.0 and $13.8 \%(\mathrm{w} / \mathrm{w})$ of the protein of $\mathrm{CMD}_{4}{ }^{\circ} \mathrm{C}$ and $\mathrm{CMD}_{20^{\circ} \mathrm{C}}$, individually. Generally, $\mathrm{CMD}_{4}{ }^{\circ} \mathrm{C}$ contained more sedimentable protein (casein micelles and or aggregates) than $\mathrm{CMD}_{20}{ }^{\circ} \mathrm{C}$. Accordingly, the protein content of supernatant was higher for $\mathrm{CMD}_{20^{\circ} \mathrm{C} .} \mathrm{CMD}_{20^{\circ} \mathrm{CIP}}$ was prepared with plasmin inhibitor added at the very beginning of redispersion. The protein content of supernatant was slightly less than that of

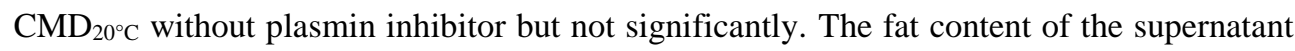
of two CMDs was not significantly different, and was much lower than that of skim milk samples. There was significantly less $\beta$-casein present in the supernatant of $\mathrm{CMD}_{20}{ }^{\circ} \mathrm{C} \%$ than in that of $\mathrm{CMD}_{4}{ }^{\circ} \mathrm{C} 3 \%$ (Figure 2-4). Figure 2-5 shows the viscosity of the studied samples as a function of the shear rate. The viscosity of the $\mathrm{CMD}_{20^{\circ} \mathrm{C}}$ and homogenized $\mathrm{CMD}_{4}{ }^{\circ} \mathrm{C}$ was below $2.0 \mathrm{mPa} \cdot \mathrm{s}$. The viscosity of the $\mathrm{CMD}_{4}{ }^{\circ} \mathrm{C}(5 \%$ and $3 \%, \mathrm{w} / \mathrm{w})$ was higher than that of the other samples. In general, $\mathrm{CMD}_{4}{ }^{\circ} \mathrm{C}$ samples had larger average particle size, more $\beta$ - 
casein casein in supernatant, less total protein in supernatant, and higher viscosity compared to $\mathrm{CMD}_{20}{ }^{\circ} \mathrm{C}$.

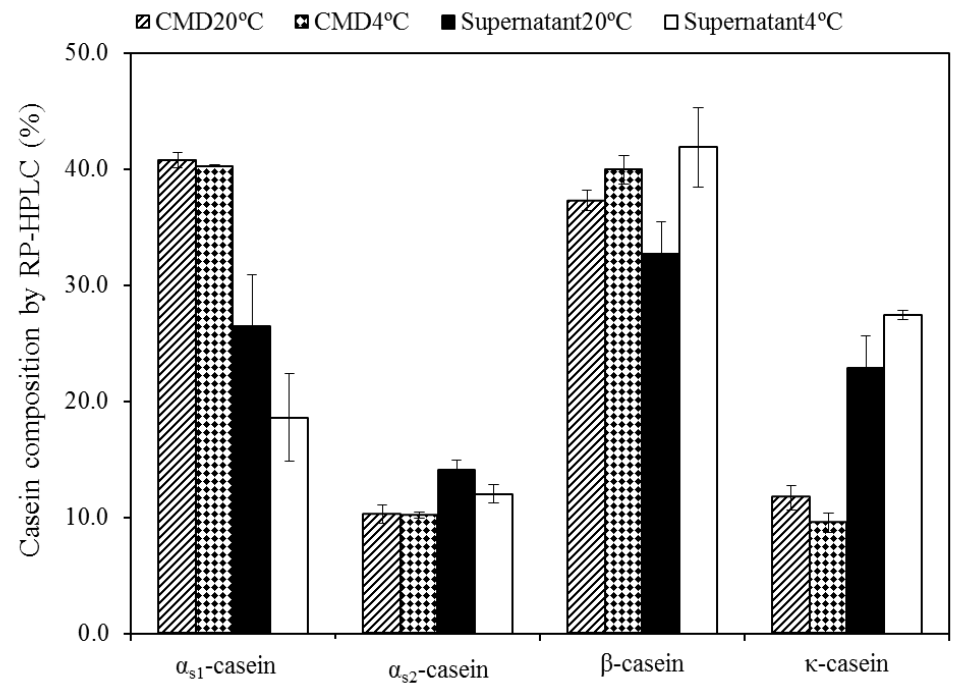

Figure 2-4. Casein composition of CMDs (3\%, w/w) and their supernatants measured by RP-HPLC.

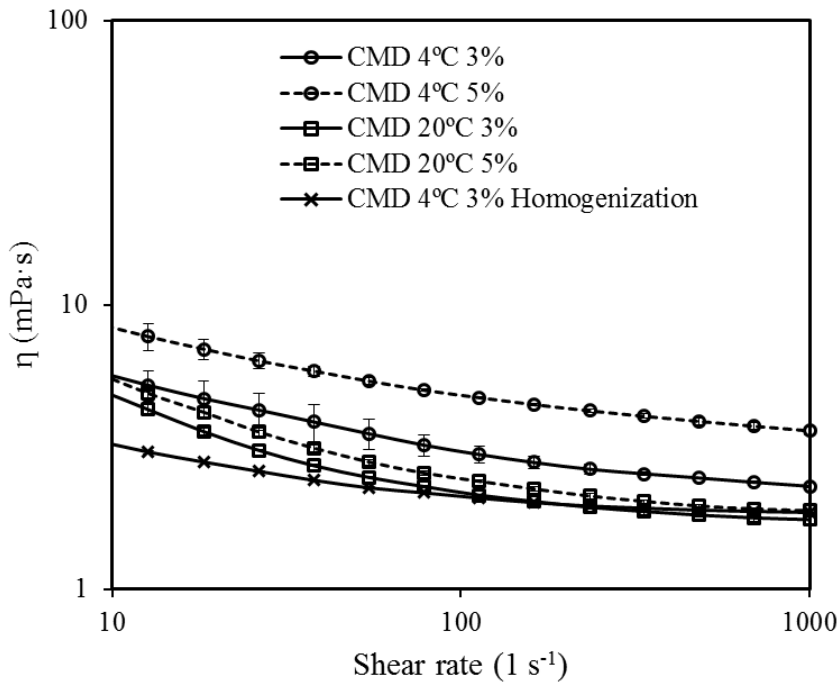

Figure 2-5. Viscosity as a function of shear rate of CMDs (3\% and 5\%,w/w) redispersed at $20^{\circ} \mathrm{C}$ and $4^{\circ} \mathrm{C}$ as well as of homogenized $\mathrm{CMD}_{4}{ }^{\circ} \mathrm{C} 3 \%$. 


\section{Chapter 2}

\subsubsection{Interfacial properties}

The dynamic surface tension was followed for $60 \mathrm{~s}$ in order to consider a time range comparable with that of the foam formation, which took about $40 \mathrm{~s}$. Figure 2-6 shows the surface pressure $(\Pi)$ of $\mathrm{CMD}_{20}{ }^{\circ} \mathrm{C}$ and $\mathrm{CMD}_{4}{ }^{\circ} \mathrm{C}$ as a function of different total protein concentrations at $1 \mathrm{~s}$ and $60 \mathrm{~s}$. There was a clear difference between the adsorption kinetics of the CMDs with $0.06 \%(\mathrm{w} / \mathrm{w})$ protein and that of the other CMDs with higher protein concentrations. In general, the surface pressure of $\mathrm{CMD}_{20^{\circ} \mathrm{C}}$ at $1 \mathrm{~min}$ was slightly higher than that of $\mathrm{CMD}_{4}{ }^{\circ} \mathrm{C}$. This might be attributed to the protein content of the supernatant, which was higher for $\mathrm{CMD}_{20^{\circ} \mathrm{C}}$ than for $\mathrm{CMD}_{4}{ }^{\circ} \mathrm{C}$. The surface pressure of skim milk samples was comparable to that of CMDs with $3 \%$ protein concentration.
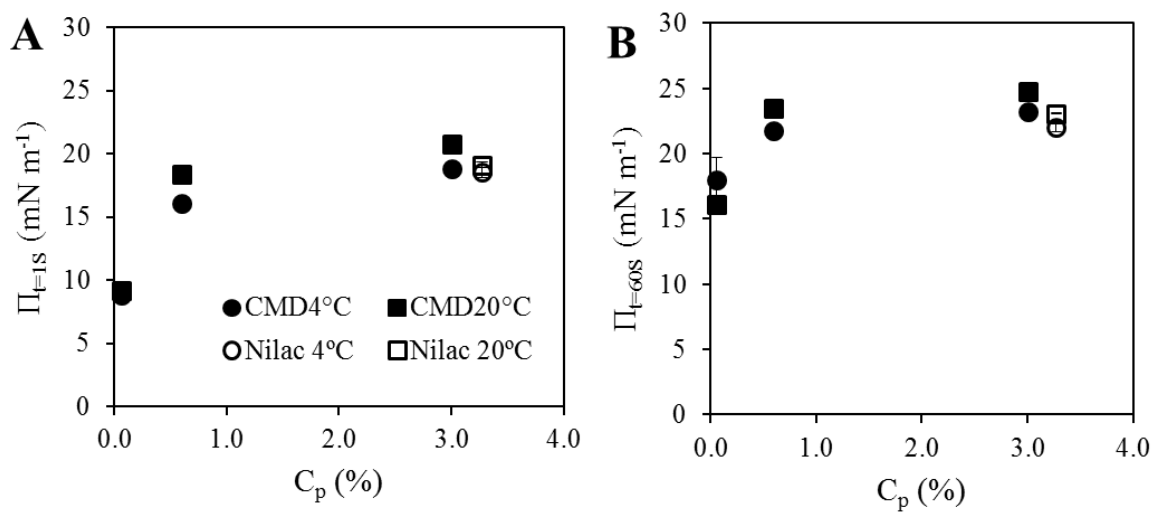

Figure 2-6. Surface pressure $\Pi\left(\mathrm{mN} \mathrm{m}^{-1}\right)$ of $\mathrm{CMD}_{20^{\circ} \mathrm{C}}$ and $\mathrm{CMD}_{4}{ }^{\circ} \mathrm{C}$ with different protein concentrations (A) $\Pi(\mathrm{t}=1 \mathrm{~s})(\mathrm{B}) \Pi(\mathrm{t}=60 \mathrm{~s})$.

A

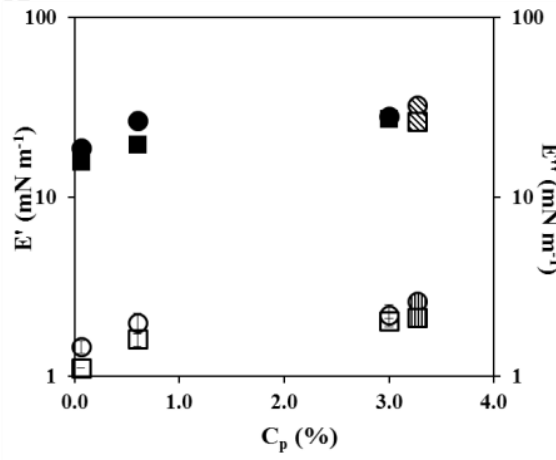

- $\mathrm{E}^{\prime} \mathrm{CMD} 4^{\circ} \mathrm{C}$ OE"CMD $4^{\circ} \mathrm{C}$ QE'Nilac $4^{\circ} \mathrm{C}$ (1) $\mathrm{E}^{\prime \prime} \mathrm{Nilac} 4^{\circ} \mathrm{C}$
- $\mathrm{E}^{\prime} \mathrm{CMD} 20^{\circ} \mathrm{C}$ 口E"CMD $20^{\circ} \mathrm{C}$ \$E'Nilac $20^{\circ} \mathrm{C}$ 四E"Nilac $20^{\circ} \mathrm{C}$
B

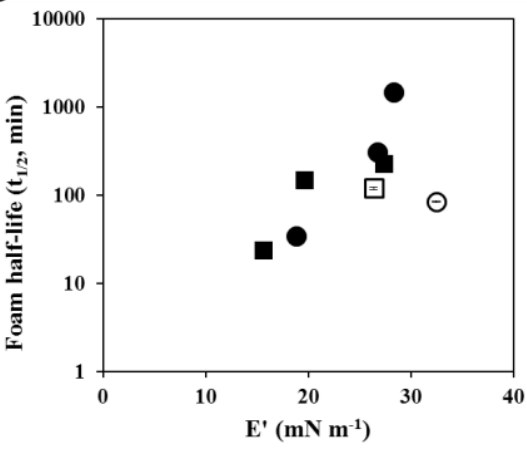

- CMD $4^{\circ} \mathrm{C}$ 口Nilac $20^{\circ} \mathrm{C}$

-CMD $20^{\circ} \mathrm{C}$ ONilac $4^{\circ} \mathrm{C}$ 
Fig. 2-7. Surface elasticity $E^{\prime}\left(\mathrm{mN} \mathrm{m}^{-1}\right)$ and surface viscosity $E^{\prime \prime}\left(\mathrm{mN} \mathrm{m}^{-1}\right)$ of $\mathrm{CMD}_{20^{\circ} \mathrm{C}}$ and $\mathrm{CMD}_{4}{ }^{\circ} \mathrm{C}$ as a function of protein concentrations

Figure 2-7 shows the dilatational elastic and viscous modulus of the air/liquid interface of studied samples. This was determined at $1000 \mathrm{~s}$ after bubble formation, which represents a situation that can be considered as equilibrium. The surface elasticity of CMD increased with increasing protein concentration. $\mathrm{CMD}_{4}{ }^{\circ} \mathrm{C}$ showed a higher surface elasticity at

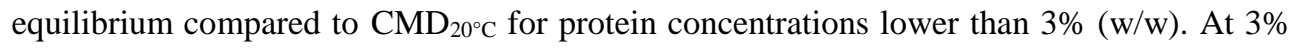
(w/w) protein, $0.1 \mathrm{~Hz}$ and $6 \%$ deformation, no significant difference was observed between $\mathrm{CMD}_{4}{ }^{\circ} \mathrm{C}$ and $\mathrm{CMD}_{20}{ }^{\circ} \mathrm{C}$ in terms of both surface elasticity and viscous modulus. The surface elastic and viscous modulus of skim milk samples were not significantly different from those of CMDs with 3\% protein concentration. It could be seen from Figure 2-7 (B) that, for each CMD, $\mathrm{t}^{1 / 2}$ increased with increasing surface elasticity. However, when $\mathrm{CMD}_{4}{ }^{\circ} \mathrm{C}$ was compared to $\mathrm{CMD}_{20}{ }^{\circ} \mathrm{C}$, there was no correlation between surface elasticity and $\mathrm{t}^{1} / 2$. The same was observed when CMDs were compared to skim milk samples. Foam stability were

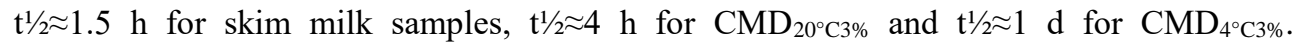
However, these samples had similar surface elasticity.

\subsection{Discussion}

\subsubsection{Role of interfacial properties on foaming properties}

In literature, the formation and stability of foams, including those made with individual milk proteins, have often been related to the adsorption rate of surface active compounds at the air/liquid interface and to the rheological properties of the formed interfacial layer, respectively [20-22]. The adsorption kinetics of proteins are mainly studied by measuring the dynamic surface tension in time [23], which is generally claimed to give information about the stabilizing properties shortly after bubble formation. In this study, all measured samples reached the set foam volume of $120 \mathrm{~mL}$ after $36 \mathrm{~s}$ according to the set gas flow rate of $200 \mathrm{~mL} \mathrm{~min}^{-1}$. This means that, during foam formation, no gas left from the foam, i.e., no coalescence of generated bubbles with the environment occurred. This can be attributed to the fact that the interface at the top of the liquid was generated 15 min before foam formation started, and had higher protein coverage and better stabilizing properties than the interface of the newly generated bubbles. Therefore, for the systems studied here, the adsorption kinetics of the surface-active components of the CMDs was not a limiting factor for foamability. However, the mean bubble size at $1 \mathrm{~min}$ after foam formation was significantly larger $(0.3 \mathrm{~mm})$ for $\mathrm{CMD}_{0.06 \%}$ than for the other samples $(0.15 \mathrm{~mm})$. The effect of the differences in surface pressure at short times $(\mathrm{t}=1 \mathrm{~s})$ which, for $\mathrm{CMD}_{0.06 \%}$ and the other samples was about 9 and $20 \mathrm{mN} \mathrm{m}^{-1}$, respectively, on the difference in bubble size directly after snap off at the orifice is negligible [24]. The same holds for the difference in Laplace pressure, which can only explain a factor of about 1.2. The larger bubble size of $\mathrm{CMD}_{0.06 \%}$ can be attributed to the lower coverage and therefore lower stabilizing properties 


\section{Chapter 2}

of $\mathrm{CMD}_{0.06 \%}$ compared to the other samples, which resulted in rapid bubble coalesce, within 1 min after foam formation.

Dilatational interfacial rheology of the air/liquid interface was conducted to explain the long-term foam stability [22]. As can be seen from Figure 2-7 (A), E' (elastic modulus) was positively correlated with protein concentration. Furthermore, E' of $\mathrm{CMD}_{4^{\circ} \mathrm{C}}$ was slightly

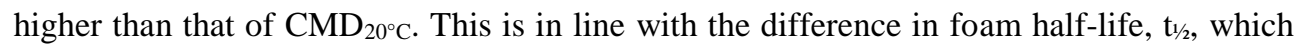
increased with increasing protein concentration for samples with equal ingredients and

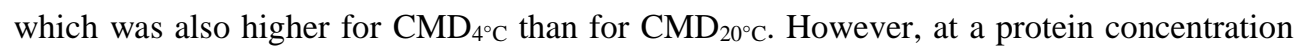
of $3 \%(\mathrm{w} / \mathrm{w})$, at which the difference between the foam stability of $\mathrm{CMD}_{4}{ }^{\circ} \mathrm{C}$ and $\mathrm{CMD}_{20^{\circ} \mathrm{C}}$ was largest, the difference in elastic modulus was negligibly small and not significant. When CMDs were compared to skim milk samples, they showed better foam stability with similar surface modulus. Similar reasoning holds for $E$ " and the relaxation rate $\tau=\omega E$ " $/ E$ '. Therefore, based on interfacial rheology, it may be concluded that the elastic modulus cannot explain the differences observed in foam stability. This supports recent findings by other researchers who did not find a correlation between foam stability and surface elastic modulus [25].

Another possibility for the worse foam stability of $\mathrm{CMD}_{20^{\circ} \mathrm{C}}$ compared to $\mathrm{CMD}_{4}{ }^{\circ} \mathrm{C}$ could be the higher amount of peptides present due to proteolytic action during redispersion at $20^{\circ} \mathrm{C}$. The protein content of its supernatant also indicated that more small molecules could be present in $\mathrm{CMD}_{20}{ }^{\circ} \mathrm{C}$. This would have led to differences in interfacial properties between two CMDs, which were however not found in this study. Also, no difference in foam halflife after addition of plasmin inhibitor at the beginning of preparation of $\mathrm{CMD}_{20^{\circ} \mathrm{C} \text { was }}$ observed. Thus the proteolytic activity of plasmin did not have influence on the foam stability of $\mathrm{CMD}_{20^{\circ} \mathrm{C}}$ in this study.

According to previous research, more $\beta$-casein would dissociate from the casein micelles into the liquid phase (serum) compared to the other casein fractions when milk is held at $4^{\circ} \mathrm{C}$, and this was supposed to result in better interfacial properties, which could contribute

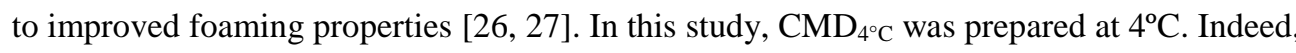
the casein composition of the supernatants confirmed that there was more $\beta$-casein present

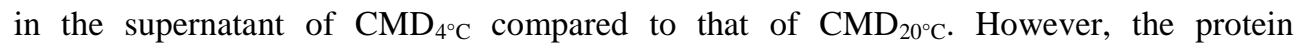
composition did not result in a difference in interfacial rheological properties. However, the elastic properties shown, which are generally used to explain foam stability, were measured at only one frequency and time (at semi equilibrium). The CMDs and skim milk samples contained peptides, different forms of caseins, a small amount of milk fat and possibly other milk proteins. It might also be a coincidence that CMDs and skim milk exhibited a similar interfacial modulus but had different interfacial composition. It is not yet clear to what extent interfacial rheological parameters of protein-stabilized interfaces are directly related to the foam stability. 


\subsubsection{Effect of the size of colloidal particles on foam stability}

A significant difference in particle size distribution was observed between samples redispersed at $20^{\circ} \mathrm{C}$ and $4{ }^{\circ} \mathrm{C}$. The particle size distribution of skimmed milk samples as well as that of all $\mathrm{CMD}_{20^{\circ} \mathrm{C}}$ samples appears as a single peak, with an average around $200 \mathrm{~nm}$. These values are comparable to the values measured for natural casein micelles present in milk [14, 19, 28, 29]. Furthermore, Martin et al. [29] reported a value of $215 \mathrm{~nm}$ for casein micelles present in low-heated skim milk reconstituted at $4{ }^{\circ} \mathrm{C}$, which is close to the values we measured. However, the particle size distribution of the CMDs redispersed at $4^{\circ} \mathrm{C}$ was significantly different from that of the other samples, with an additional peak appearing near $1 \mu \mathrm{m}$. Most probably, this peak corresponds to aggregates of casein micelles that accounted for $20 \%$ volume fraction mostly ranging from $500 \mathrm{~nm}$ to $2 \mu \mathrm{m}$. The relationship between particle size distribution and foam stability can lead to the conclusion that the presence of larger colloidal particles is advantageous for foam stability in this case. In order to check this, $\mathrm{CMD}_{4^{\circ} \mathrm{C} 3 \%}$ samples were also homogenized at 200 bar for $10 \mathrm{~min}$, to dissociate the aggregates. After homogenization, the particle size distribution of the $\mathrm{CMD}_{4}{ }^{\circ} \mathrm{C} 3 \%$ appeared similar to that of $\mathrm{CMD}_{20}{ }^{\circ} \mathrm{C} 3 \%$ and skimmed milk samples (about $200 \mathrm{~nm}$ ). Furthermore, foaming experiments showed a significant decrease in foam stability of the homogenized sample to similar to that of the other samples. One might argue that a lower amount of phospholipids could be released from phospholipid-rich fractions sedimentable by ultracentrifugation, like the milk fat globule membrane MFGM [30], during the limited resuspension of casein micelle pellets at low temperature compared to room temperature. This would result in less phospholipids present in the Supernatant $4^{\circ} \mathrm{C}$ compared to Supernatant $20^{\circ} \mathrm{C}$, and thereby less components able to destabilize the foam of $\mathrm{CMD}_{4}{ }^{\circ} \mathrm{C}$. One might also argue that, after homogenization the unreleased phospholipids within the casein micelle aggregates might be released, with a consequent destabilisation of the foam of $\mathrm{CMD}_{4}{ }^{\circ} \mathrm{C}$. To check this possibility, the total fat content of the Supernatant $4^{\circ} \mathrm{C}$ and Supernatant $20^{\circ} \mathrm{C}$ was measured as an indicator of the content of phospholipids. The amount of fat content in these two supernatants was the same. Therefore, it is unlikely that phospholipids can play a role in the differences in foam stability observed in our research. It can be concluded that the size of the colloidal particles or the presence of larger aggregates determine the foam stability of CMDs observed.

The precise reason for this is at the moment not completely clear. The viscosity of CMDs was slightly higher when casein micelles aggregates were present. The viscosity is an important parameter for foam stability because it is inversely proportional to the drainage rate. A higher viscosity will slow down plateau border drainage and drainage from the thin film to the plateau border. However, viscosity alone cannot explain the large difference in foam stability between $\mathrm{CMD}_{4}{ }^{\circ} \mathrm{C} 3 \%$ and $\mathrm{CMD}_{20}{ }^{\circ} \mathrm{C} 3 \%$. Casein micelles and their aggregates might be confined in the thin film lamellae between bubbles. These trapped colloidal particles can decrease the thinning rate of the film. Furthermore, when colloidal particles have good wetting properties, they can also slow down film drainage and prevent contact 


\section{Chapter 2}

between the two air/liquid interfaces, with subsequent rupture. In previous studies, a similar role of protein aggregates in foam stability has been proposed. The presence of small $\beta$ lactoglobulin aggregates with size of tens of $\mathrm{nm}$ decelerated foam drainage rate, while aggregates with size around $200 \mathrm{~nm}$ were too large to give a stable foam [31, 32]. Similar observations are also described by Nicolai et al. [33], whey protein aggregates induced by heating were claimed to associate and build a network within thin films to enhance foam stability. Recently, a study has shown that protein particles/aggregates slow down foam drainage and disproportionation [34]. The observations that the size of the aggregates primarily control the stability of CMDs are of great importance for a better prediction of the foaming properties of complex systems, such as food foams made from commercial protein concentrates, which often contain both native protein molecules and various amounts of protein aggregates.

In summary, even though a correlation between interfacial properties and foam stability was not found in this study, further research on interfacial properties needs to be conducted as a function of amplitudes of deformation and frequency. This way, more info about mechanical properties of air/liquid interface of two CMDs made at different temperatures can hopefully be uncovered. The presence of casein micelle aggregates appears to be the key factor for the foam stability of CMD. Thin film stability should also be measured to further understand the mechanism by which casein micelle aggregates improve foam stability, by being trapped and confined in the lamella or by formation of a network that slows down the drainage. 


\subsection{Conclusion}

Casein micelle dispersions (CMDs) with different average size of the colloidal particles (casein micelles and/or aggregates thereof) could be obtained by redispersion of casein micelle pellets at different temperatures. CMDs redispersed at $4^{\circ} \mathrm{C}\left(\mathrm{CMD}_{4^{\circ}}\right)$ exhibited significantly higher foam stability than those redispersed at $20^{\circ} \mathrm{C}\left(\mathrm{CMD}_{20^{\circ}}\right)$, almost by a factor of 6 for foam half-life. These differences could not be explained by surface rheological properties and/or protein composition, but could be ascribed to the average size of the colloidal particles present in dispersion. $\mathrm{CMD}_{4^{\circ} \mathrm{C}}$ showing the highest foam stability contained colloidal particles with an average size of about $500 \mathrm{~nm}$ (micelles and/or aggregates), while that of $\mathrm{CMD}_{20}{ }^{\circ} \mathrm{C}$ was about $200 \mathrm{~nm}$. Homogenisation of CMD containing large casein micelle aggregates reduced the average particle size and the foam stability to those of CMD and skimmed milk samples with average particle size of $200 \mathrm{~nm}$. Therefore, the presence of casein micelle aggregates and thus the size of the colloidal particles determine the foam stability of casein micelle dispersions. 


\section{Chapter 2}

\section{References}

1. Huppertz, T., Foaming properties of milk: A review of the influence of composition and processing. International Journal of Dairy Technology, 2010. 63(4): p. 477-488.

2. Ward, B.R., et al., EDTA-induced dissociation of casein micelles and its effect on foaming properties of milk. Journal of Dairy Research, 1997. 64(4): p. 495-504.

3. Borcherding, K., et al., Effect of foaming temperature and varying time/temperature-conditions of preheating on the foaming properties of skimmed milk. International Dairy Journal, 2008. 18(4): p. 349358.

4. Zhang, Z., Dalgleish, D.G. and Goff, H.D., Effect of pH and ionic strength on competitive protein adsorption to air/water interfaces in aqueous foams made with mixed milk proteins. Colloids and Surfaces B: Biointerfaces, 2004. 34(2): p. 113-121.

5. Kamath, S., Webb, R.E. and Deeth, H.C., The composition of interfacial material from skim milk foams. Journal of Dairy Science, 2011. 94(6): p. 2707-2718.

6. Dickinson, E., et al., Adsorption at interfaces in dairy systems. International Journal of Dairy Technology, 1989. 42(1): p. 18-22.

7. Murray, B.S., Stabilization of bubbles and foams. Current Opinion in Colloid \& Interface Science, 2007. 12(4): p. 232-241.

8. Meinders, M.B.J. and van Vliet, T., The role of interfacial rheological properties on Ostwald ripening in emulsions. Advances in Colloid and Interface Science, 2004. 108: p. 119-126.

9. Hilgenfeldt, S., S.A. Koehler, and H.A. Stone, Dynamics of Coarsening Foams: Accelerated and SelfLimiting Drainage. Physical Review Letters, 2001. 86(20): p. 4704-4707.

10. Mulder, H. and P. Walstra, The Milk Fat Globule: Emulsion Science as Applied to Milk Products and Comparable Foods. No. 4. Wageningen, Netherlands, Centre for Agricultural Publishing and Documentation., 1974.

11. Brooker, B.E., Observations on the air-serum interface of milk foams. Food Structure, 1985. 4(2): p. 12.

12. Schmitt, C., et al., Whey protein soluble aggregates from heating with NaCl: Physicochemical, interfacial, and foaming properties. Langmuir, 2007. 23(8): p. 4155-4166.

13. Huppertz, T. and de Kruif, C.G. Rennet-induced coagulation of enzymatically cross-linked casein micelles. International dairy journal, 2007. 17(5): p. 442-447.

14. Beliciu, C.M. and Moraru, C.I., Effect of solvent and temperature on the size distribution of casein micelles measured by dynamic light scattering. Journal of Dairy Science, 2009. 92(5): p. 1829-1839.

15. Ambrose Griffin, M.C. and Griffin, W.G., A simple turbidimetric method for the determination of the refractive index of large colloidal particles applied to casein micelles. Journal of Colloid and Interface Science, 1985. 104(2): p. 409-415.

16. Ribadeau-Dumas, B. and Grappin, R., Milk protein analysis. Le Lait, 1989. 69(5): p. 357-416.

17. Bonfatti, V., et al., Validation of a new reversed-phase high-performance liquid chromatography method for separation and quantification of bovine milk protein genetic variants. Journal of Chromatography A, 2008. 1195(1): p. 101-106.

18. Wüstneck, R., et al., Surface dilatational behavior of $\beta$-casein at the solution/air interface at different pH values. Colloids and Surfaces A: Physicochemical and Engineering Aspects, 2012. 404: p. 17-24.

19. De Kruif, C. and Holt, C., Casein micelle structure, functions and interactions. Advanced Dairy Chemistry-1 Proteins. 2003, p. 233-276. Springer US.

20. Sánchez, C.C. and Patino, J.M.R., Interfacial, foaming and emulsifying characteristics of sodium caseinate as influenced by protein concentration in solution. Food Hydrocolloids, 2005. 19(3): p. $407-$ 416.

21. Rouimi, S., et al., Foam stability and interfacial properties of milk protein-surfactant systems. Food Hydrocolloids, 2005. 19(3): p. 467-478.

22. Wierenga, P. and Gruppen, H., New views on foams from protein solutions. Current Opinion in Colloid \& Interface Science, 2010. 15(5): p. 365-373. 
23. Bos, M.A. and van Vliet, T., Interfacial rheological properties of adsorbed protein layers and surfactants: a review. Advances in Colloid and Interface Science, 2001. 91(3): p. 437-471.

24. Davidson, J.F. and Schüler, B.O.G., Bubble formation at an orifice in a viscous liquid. Chemical Engineering Research and Design, 1997. 75: p. S105-S115.

25. Lech, F.J., et al., Identifying changes in chemical, interfacial and foam properties of $\beta$-lactoglobulinsodium dodecyl sulphate mixtures. Colloids and Surfaces A: Physicochemical and Engineering Aspects, 2014. 462: p. 34-44.

26. Dalgleish, D.G., On the structural models of bovine casein micelles-review and possible improvements. Soft Matter, 2011. 7(6): p. 2265.

27. Reimerdes, E. and H. Klostermeyer, Temperature-dependent changes in milk and milk products. I Change in the ratio of micelle protein to serum protein during refrigeration of milk. 1976. Kiel. Milchwirtsch. Forschungsber, 1976. 28: p. 17-25.

28. Bijl, E., et al., Factors influencing casein micelle size in milk of individual cows: Genetic variants and glycosylation of $\kappa$-casein. International Dairy Journal, 2014. 34(1): p. 135-141.

29. Martin, G.J.O., Williams, R.P.W. and Dunstan, D.E., Comparison of Casein Micelles in Raw and Reconstituted Skim Milk. Journal of Dairy Science, 2007. 90(10): p. 4543-4551.

30. Singh, H., The milk fat globule membrane-A biophysical system for food applications. Current Opinion in Colloid \& Interface Science, 2006. 11(2): p. 154-163.

31. Rullier, B., Novales, B. and Axelos, M.A., Effect of protein aggregates on foaming properties of $\beta$ lactoglobulin. Colloids and Surfaces A: Physicochemical and Engineering Aspects, 2008. 330(2): p. 96-102.

32. Rullier, B., et al., $\beta$-Lactoglobulin aggregates in foam films: Effect of the concentration and size of the protein aggregates. Journal of colloid and interface science, 2010. 343(1): p. 330-337.

33. Nicolai, T., M. Britten, and C. Schmitt, $\beta$-Lactoglobulin and WPI aggregates: Formation, structure and applications. Food Hydrocolloids, 2011. 25(8): p. 1945-1962.

34. Schmitt, C., Bovay, C. and Rouvet, M., Bulk self-aggregation drives foam stabilization properties of whey protein microgels. Food Hydrocolloids, 2014. 42: p. 139-148. 


\title{
Chapter 3
}

\section{Interfacial properties, thin film stability and foam stability of casein micelle dispersions}

\begin{abstract}
Foam stability of casein micelle dispersions (CMDs) strongly depends on aggregate size. To elucidate the underlying mechanism, the role of interfacial and thin film properties was

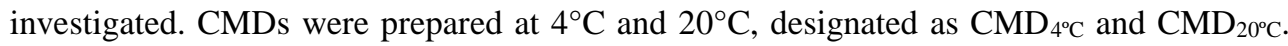
At equal protein concentrations, foam stability of $\mathrm{CMD}_{4}{ }^{\circ} \mathrm{C}$ (with casein micelle aggregates) was markedly higher than $\mathrm{CMD}_{20^{\circ} \mathrm{C}}$ (without aggregates). Although the elastic modulus of $\mathrm{CMD}_{4}{ }^{\circ} \mathrm{C}$ was twice as that of $\mathrm{CMD}_{20^{\circ} \mathrm{C}}$ at $0.005 \mathrm{~Hz}$, the protein adsorbed amount was slightly higher for $\mathrm{CMD}_{20^{\circ} \mathrm{C}}$ than for $\mathrm{CMD}_{4}^{\circ} \mathrm{C}$, which indicated a slight difference in interfacial composition of the air/water interface. Non-linear surface dilatational rheology showed minor differences between mechanical properties of air/water interfaces stabilized by two CMDs. These differences in interfacial properties could not explain the large difference in foam stability between two CMDs. The thin film analysis showed that films made with $\mathrm{CMD}_{20^{\circ} \mathrm{C}}$ drained to a more homogeneous film compared to films stabilized by $\mathrm{CMD}_{4}{ }^{\circ} \mathrm{C}$. Large casein micelle aggregates trapped in the thin film of $\mathrm{CMD}_{4^{\circ} \mathrm{C}}$ made the film more heterogeneous. The rupture time of thin films was significantly longer for $\mathrm{CMD}_{4^{\circ} \mathrm{C}}(>1 \mathrm{~h})$ than for $\mathrm{CMD}_{20^{\circ} \mathrm{C}}(<600 \mathrm{~s})$ at equal protein concentration. After homogenization, which broke down the aggregates, the thin films of $\mathrm{CMD}_{4}{ }^{\circ} \mathrm{C}$ became much more homogeneous, and both the rupture time of thin films and foam stability decreased significantly. In conclusion, the increased stability of foam prepared with $\mathrm{CMD}_{4^{\circ}} \mathrm{C}$ appears to be the result of entrapment of casein micelle aggregates in the liquid films of the foam.
\end{abstract}

Published as:

Chen, M., Sala, G., Meinders, M. B., van Valenberg, H. J., van der Linden, E., \& Sagis, L. M. (2017). Interfacial properties, thin film stability and foam stability of casein micelle dispersions. Colloids and Surfaces B: Biointerfaces, 149, 56-63. 


\section{Chapter 3}

\subsection{Introduction}

Milk proteins are widely used to produce aerated products in food industry, like e.g. aerated desserts, whipped cream, and cappuccino foam. Caseins, which make up about $80 \%$ of cow milk protein and are predominantly present in the form of colloidal particles, termed casein micelles, exhibit good foaming properties[1]. Kamath et al. (2011)[2] discovered that isolated micellar casein fractions could produce foams with much higher stability than skim milk. The improved foam stability of micellar casein fractions was ascribed to improved interfacial properties. In a recent study, we found that casein micelle dispersions prepared at $4^{\circ} \mathrm{C}\left(\mathrm{CMD}_{4^{\circ} \mathrm{C}}\right)$, with an average particle size of $500 \mathrm{~nm}$ and which contained aggregates of casein micelles, formed much more stable foams compared to foams made from CMD prepared at $20^{\circ} \mathrm{C}\left(\mathrm{CMD}_{20^{\circ}} \mathrm{C}\right)$. The latter CMD had a smaller average particle size $(200 \mathrm{~nm})$, and consisted predominantly of non-aggregated micelles. The aggregates present in $\mathrm{CMD}_{4}{ }^{\circ} \mathrm{C}$, which appeared to play a crucial role in the increased foam stability, caused only marginal changes in linear dilatational properties of the air/water interface, and these minor differences could not explain the large difference in foam stability between the two CMDs.

There are several factors that can influence the stability of aqueous foams. Among these are the properties of the adsorbed interfacial layer between air and liquid phase (surface tension, dilatation modulus, surface shear modulus), and the bulk properties of the liquid films that separate the bubbles[3]. For relatively simple systems, like foams stabilized by LMW-surfactants, the interfacial properties of the air/water interface are often found to be dominant for foam stabilization[4, 5], [6]. For more complex systems, stabilized by (mixtures of) proteins or colloidal particles, it is still unclear whether interfacial or bulk film properties are dominant for the foam stability. Previous studies have reported that protein aggregates can have a large influence on foam stability. The presence of whey protein soluble aggregates [7], $\beta$-Lactoglobulin aggregates [8-10] and whey protein fibrils [11] was shown to improve foam stability, but other studies indicated that their presence can also decrease foam stability [12]. Rullier et al.[8-10] studied films and foams made from mixtures of non-aggregated $\beta$-Lactoglobulin and their aggregates, and found that film stability was dependent on the aggregate size and on the ratio between non-aggregated proteins and protein aggregates. For aggregate fractions ranging from 1 to $90 \%$ of the total protein concentration $(1 \mathrm{~g} / \mathrm{L})$, gel formation in the thin film was observed. For higher fractions of aggregates, it was shown that the amounts of non-aggregated proteins were no longer sufficient to completely cover the interface, and as the larger aggregates did not reduce the surface tension at short times as much as the non-aggregated protein, the corresponding films and foams were less stable. For the fractions between 1 and $90 \%$, the rheological properties of the interface were not determined. It is therefore hard to establish whether the immobilization of the films is the result of in-plane (surface) gel formation, cross-film (bulk) gel formation, or a combination of both. 
A recent review reported improved foam stability in the presence of protein aggregates without causing significant differences in the interfacial properties of the air/water interface[13], which is in line with our previous research [14]. In our previous study the minor differences in linear surface rheology of air/water interfaces stabilized by CMDs could not explain the large difference in foam stability. However, we determined the dilatational properties only at small deformations and constant frequency, and did not perform large amplitude dilatations, which are more sensitive to subtle changes in the microstructure of the interface. Particularly when coarsening of the foam is predominantly driven by disproportionation, interfaces are subjected to large deformations, and dilatational moduli data determined at small deformations are therefore not a good indicator to establish whether surface properties play a role in foam stability.

The composition of air/water interfaces stabilized by different CMDs is still largely unknown. CMD is a mixture of four kinds of caseins, peptides, small micelles, casein micelles and casein micelle aggregates. The adsorption of casein micelles on the interface is still under debate. Borcherding et al. (2008 )[15] indicated that casein micelles are not likely to be present at the air/water interface. In another study, microscopic images of bubble ghosts of milk foam suggested that casein micelles were adsorbed at the air/ liquid interface, possibly reversibly[16].

In the current study, foaming properties, interfacial properties and thin film stability of CMDs with different particle size distribution and of their supernatants were investigated. Samples were characterised for size distribution of the casein micelles (aggregates) and protein concentration. Sodium-caseinate was studied as a control. Frequency and strain amplitude dependence of the surface dilatational modulus of the CMDs were checked in large amplitude oscillatory dilatation. The absorbed amount of protein at the air/water interface for the different samples was determined by ellipsometry. Thin film properties including rupture time and morphology of the thin liquid film were studied by a microscope equipped with a Scheludko cell. Foam properties such as the foam half-life $\left(t_{1 / 2}\right)$ and mean bubble diameter were obtained from bubble image analysis. By combining the above measurements, the relation between interfacial properties and foam stability as well as relationship between thin film stability and foam stability was examined to establish the mechanism behind the significantly improved foam stability of CMDs prepared at low temperature.

\subsection{Material and Methods}

\subsubsection{Materials}

Low-heated skim milk powder NILAC was obtained from NIZO food research (Ede, Netherland). Sodium caseinate (EM7-A9040445) was obtained from DMV International (Veghel, The Netherlands). Sodium azide was purchased from Sigma Aldrich (Zwijndrecht, The Netherlands). Ultra-pure water (MilliQ Purelab Ultra, Darmstadt, Germany), free of 


\section{Chapter 3}

surface active contaminants, was used in all experiments $(>18.2 \mathrm{M} \Omega-\mathrm{cm}$, surface tension of $72.26 \pm 0.4 \mathrm{mN} / \mathrm{m}$ at $\left.20^{\circ} \mathrm{C}\right)$.

\subsubsection{Preparation of casein micelle dispersions (CMDs) and their supernatants}

Skim milk was reconstituted $(10 \%, \mathrm{w} / \mathrm{w})$ by dissolving NILAC milk powder in MilliQ water and stirring overnight at room temperature. Sodium azide $(0.02 \%, \mathrm{w} / \mathrm{w})$ was added as a preservative. The reconstituted skim milk was ultracentrifuged (L-60 Beckman Ultracentrifuge, rotor type $70 \mathrm{Ti}$, Krefeld, Germany) at $100,000 \mathrm{~g}$ for 90 minutes at $20^{\circ} \mathrm{C}$ according to Huppertz and de Kruif[17]. The obtained casein micelle pellets were separated from the serum phase and ground using a Mixer Mill MM 400 (Retsch GmbH, Haan, Germany) at a frequency of $30 \mathrm{~Hz}$ for 10 minutes at room temperature. Subsequently, different amounts of the obtained casein micelle paste were redispersed in milk permeate either at $20^{\circ} \mathrm{C}$ or at $4^{\circ} \mathrm{C}$ for 60 hours to obtain casein micelle dispersions (CMD) with $2.5 \%$ (w/w) protein concentrations. $\mathrm{CMD}_{20^{\circ} \mathrm{C}}$ denotes the $\mathrm{CMD}$ redispersed at $20^{\circ} \mathrm{C}$ and $\mathrm{CMD}_{4}{ }^{\circ} \mathrm{C}$ is a CMD made at $4{ }^{\circ} \mathrm{C}$. The milk permeate was prepared by reconstitution of milk permeate powder $(5.76 \%$, w/w) in MilliQ water for 30 minutes. Milk permeate powder was prepared by ultrafiltration of the reconstituted skim milk $(10 \%, \mathrm{w} / \mathrm{w})$ using a polysulfone membrane with a pore size of $10 \mathrm{kDa}$ and surface area of $0.48 \mathrm{~m}^{2}$. The dimensions of the membrane were $73.5 \mathrm{~L}$ x $3.2 \mathrm{~cm}$ o.d. The skim milk was stirred and cooled at $4^{\circ} \mathrm{C}$ for one hour before being poured into the cold trap $\left(8^{\circ} \mathrm{C}\right)$. Subsequently it was filtered through the membrane under pressure. The milk permeate was collected, freeze-dried and stored at $-20^{\circ} \mathrm{C}$. The calcium activity of the permeate is $4.76 \mathrm{E}-04$, which is comparable to that of skim milk (4.88E-04).

For the thin film studies with homogenized $\mathrm{CMD}_{4}{ }^{\circ} \mathrm{C}, \mathrm{CMD}_{4}{ }^{\circ} \mathrm{C}$ samples with protein concentration of $2.5 \%(\mathrm{w} / \mathrm{w})$ were homogenized at $20 \mathrm{MPa}$ for $10 \mathrm{~min}$ with a homogenizer (Delta Instruments, Drachten, the Netherlands).

For the preparation of the supernatants, CMDs and skim milk samples were ultracentrifuged for a second time according to the procedure described above. Their protein content was further analysed as described below.

\subsubsection{Characterization of samples}

\section{Particle size}

The size distribution of the colloidal particles (casein micelles and/or aggregates) present in milk and CMDs was measured using a Malvern Zetasizer Nano-ZS (Malvern Instruments Ltd, Worcestershire, United Kingdom). The samples were diluted with milk permeate to a protein concentration of $0.03 \%(\mathrm{w} / \mathrm{w})$ and subsequently transferred into a cuvette (DTS0012) using a syringe. A single measurement consisted of 11 runs and the duration of each run was $10 \mathrm{~s}$. The refractive indices used for the calculation of the sizes were 1.341[18] for the milk permeate and 1.57[19] for the casein micelles, respectively. The measurement angle was set to $173^{\circ}$ backscatter (NBS default) with automatic measurement duration. Three measurements of each sample without pausing were performed at $20^{\circ} \mathrm{C}$. 


\section{Protein content}

The total nitrogen content of the samples was determined using the Dumas method[20]. Specimens of $200 \mu \mathrm{L}$ were dried in an oven at $60^{\circ} \mathrm{C}$ overnight. A factor of 6.38 was used for the conversion of the nitrogen content into total protein content.

\subsubsection{Foaming properties}

The foaming properties were assessed with a FoamScan (Teclis IT-Concept, Longessaigne, France). Foam was generated by sparging air through a porous frit in $40 \mathrm{~mL}$ solution. The gas flow rate was set at $200 \mathrm{~mL} \mathrm{~min}^{-1}$ until the volume of the foam reached $120 \mathrm{~mL}$. After reaching this volume, the gas flow rate was set to 0 . All experiments were carried out at $20^{\circ} \mathrm{C}$. All solutions were stirred for one hour prior to foaming at room temperature. The foam volume was estimated from light intensity of tube images based on calibration of pixels and the black/white coefficient (greyscale level) was set to 55\%. Foam volume was recorded as a function of time. The measurement stopped when the foam volume reached half of its initial value. The corresponding time $t_{1 / 2}$ (foam half-life) was used as a measure for foam stability. For $\mathrm{CMD}_{4}{ }^{\circ} \mathrm{C}$, the foam stability was also checked using a foaming tube $(2.0 \mathrm{~cm}$ in diameter, $34.0 \mathrm{~cm}$ in height, glass grid at the bottom) and sparging.

\section{Bubble size distribution}

2D images of the bubbles of the foam at the wall of the FoamScan tubes were recorded using a CCD camera. The image covered an area of $1.0 \mathrm{~cm}^{2}$. From the images, analysed using Matlab V.2013a (Mathworks) and the Dip Image software (Quantitative Imaging Group, Faculty of Applied Sciences, Delft University of Technology, Delft, The Netherlands), the mean bubble diameter, $D$, was calculated.

\subsubsection{Determination of the interfacial properties with Profile Analysis Tensiometer (PAT)}

The surface properties were measured using a SINTERFACE PAT 1-M (SINTERFACE Technologies, Berlin, Germany) and data were analysed using SINTERFACE Profile Analysis Tensiometer PAT 1-M version 1.4.0.685 software according to van Kempen et al. [21] with some modifications. The pendant drop method was used and the area of the droplet was $25 \mathrm{~mm}^{2}$, with volume ranging from $13-14 \mathrm{~mm}^{3}$. The surface tension of ultrapure water used in this experiment was $72.26 \pm 0.4 \mathrm{mN} / \mathrm{m}$. Sinusoidal oscillation was applied after reaching equilibrium ( $\mathrm{t}=1000 \mathrm{~s})$ with 5 oscillations in one sweep to obtain the surface elastic modulus E' and surface viscous modulus E'. There were 10 cycles of sweeps with $10 \mathrm{~s}$ pause in between for each measurement. The dependence of $\mathrm{E}^{\prime}$ on different deformation amplitudes $(7.5 \%, 10 \%, 15 \%, 20 \%$ and $30 \%)$ was assessed at frequency of $0.1 \mathrm{~Hz}$. Results of non-linear dilatational rheology were analysed by Lissajous plots of surface pressure versus strain. Besides, the frequency dependence of E' was determined with amplitude of $7.5 \%$ at various frequencies $(0.005 \mathrm{~Hz}, 0.01 \mathrm{~Hz}, 0.05 \mathrm{~Hz}$, $0.1 \mathrm{~Hz}$ and $0.2 \mathrm{~Hz}$ ). The slope of a double logarithmic plot of $\mathrm{E}^{\prime}$ versus frequency was determined using linear regression. The protein concentrations of the studied samples were the same as those shown in Table 3-1. 


\section{Chapter 3}

\subsubsection{Ellipsometry}

The adsorption to the air-liquid interfaces of the samples was monitored using a Multiskop ellipsometer (Optrell, Germany). Surface load $\left(\Gamma, \mathrm{mg} / \mathrm{m}^{2}\right)$ in time was measured. $21.0 \mathrm{~mL}$ of each sample $(0.1 \%$, w/w) was placed in a plastic plate with a diameter of $5.0 \mathrm{~cm}$. The rate of adsorption from $1.0 \mathrm{mg} / \mathrm{mL}$ solutions was measured at least in duplicate at $20^{\circ} \mathrm{C}$. The wavelength of the laser was set to be $6328 \AA$. The values for the ellipsometric angles $\Delta$ and $\varphi$ were used to calculate $\Gamma$, using software from the supplier (Optrell). To do this, the refractive index and thickness of the adsorbed protein layer were fitted in a model based on two bulk phases (air and water) and one adsorbed layer, with parameters: $\mathrm{n}_{\text {air }}=1.000$, $\mathrm{n}_{\text {permeate }}=1.333, \mathrm{n}_{\text {proteinsolution }}=1.456, \mathrm{dn} / \mathrm{dc}=0.185$. The angle of incidence was $50^{\circ}$. Control experiments with ultra-pure water between measurements confirmed the right ellipsometric angles $\Delta$ and $\varphi$.

\subsubsection{Thin film stability}

The thin film stability was measured by micro interferometry using a microscope (Axio plan 01, Zeiss, Jena, Germany) according to Lech et al.[22] with some modifications. Thin liquid films (diameter $=200 \mu \mathrm{m})$ were made in a Scheludko cell $($ diameter $=0.3 \mathrm{~cm})$ closed with a glass cover. The casing had a reservoir of milk permeate at the bottom to ensure a relative humidity of $100 \%$ in the cell during measurements. Samples had initial concentrations equal to those given in Table 3-1, and were diluted by a factor of 2000 prior to measurement. All samples were equilibrated to room temperature $\left(20^{\circ} \mathrm{C}\right)$ for $1 \mathrm{~h}$ before measurements. Liquid was drawn into the capillary with a syringe $(500 \mu \mathrm{L}$, Hamilton, Reno, NV, USA) and the whole setup was left to equilibrate for $10 \mathrm{~min}$ before a thin film was made by drawing sample solution into the capillary. The microscope was in reflected light mode, equipped with a five mega pixel CCD camera (Mightex Systems, Pleasanton, CA, USA). If a film did not break after $60 \mathrm{~min}$, it was considered stable. In this case, the lifetime was expressed as $>3600 \mathrm{~s}$. The rupture time was the time from reaching a diameter of $200 \mu \mathrm{m}$ to the time of rupture. In case of stable films, samples were measured for 5 times. In the case of rupturing films, experiments were repeated 10 times to calculate the average and standard deviation of the rupture time and film thickness. Images of the thin films were collected with a software script (developed at the Laboratory of Food Chemistry, Wageningen University) for Matlab (Software version 2013b, MathWorks, Natick). The magnification was $\times 100$.

\subsubsection{Statistical analysis}

All the tests were conducted at least in triplicate. The results obtained were subjected to one-way analysis of variance (ANOVA). Duncan's new multiple range test was performed using SPSS 22.0 software (SPSS Inc., Chicago, IL, USA) to determine the difference between samples which is significant when $p<0.05$. 


\subsection{Results and discussion}

Table 3-1. Particle size and protein content of casein micelle dispersions (CMDs), their supernatants, and sodium caseinate.

\begin{tabular}{lll}
\hline & $\begin{array}{l}\text { Average size of the } \\
\text { Samples }\end{array}$ & $\begin{array}{l}\text { Protein content } \\
\text { casein micelles }\end{array}$ \\
& $(\%, w / w)$ \\
& (aggregates) & \\
\hline $\mathrm{CMD}_{20^{\circ} \mathrm{C}}$ & $262 \pm 90$ & $2.52 \pm 0.13$ \\
$\mathrm{CMD}_{4^{\circ} \mathrm{C}}$ & $555 \pm 143$ & $2.64 \pm 0.03$ \\
Supernatant $_{\mathrm{CDM} 20^{\circ} \mathrm{C}}$ & $88 \pm 4$ & $0.22 \pm 0.01$ \\
Supernatant $_{\mathrm{CMD} 4^{\circ} \mathrm{C}}$ & $144 \pm 6$ & $0.15 \pm 0.01$ \\
Sodium caseinate & ------ & $2.59 \pm 0.00$ \\
\hline
\end{tabular}

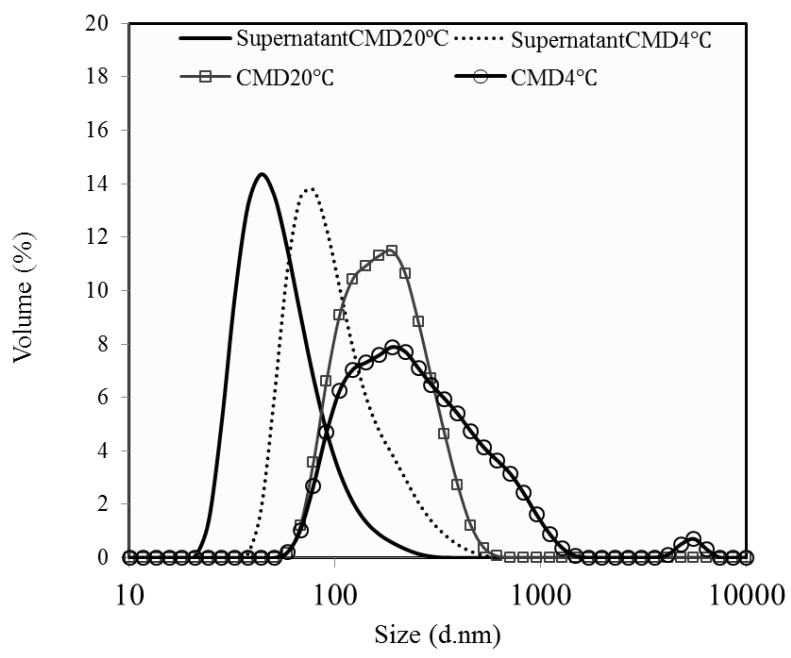

Figure 3-1. Particle size distribution of CMDs and supernatants.

As shown in Table 3-1, the average particle size of the $\mathrm{CMD}_{20^{\circ} \mathrm{C}}$ was around $200 \mathrm{~nm}$ and that of $\mathrm{CMD}_{4}{ }^{\circ} \mathrm{C}$ around $500 \mathrm{~nm} . \mathrm{CMD}_{4}{ }^{\circ} \mathrm{C}$ had some aggregates of casein micelles ranging

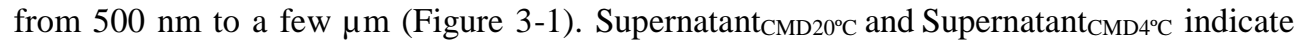
the supernatants of $\mathrm{CMD}_{20^{\circ} \mathrm{C}}$ and $\mathrm{CMD}_{4}{ }^{\circ} \mathrm{C}$, which contained the small molecular weight fractions of the two CMDs, respectively. There was still some small casein micelles present 


\section{Chapter 3}

in these supernatants. The particle size was $88 \mathrm{~nm}$ for Supernatant ${ }_{\mathrm{CMD} 20^{\circ} \mathrm{C}}$ and $144 \mathrm{~nm}$ for Supernatant $\mathrm{CMD}_{\mathrm{C}^{\circ} \mathrm{C}}$. The protein content of Supernatant ${ }_{\mathrm{CMD} 20^{\circ} \mathrm{C}}$ was slightly higher than that of Supernatant $\mathrm{CMD}^{\circ} \mathrm{C}$, indicating that $\mathrm{CMD}_{20^{\circ} \mathrm{C}}$ contained more non-sedimentable protein.

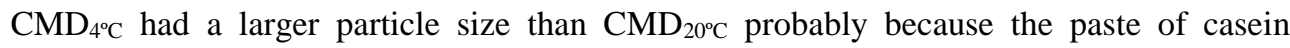
micelles, which contained mostly pieces of casein pellet, had a worse dispersibility at low temperature. Since the $\mathrm{pH}$ and ionic strength of the two dispersions were the same, we assumed that the temperature-dependent dispersibility of the casein micelles pastes was controlled by the temperature dependence of electrostatic and hydrophobic interactions between casein micelles as described by Horne (1998)[23].

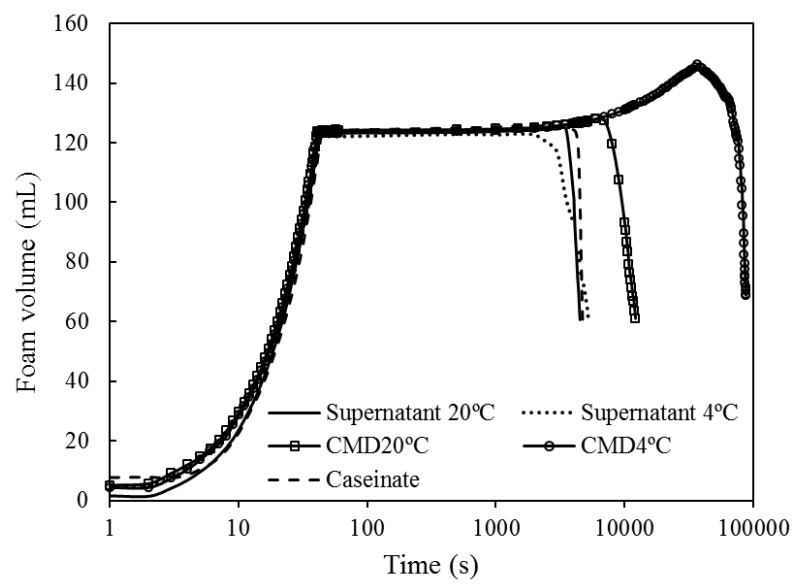

Figure 3-2. Foam volume decay curve of CMDs, supernatants and sodium caseinate till half of the initial foam volume.

All measured samples reached the set foam volume of $120 \mathrm{~mL}$ after $36 \mathrm{~s}$, with a gas flow rate of $200 \mathrm{~mL} \mathrm{~min}{ }^{-1}$. The decay of the foam volume as a function of time was measured, and the foam half-life ( $t_{1 / 2}$, the time at which the foam volume had decreased to half of its initial value) was determined. As shown in Figure 3-2, $t_{1 / 2}$ was similar for Supernatant ${\mathrm{CMD} 20^{\circ} \mathrm{C}}^{\circ}$, Supernatant $\mathrm{CMD}^{\circ}{ }^{\circ} \mathrm{C}$ and sodium caseinate, equal to about $1.5 \mathrm{~h}$, in spite of the fact that the sodium caseinate sample had a much higher protein concentration than the supernatants. For samples with the same protein concentration of $2.5 \%(\mathrm{w} / \mathrm{w})$, the $t_{1 / 2}$ was

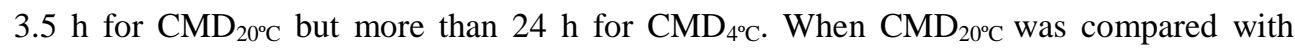
Supernatant $\mathrm{CMD}_{\mathrm{C} 20^{\circ} \mathrm{C}}, t_{1 / 2}$ of the supernatant was lower by a factor of 2 , while its protein concentration was lower by a factor of 11.5 . For $\mathrm{CMD}_{4^{\circ} \mathrm{C}}$ and Supernatant ${ }_{\mathrm{CMD} 4}{ }^{\circ} \mathrm{C}$, the foam half-life of the CMD was higher by a factor of 16 , while its protein concentration was higher by a factor of about 17 . This shows that removing casein micelle aggregates from $\mathrm{CMD}_{4^{\circ} \mathrm{C}}$ dramatically decreased the foam stability. For $\mathrm{CMD}_{4^{\circ}} \mathrm{C}$, a slight increase in foam volume with time was observed. This increase was a result of the slow leakage of a small amount of gas form the sparger. The foam stability of $\mathrm{CMD}_{4^{\circ} \mathrm{C}}$ was also determined with a 
glass foaming tube, also by sparging: the foam volume did not increase in time, and the foam stability was even longer than that determined with the FoamScan. To check for any influence of proteolytic action during redispersion of $\mathrm{CMD}_{20^{\circ} \mathrm{C}}$ on foam stability, a plasmin inhibitor was added to the samples. No difference in foam half-life was observed in samples prepared with or without plasmin inhibitor added. One minute after foam formation there was no significant difference in the mean bubble size of the studied samples (results not shown). However, $60 \mathrm{~min}$ after foam formation bubble coalescence clearly had occurred in the foam made with sodium caseinate and with the two supernatants. The mean bubble size increased by a factor of 2 , while the mean bubble size of $\mathrm{CMD}_{20^{\circ} \mathrm{C}}$ and $\mathrm{CMD}_{4}{ }^{\circ} \mathrm{C}$ increased by a factor of 1.5 . After $240 \mathrm{~min}$, the foam made with $\mathrm{CMD}_{4}{ }^{\circ} \mathrm{C}$ turned into a kind of solid foam and its structure did not change any more.

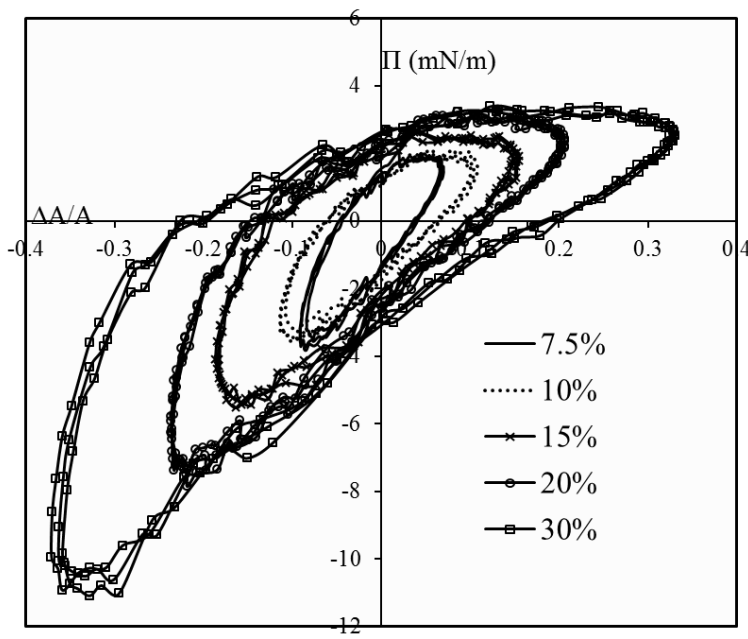

Figure 3-3. Lissajous plots of $\mathrm{CMD}_{4}{ }^{\circ} \mathrm{C}$ at different amplitudes of deformation at $0.1 \mathrm{~Hz}: 7.5 \%$ (solid line), 10\% (dotted line), 15\% (solid line with cross), 20\% (solid line with blank circle) and $30 \%$ (solid line with blank square).

Figure 3-3 shows the Lissajous plots of the liquid/air interface stabilized by $\mathrm{CMD}_{4}{ }^{\circ} \mathrm{C}$ at different amplitudes of deformation $(7.5 \%, 10 \%, 15 \%, 20 \%$ and $30 \%)$ at a frequency of 0.1 Hz. The Lissajous curves have asymmetric shapes even at the lowest deformation of $7.5 \%$, which indicates that the maximum linear strain for this interface was below $7.5 \%$. With increasing amplitude of deformation, the response of the air/water interface became more viscous. The asymmetric shape of the Lissajous curves indicates that the air/liquid interfaces were strain softening during extension and strain hardening during compression. Interestingly, for the highest amplitude, when maximum compression is reached $(\Delta \mathrm{A} / \mathrm{A}=$ $30 \%$ ), and the interface is subsequently expanded again, the slope of the Lissajous curve at the start of the extension within the cycle is very steep, which is indicative of an initially 


\section{Chapter 3}

strong resistance against extension. This indicates that compression leads to increased cohesion between interfacial structural elements. This is a response typical of interfaces stabilized by components that assemble into a gelled or jammed state after adsorption to the interface (for example, particles, proteins, or certain types of oligosaccharide esters [11]). Both the asymmetry in the Lissajous curves and the strain amplitude dependence of the response are indications that in-plane deviatoric stresses contribute to the response to dilatation [11],[24], [25], [26].

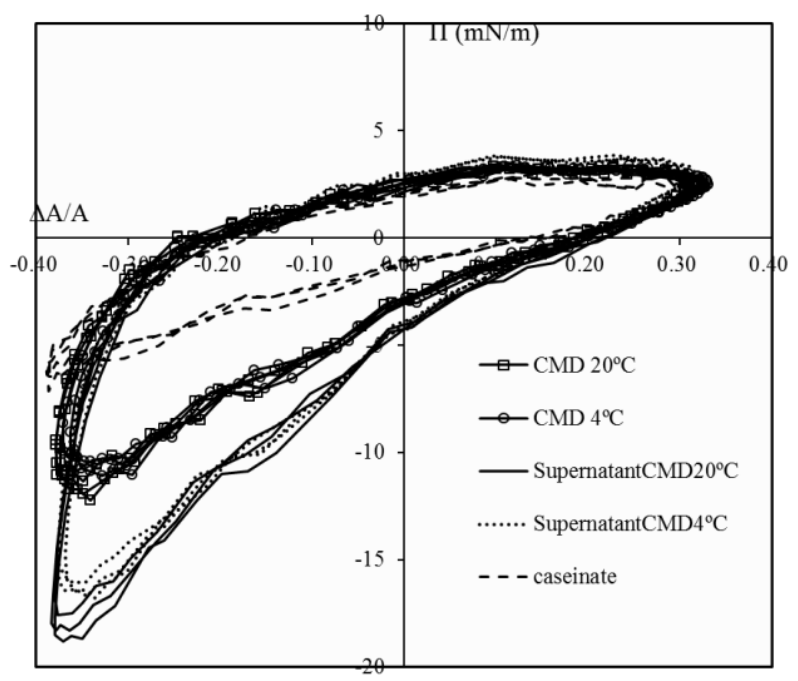

Figure 3-4. Lissajous plots of CMDs, supernatants and sodium caseinate at $30 \%$ deformation at $0.1 \mathrm{~Hz}$.

In Figure 3-4, the Lissajous plots at $30 \%$ deformation and $0.1 \mathrm{~Hz}$ of air/water interfaces stabilized by CMDs, supernatants and sodium caseinate are shown. Compared to the two CMDs, sodium caseinate-stabilized interfaces had a significantly lower resistance against dilation, and did not show a strong increase in cohesion upon compression, which indicates the air/water interface formed by pure sodium caseinate is quite different in microstructure from interfaces stabilized by CMDs. The presence of casein micelles in the sub phase is hence affecting the microstructure of the interface, either by adsorption of micelles into the interface or by attachment to a primary layer formed by individual protein molecules. When supernatants were compared with CMDs, the response of the air/water interfaces showed no significant difference to dilation in the extension part of the cycle (upper right quadrant of the Lissajous curve). However, the supernatant-stabilized interfaces displayed stronger strain hardening during compression, and had a higher modulus in this part of the cycle. According to the size distributions in Figure 3-1, the supernatants contained significantly smaller micelles, and in spite of a much lower protein concentration than the CMDs, these 
smaller micelles may lead to a denser and more homogeneous interfacial structure, with a higher resistance to compression.

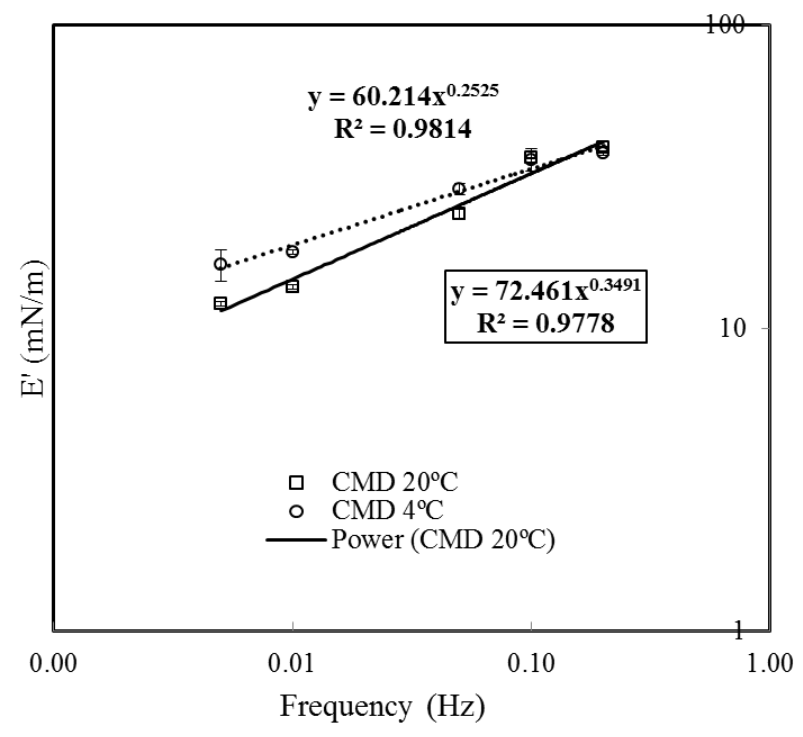

Figure 3-5. Surface elastic modulus (E') of air/water interface stabilized with $\mathrm{CMD}_{20^{\circ} \mathrm{C}}$ and $\mathrm{CMD}_{4}{ }^{\circ} \mathrm{C}$ as a function of frequency.

At a frequency of $0.1 \mathrm{~Hz}$ and $30 \%$ deformation amplitude, there was no significant difference between the mechanical properties of $\mathrm{CMD}_{20^{\circ} \mathrm{C}}$ and $\mathrm{CMD}_{4}{ }^{\circ} \mathrm{C}$. To check if the structures of the interfaces were indeed similar, we determined the frequency dependence of the elastic modulus (E'). The slope of a double logarithmic plot of complex surface dilatational modulus as a function of frequency was determined. From Figure 3-5, we can see that at the lowest frequency of $0.005 \mathrm{~Hz} \mathrm{CMD}_{4}{ }^{\circ} \mathrm{C}$-stabilized interfaces had a significantly higher E' than those stabilized by $\mathrm{CMD}_{20^{\circ} \mathrm{C}}$, approximately a factor of 2 . The slope $n$ of the scaling relation $E_{d}^{\prime} \sim \omega^{n}$ was equal to 0.35 for $\mathrm{CMD}_{20^{\circ} \mathrm{C}}$ and 0.25 for $\mathrm{CMD}_{4}{ }^{\circ} \mathrm{C}$, which

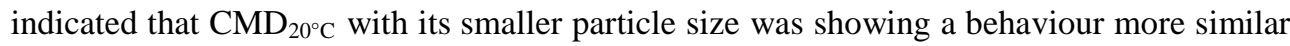
to that of a surfactant system (which according to the Lucassen van den Tempel model[27] have an exponent $n=0.5$ ). This is consistent with the fact that there was more nonsedimentable protein (small peptides, free caseins, and small micelles) in $\mathrm{CMD}_{20^{\circ} \mathrm{C}}$ compared to $\mathrm{CMD}_{4}{ }^{\circ} \mathrm{C}$.

CMDs contained small peptides, individual caseins, casein micelles and casein micelle aggregates, which all differ significantly in size. Small surface-active agents diffuse significantly faster than large particles[28]. Based on the surface rheology results, one possible structure for the CMD interface could be a heterogeneous structure consisting of patches of peptides and individual caseins. Aggregates could either be randomly 


\section{Chapter 3}

incorporated in this structure or randomly attached to a primary layer of peptides, caseins and small micelles. Upon compression, small peptides and caseins, which are often reversibly adsorbed, can be pushed out of the interface, leading to an increase in surface fraction of by micelles and aggregates. The observed strain hardening is then a result of jamming of these larger structures. This would also explain the increased cohesion after full compression.
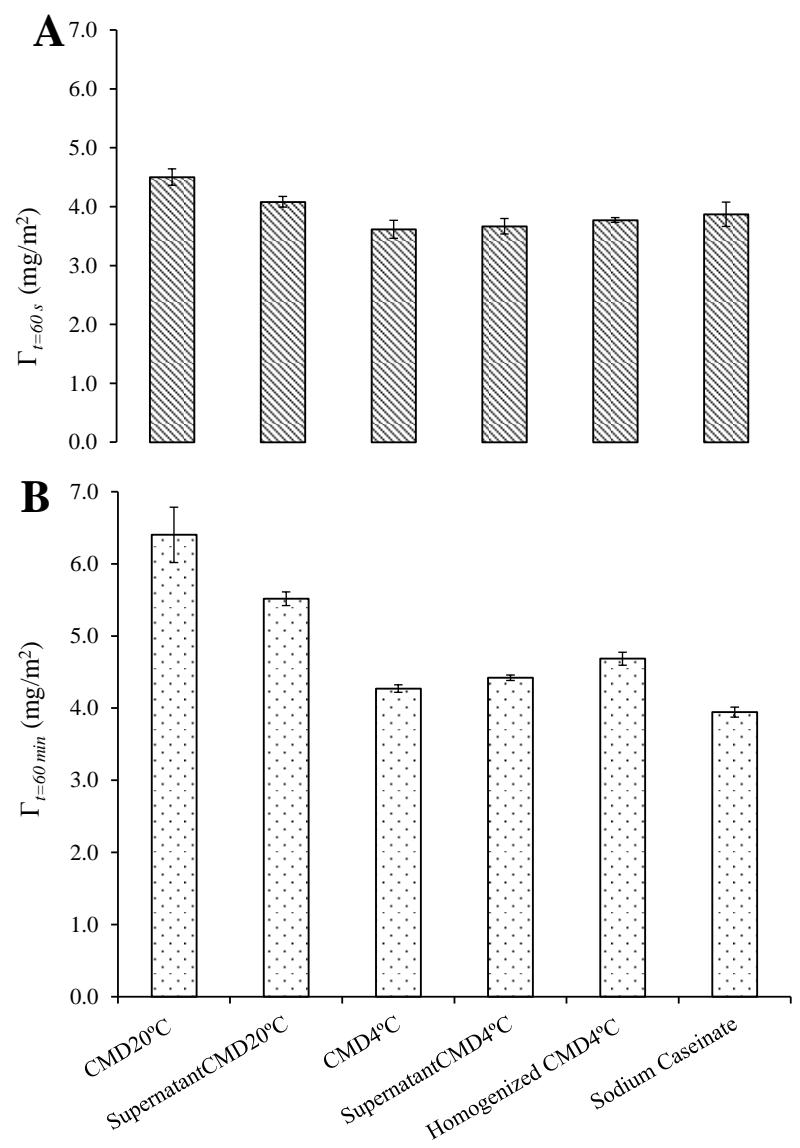

Figure 3-6. Adsorbed amount $\Gamma\left(\mathrm{mg} / \mathrm{m}^{2}\right)$ of CMDs, supernatants and sodium caseinate at $\mathrm{C}_{\mathrm{p}}=0.1 \%$, w/w. (A) $\Gamma_{\mathrm{t}=60 \mathrm{~s}}$ (B) $\Gamma_{\mathrm{t}=60 \mathrm{~min}}$

The adsorbed amount of protein at a single air/water interface of all samples at $\mathrm{t}=60 \mathrm{~s}$ and $60 \mathrm{~min}$ is shown in Figure 3-6. The protein concentration in the sub phase was $0.1 \%(\mathrm{w} / \mathrm{w})$ for all studied samples. When the CMDs were compared to their respective supernatants, there was no significant difference between the adsorbed amounts. In the surface dilatational rheology experiments we saw that the responses of the CMD- and supernatant- 
stabilized interfaces to extension was also identical. In spite of the equal protein loading of CMD- and supernatant-stabilized interfaces, the latter displayed a higher degree of strain hardening in compression. As we postulated before, the smaller micelles in the supernatant may form a somewhat more homogeneous microstructure, with a slightly higher resistance

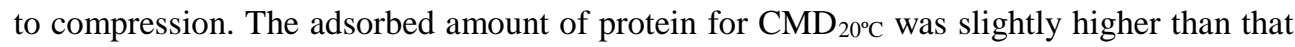
for $\mathrm{CMD}_{4}{ }^{\circ} \mathrm{C}$, yet the dilatational modulus of interfaces stabilized by the latter was slightly higher, particularly at low frequencies. So the presence of large aggregates in the sub phase was affecting the surface rheology of the air/water interface, albeit to a minor extent.

Summarising, interfaces stabilized by these CMDs differed only slightly in their surface rheology, even though the half-life of their foams was remarkably different. Supernatants showed a stronger strain hardening effect during compression than CMD stabilized interfaces, in spite of the fact that former had much lower protein concentrations, and contained smaller casein micelles and no aggregates of micelles. However, the stability of foams prepared from the supernatants was much worse than that of foam prepared from either CMD. We conclude from the above that there is no direct correlation between the surface rheological properties and foam stability of CMDs. Several recent articles also reported that aggregates had large effects on foam stability, without inducing differences in surface rheological properties [13, 29, 30]. However, this does not mean that interfacial properties are not important for foam stability, but the thin film properties are probably more dominant. Rouimi et al. (2005)[31], who studied milk protein-surfactant systems, found a correlation between elastic component of the dilatational modulus of the air-water interface and foam stability. However, Georgieva et al. (2009)[32], who studied non-ionic surfactants and pluronics copolymers, and Fruhner et al. (2000)[5], who investigated different types of surfactants and surface active substances like sodium dodecyl sulfate (SDS), cetyltrimethylammonium bromide (CTAB) and Triton-X-100, reported that a direct relation between surface dilatational elasticity values and foam stability could not be detected. Instead of surface elasticity, the surface viscosity of protein films was implicated in stabilizing foams against drainage[32]. Wierenga et al. (2010)[33] suggested that researchers should reconsider the relationship between foam stability and interfacial properties, especially for systems with protein aggregates or surfactant and particle mixtures. 


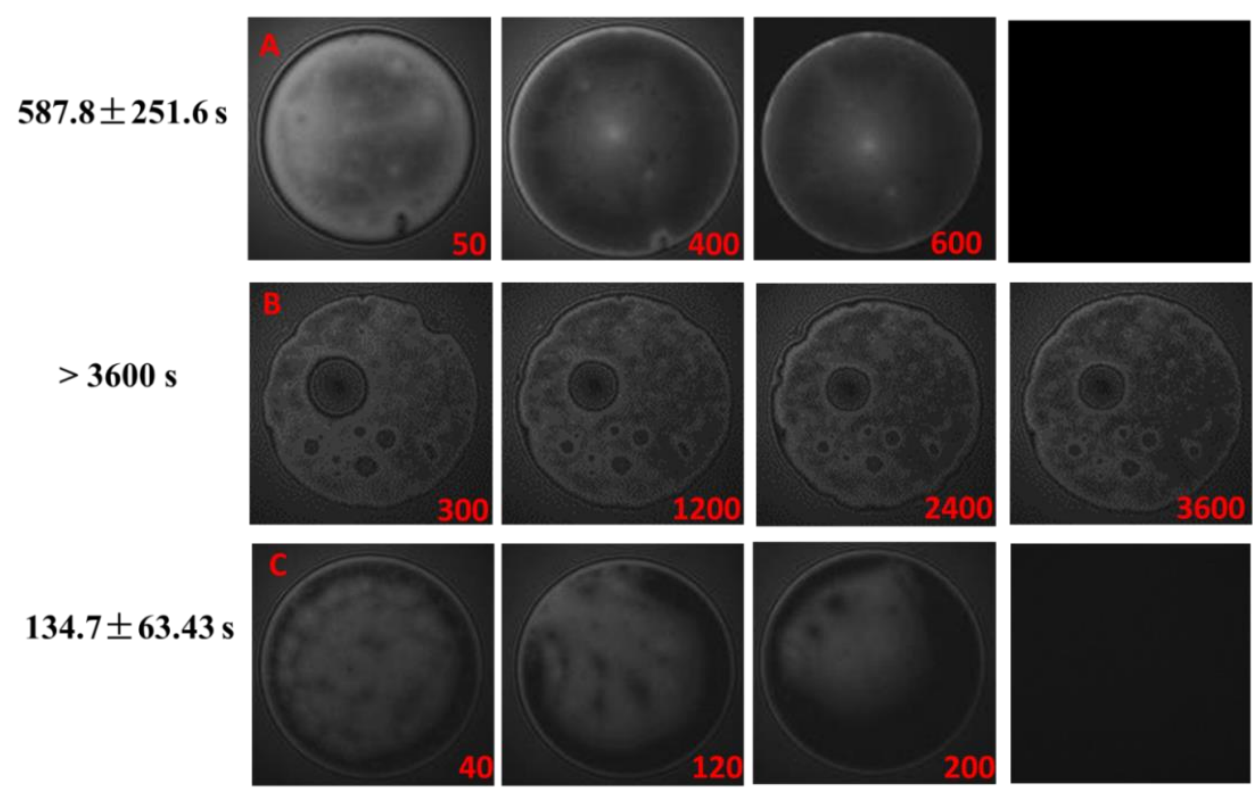

Figure 3-7. Microscopic images at different time points and rupture times of thin films made with (A) $\mathrm{CMD}_{20^{\circ} \mathrm{C}}$, (B) $\mathrm{CMD}_{4}{ }^{\circ} \mathrm{C}$ and (C) homogenized $\mathrm{CMD}_{4}{ }^{\circ} \mathrm{C}$ at $\mathrm{C}_{\mathrm{p}}=0.00125 \%$, w/w. The number at the left side is the rupture time of the film. The red number on each image is the time scale at which the image was collected. The magnification is $\times 100$.

The thin film balance technique was used to examine the effects of particle size on drainage from the lamellae to the plateau borders as well as on the thin film stability. Films with a diameter of $200 \mu \mathrm{m}$ were generated in a Scheludko cell with a diameter of $0.3 \mathrm{~cm}$. The film thickness could not be measured because the films stabilized by both CMDs were inhomogeneous and scattered the light so that no clear interference pattern with varying

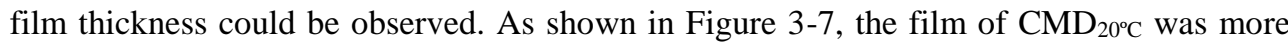
homogenous than that of $\mathrm{CMD}_{4}{ }^{\circ} \mathrm{C}$, with no large patches or aggregates present. Before the

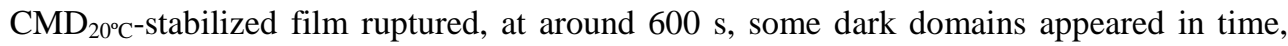
corresponding to local thinning of the film due to drainage, in line with the stepwise stratification of casein submicelles film observed by Koczo et al. (1995)[34]. The behaviour

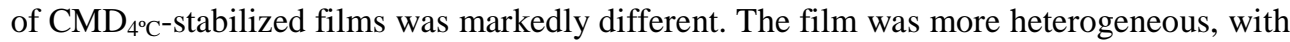
large casein micelle aggregates stuck in the thin film. There was no obvious thinning of the film, and aggregates were not moving. After $3600 \mathrm{~s}$, the film of $\mathrm{CMD}_{4}{ }^{\circ} \mathrm{C}$ was still stable and in the same state as it was at the start of the measurement, although a minor degree of thinning in regions between aggregates could be observed. After homogenization, the film of the $\mathrm{CMD}_{4}{ }^{\circ} \mathrm{C}$ sample was more homogeneous. Casein micelle aggregates were no longer present in this sample and casein micelles gradually drained out from one side of the cell. 
After about 150 to $200 \mathrm{~s}$, the film ruptured, compared to a rupture time of more than $1 \mathrm{~h}$ for the non-homogenized sample. The morphology of thin film made with homogenized

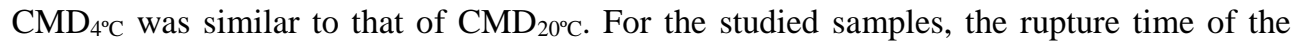
thin films was in the same order as of the foam half-life. This indicates that the much higher foam stability of $\mathrm{CMD}_{4}{ }^{\circ} \mathrm{C}$ was not due to a surface effect, but rather the result of entrapment of large aggregates in the lamellae and plateau borders of the foam, which slowed (and even stopped) drainage of liquid from the foam. The mechanism by which the aggregates contribute to film stabilization and to more stable foam cannot be deduced from these measurements with complete certainty. Our study of the interfacial properties strongly suggests that aggregates are not adsorbed in the interface, and are either attached to it as a sublayer or remain in the bulk phase. Both of these options can lead to a pinning of the thin film, and a slowing down of the drainage of liquid from the film (and foam). Saint-Jalmes et al. (2005)[4], also found that during aging thin liquid films became static, with casein micelle aggregates confined and trapped in them, which slowed down the film thinning. Other studies also suggest that aggregates that do not adsorb at the air/water interface might be confined inside the lamella or entrapped inside the plateau borders, as observed in foam stabilized by hydrophilic non-absorbing nanoparticles[35]. Nicolai et al. (2011)[36] claimed that whey protein aggregates formed by heating associated and built a network within thin films, leading to enhanced foam stability. Whether this also occurs for the casein micelle dispersions above sufficiently high concentrations is not yet clear. 


\section{Chapter 3}

\subsection{Conclusions}

Foam prepared from casein micelle dispersions (CMDs) with different preparation histories exhibited vastly different foam stability, with half-life times around $24 \mathrm{~h}$ for dispersions prepared at $4^{\circ} \mathrm{C}$, and $3.5 \mathrm{~h}$ for dispersions prepared at $20^{\circ} \mathrm{C}$. The dilatational properties of air/liquid interfaces stabilized by both CMDs and their supernatants were determined in large amplitude oscillatory dilatation as a function of frequency and deformation amplitude and were compared with the properties of interfaces between air and aqueous sodium caseinate dispersions. The CMD-stabilized interfaces had clearly different interfacial mechanical properties compared to caseinate-stabilized air/water interfaces. Nevertheless, both CMDs were fairly similar in their response and no correlation between the surface rheology and foam stability of CMDs was found. Thin films stabilized with CMD without casein micelle aggregates were more homogeneous compared to those of CMD containing large casein micelle aggregates. The latter films had a much longer rupture time. There was a strong link between thin film properties and foam stability of CMDs with different particle size distribution. We conclude that rather than changing the surface rheology, micellar aggregates become trapped in the lamellae and plateau borders of the foam, and subsequently slow down (and even stop) drainage of liquid from the foam. 


\section{References}

1. Fox, P.F. and McSweeney, P.L.H., Advanced Dairy Chemistry. New York: kluwer Academic/Plenum Publishers, 2003. 1: p. 1-48.

2. Kamath, S., Webb, R.E. and Deeth, H.C., The composition of interfacial material from skim milk foams. Journal of Dairy Science, 2011. 94(6): p. 2707-2718.

3. Cantat, I., et al., Foams: Structure and Dynamics. 2013: OUP Oxford.

4. Saint-Jalmes, A., et al., Differences between protein and surfactant foams: microscopic properties, stability and coarsening. Colloids and Surfaces A: Physicochemical and Engineering Aspects, 2005. 263(1): p. 219-225.

5. Fruhner, H., Wantke, K. D. and Lunkenheimer, K., Relationship between surface dilational properties and foam stability. Colloids and Surfaces A: Physicochemical and Engineering Aspects, 2000. 162(1): p. 193-202.

6. Pugh, R., Foaming, foam films, antifoaming and defoaming. Advances in Colloid and Interface Science, 1996. 64: p. 67-142.

7. Schmitt, C., et al., Whey protein soluble aggregates from heating with NaCl: Physicochemical, interfacial, and foaming properties. Langmuir, 2007. 23(8): p. 4155-4166.

8. Rullier, B., Novales, B. and Axelos, M.A.V., Effect of protein aggregates on foaming properties of $\beta$ lactoglobulin. Colloids and Surfaces A: Physicochemical and Engineering Aspects, 2008. 330(2): p. 96-102.

9. Rullier, B., et al., $\beta$-Lactoglobulin aggregates in foam films: Correlation between foam films and foaming properties. Journal of Colloid and Interface Science, 2009. 336(2): p. 750-755.

10. Rullier, B., et al., $\beta$-Lactoglobulin aggregates in foam films: Effect of the concentration and size of the protein aggregates. Journal of colloid and interface science, 2010. 343(1): p. 330-337.

11. Oboroceanu, D., et al., Fibrillization of whey proteins improves foaming capacity and foam stability at low protein concentrations. Journal of Food Engineering, 2014. 121: p. 102-111.

12. Schmidt, I., et al., Foaming properties of protein/pectin electrostatic complexes and foam structure at nanoscale. Journal of Colloid and Interface Science, 2010. 345(2): p. 316-324.

13. Wierenga, P.A., van Norél, L. and Basheva, E.S., Reconsidering the importance of interfacial properties in foam stability. Colloids and Surfaces A: Physicochemical and Engineering Aspects, 2009. 344(1-3): p. 72-78.

14. Chen, M., et al., Particle size determines foam stability of casein micelle dispersions. International Dairy Journal, 2016. 56: p. 151-158.

15. Borcherding, K., et al., Effect of foaming temperature and varying time/temperature-conditions of preheating on the foaming properties of skimmed milk. International Dairy Journal, 2008. 18(4): p. 349358.

16. Brooker, B.E., Observations on the air-serum interface of milk foams. Food Structure, 1985. 4(2): p. 12.

17. Huppertz, T. and de Kruif, C.G., Rennet-induced coagulation of enzymatically cross-linked casein micelles. International dairy journal, 2007. 17(5): p. 442-447.

18. Beliciu, C.M. and Moraru, C.I., Effect of solvent and temperature on the size distribution of casein micelles measured by dynamic light scattering. Journal of Dairy Science, 2009. 92(5): p. 1829-1839.

19. Ambrose Griffin, M.C. and W.G. Griffin, A simple turbidimetric method for the determination of the refractive index of large colloidal particles applied to casein micelles. Journal of Colloid and Interface Science, 1985. 104(2): p. 409-415.

20. Ribadeau-Dumas, B. and Grappin, R., Milk protein analysis. Le Lait, 1989. 69(5): p. 357-416.

21. van Kempen, S.E., et al., Non-linear surface dilatational rheology as a tool for understanding microstructures of air/water interfaces stabilized by oligofructose fatty acid esters. Soft Matter, 2013. 9(40): p. 9579-9592.

22. Lech, F.J., et al., Stability Properties of Surfactant-Free Thin Films at Different Ionic Strengths: Measurements and Modeling. Langmuir, 2015. 31(9): p. 2777-2782. 


\section{Chapter 3}

23. Horne, D.S., Casein Interactions: Casting Light on the Black Boxes, the Structure in Dairy Products. International Dairy Journal, 1998. 8(3): p. 171-177.

24. Sagis, L., Humblet-Hua, K. and van Kempen, S., Nonlinear stress deformation behavior of interfaces stabilized by food-based ingredients. Journal of Physics: Condensed Matter, 2014. 26(46): p. 464105.

25. Sagis, L., Generalized surface momentum balances for the analysis of surface dilatational data. The European Physical Journal Special Topics, 2013. 222(1): p. 31-38.

26. Sagis, L.M., Dynamic properties of interfaces in soft matter: Experiments and theory. Reviews of Modern Physics, 2011. 83(4): p. 1367.

27. Lucassen, J. and Van Den Tempel, M., Dynamic measurements of dilational properties of a liquid interface. Chemical Engineering Science, 1972. 27(6): p. 1283-1291.

28. Bos, M.A. and van Vliet, T., Interfacial rheological properties of adsorbed protein layers and surfactants: a review. Advances in Colloid and Interface Science, 2001. 91(3): p. 437-471.

29. Bals, A. and Kulozik, U., Effect of pre-heating on the foaming properties of whey protein isolate using a membrane foaming apparatus. International Dairy Journal, 2003. 13(11): p. 903-908.

30. Davis, J.P. and Foegeding, E.A., Foaming and Interfacial Properties of Polymerized Whey Protein Isolate. Journal of Food Science, 2004. 69(5): p. C404-C410.

31. Rouimi, S., et al., Foam stability and interfacial properties of milk protein-surfactant systems. Food Hydrocolloids, 2005. 19(3): p. 467-478.

32. Georgieva, D., Cagna, A. and Langevin, D. Link between surface elasticity and foam stability. Soft Matter, 2009. 5(10): p. 2063-2071.

33. Wierenga, P. and Gruppen, H., New views on foams from protein solutions. Current Opinion in Colloid \& Interface Science, 2010. 15(5): p. 365-373.

34. Koczo, K., et al., Layering of Sodium Caseinate Submicelles in Thin Liquid Films- A New Stability Mechanism for Food Dispersions. Journal of Colloid and Interface Science, 1996. 178(2): p. 694-702.

35. Fameau, A.L. and Salonen, A., Effect of particles and aggregated structures on the foam stability and aging. Comptes Rendus Physique, 2014. 15(8): p. 748-760.

36. Nicolai, T., Britten, M. and Schmitt, C., $\beta$-Lactoglobulin and WPI aggregates: Formation, structure and applications. Food Hydrocolloids, 2011. 25(8): p. 1945-1962. 


\title{
Chapter 4
}

\section{Mechanism of ultra-stabilization of foam by casein micelle aggregates}

\begin{abstract}
The effect of concentration and size of casein micelle aggregates (CMAs) on foam stability and thin film stability was investigated. The majority of the aggregates were spherical particles, which were visualized in the foam lamella by optical microscopy. Foam and thin film properties were investigated of mixtures with varying ratios of two casein micelle dispersions being a casein micelle aggregate dispersion (CMAD) with average aggregate/particle size of $6.7 \pm 0.5 \mu \mathrm{m}$ and a casein micelle dispersion (CMD) with average micelle/particle size of $0.13 \pm 0.02 \mu \mathrm{m}$. Foam stability increased with increasing CMAD concentration. Foam half-life correlated well with the aggregate concentration in the dispersions as well as to the number of aggregates present in the lamella, measured using optical microscopy. Thin film properties of diluted dispersions were studied showing also good correlation between aggregate concentration in the thin films and film rupture times. At the protein concentration studied (2\%), the aggregates did not form a gel network in the lamella but were more or less randomly distributed over the film and not only located at the outer region of the film. We suggest to ascribe the film and foam stabilization by CMAs to the fact that they effectively divided the whole film into film elements with smaller radius, resulting in a smaller critical film thickness for film rupture, in combination with slower film drainage due to the wetting of the film of hydrophilic particles and resistance of fluid flow by the presence of the aggregated particles.
\end{abstract}

Submitted as:

M. Chen, S. Feijen, G. Sala, M.B.J. Meinders, H.J.F. van Valenberg, A.C.M. van Hooijdonk, E. van der Linden. Mechanism of ultra-stabilisation of foam by casein micelle aggregates. 


\section{Chapter 4}

\subsection{Introduction}

Previous research has shown that protein aggregates or particles can have a large influence on foam stability. Whey protein aggregates [1], $\beta$-Lactoglobulin aggregates [2] and whey protein fibrils [3] were shown to be advantageous for foam stabilization, while other studies indicated that protein aggregates can also decrease foam stability [2, 4]. [5] published a review on the effect of protein aggregates on foaming properties. The aggregate size resulting in high foam stability varied for different materials; for example, the maximum particle size to improve the foam stability was around $70 \mathrm{~nm}$ for $\beta$-lactoglobulin, but a few hundred nanometers for napin/pectin complexes [2,4]. There seems to be an optimal particle size for aggregates to stabilize foam and this optimal size is system-related, ranging from tens of nanometers to a few micrometers [6-10].

The relation between aggregate properties and foam stabilization is still not clear. Foam stabilization by solid particles like silica particles is an extensively studied topic [5, 11]. Partially hydrophobic silica particles with contact angle, $\theta$, close to $90^{\circ}$ can act as a foam stabiliser, whereas very hydrophobic particles $\left(\theta>90^{\circ}\right)$ are used as antifoams through a bridging/de-wetting mechanism [11]. The partially hydrophobic particles with contact angles around $65^{\circ}$ and smaller than $90^{\circ}$ were found to be optimal for foam stabilization [1214]: these particles will adsorb at the air/water interface, while hydrophilic particles that will remain in the continuous phase of the foam. The adsorption of partially hydrophobic particles at the interface has been found to reduce disproportionation [15, 16], or induce structural reinforcement of the film against coalescences [17]. However, the presence of hydrophilic particles in the continuous phase of a foam has been related to retarded drainage: these particles are suggested to act as a liquid-trapping structural element or to create a jammed structure in the Plateau borders [18, 19]. Aggregation of particles in the foam network (lamella and Plateau borders) could also occur depending on the bulk concertation and interaction among particles[20], which would further improve foam stability. These phenomena were observed even at concentrations that were initially much lower than closed packing density $(3 \%, \mathrm{w} / \mathrm{w})$ by $[20,21]$. Previous research demonstrated that casein micelles and presumably their aggregates (unpublished data in review) are not an integral part of the air/water interface [8, 22-24], which is in line with research on other types of protein aggregates that also did not find an effect on the interfacial properties of aggregate dispersions [25-27]. Therefore, protein aggregates probably stay in the continuous phase, i.e. in the lamella or Plateau borders, similarly to hydrophilic solid particles. However, whether there is a jammed or gelled network formed in the lamella and/or Plateau borders probably depends on the type of protein or is even system dependent for the same type of protein, for instance the size and concentration of protein aggregates or the ratio between these protein aggregates and other components.

Rullier et al. [28] [2, 29] studied the influence of concentration of whey protein aggregates on their foam stability and thin film stability. They showed a correlation between thin film 
stability and the foam stability, which was in line with the results of Saint-Jalmes et al. [30]. More important, the thin film stability was dependent on the mobility of aggregates at the film surface which was influenced by the aggregate size and on the ratio between nonaggregated proteins and protein aggregates. In particular, the observed immobility of aggregates (around $200 \mathrm{~nm}$ ) on the film surface was interpreted as formation of a gel-like network within the foam film, which was thought to be responsible for the improved foam stability. Saint-Jalmes et al. [30] investigated a casein micelle dispersion (CMD) with a particle size range between $50 \mathrm{~nm}$ and $300 \mathrm{~nm}$. The stabilization mechanism of the casein thin films was related by these authors to the confinement and percolation of so-called "casein aggregates" with a size not larger than $300 \mathrm{~nm}$. The sizes of thick spot-regions were respectively in the order of a few microns and hundreds of nanometers in the thin film. These thick spots were interpreted as confined casein aggregates containing probably many casein micelles. They also indicated that an increase in concentration of the casein aggregates yielded higher film stability. However, there is no further information on whether these "casein aggregates" in the thin film were formed by normal casein micelles within the size range of $300 \mathrm{~nm}$ and how many of these aggregates actually contributed to the final foam stability. According to our previous research [8], the half-life of a foam prepared with a dispersion of non-aggregated micelles (CMD) (3\% protein) was only a few hours. Compared to this, the foam half-life of a CMD with certain amount of micrometersized casein micelle aggregates (CMAs) was markedly longer (24 h). Homogenization was conducted to disrupt the CMAs, which resulted in a reduction of the foam half-life, back again to values typical to those of CMD. A long-term stability of foams made with particles or protein aggregates was mostly ascribed to a final jamming of the particles or to the formation of a gelled network in the lamella and/or Plateau borders [4, 5, 29-31]. For CMAs, it is still unproven whether these aggregates form a gel network in the foam lamella or not.

To establish the mechanism leading to ultra-stable foams as made using CMAs, a series of samples was prepared by mixing two well-defined systems, i.e. CMD and casein micelle aggregates dispersion (CMAD), in different ratios. Varying the mixing ratio between a dispersion with aggregates and a dispersion with only micelles allowed us to investigate the influence of size distribution and concentration of casein micelle aggregates on foam stability and thin film stability. Samples were characterized for particle size distribution, and the morphologies of the colloidal particles present in CMD and CMAD were studied by SEM. Foam was produced in two ways: by shaking and by sparging. The microstructure of the foams was visualized using light microscopy and the thin film stability was measured by the thin film balance technique using a Scheludko cell. Correlations between the concentration of CMAs in the bulk and in the lamella with foam stability and thin film stability were determined to uncover the mechanism of ultra-stabilization of foams by CMAs in the dispersions. 


\section{Chapter 4}

\subsection{Materials and Methods}

\subsubsection{Materials}

Low-heated skim milk powder NILAC was obtained from NIZO (Ede, The Netherlands). Ultra-pure water (MilliQ Purelab Ultra, Darmstadt, Germany), free of surface active contaminants, was used in all experiments (resistivity $>18.2 \mathrm{M} \Omega-\mathrm{cm}$, surface tension is $72.26 \pm 0.4 \mathrm{mN} \mathrm{m}^{-1}$ at $20^{\circ} \mathrm{C}$ ). Poly-L-lysine hydrobromide $0.01 \%$ and Glutaraldehyde $50 \%$, w/w were purchased from Sigma-Aldrich (Steinheim, Germany). Other chemicals were of analytical grade and purchased from Sigma Aldrich (Steinheim, Germany).

\subsubsection{Preparation of casein micelle dispersion (CMD) and casein micelle aggregates dispersion (CMAD)}

Skim milk was reconstituted by dissolving NILAC milk powder in MilliQ water $(10 \%$, w/w) and stirring overnight at room temperature (RT). Sodium azide $(0.02 \%$, w/w) was added as preservative. The reconstituted skim milk was ultracentrifuged (L-60 Beckman Ultracentrifuge, rotor type $70 \mathrm{Ti}$, Krefeld, Germany) at $100,000 \mathrm{~g}$ for $90 \mathrm{~min}$ at $20^{\circ} \mathrm{C}$, as described by [32]. Subsequently the pellets were milled at $30 \mathrm{~Hz}$ at $20^{\circ} \mathrm{C}$ using a Mixer Mill MM400 (Retch GmbH, Haan, Germany) for different times depending on the samples to be obtained. The ground casein pellets were re-dispersed in milk permeate (2\%, w/w). Milk permeate powder was prepared as described by Chen et al. (2016) and reconstituted in MilliQ water $(5.76 \%, \mathrm{w} / \mathrm{w})$ for 30 minutes. CMD refers to casein micelle dispersion. This dispersion was prepared by milling for 20 minutes, re-dispersing in milk permeate for 60 hours and subsequent homogenization at $40 \mathrm{~Pa}$ with a Labhoscop Homogenizer HU 3.0 (Delta Instruments, Drachten, the Netherlands). A dispersion of casein micelle aggregates (CMAD) was prepared by milling pellets for 30 minutes and redispersing in milk permeate for 3 hours at room temperature. The CMD and CMAD were mixed in varying ratios and mixtures containing 25\%, 50\%, 75\% and 100\% CMAD were obtained. Sodium azide $(0.02 \% \mathrm{w} / \mathrm{w})$ was added to all samples to prevent microbial growth.

\subsubsection{Characterization of samples}

\section{Particle size distribution}

The size distribution of all samples was measured using a Mastersizer 2000 (Malvern instrument Ltd, Worcestershire, United Kingdom). The refractive index was set to 1.341 for milk permeate [33] and 1.57 for casein micelles [34]. Samples were placed in the Mastersizer 2000 undiluted and measured in three runs.

\section{Scanning Electron Microscopy (SEM)}

Clean circular cover slips of $8 \mathrm{~mm}$ (Menzel, Brauschweig, Germany) were coated with Poly-L-lysine hydrobromide (Sigma), $0.2 \%$ in water, dried overnight and stored in the 
fridge. $150 \mu \mathrm{L}$ of the CMD and CMAD were put on these coated cover slips for 30 minutes. After gently rinsing in water, the samples were fixed in $3 \%$ glutaraldehyde in phosphate buffer ( $\mathrm{pH} 7.4)$, rinsed in water and dehydrated in series of acetone $(30,50,70$, $100 \%, 10$ minutes per step). The samples were subsequently critical point dried with carbon dioxide and visualized with a magnification between 2000 and 200000.

\subsubsection{Foam preparation and determination of the foaming properties}

\section{Shaking}

Two specimens of $10 \mathrm{~mL}$ of each sample were shaken by hand for 30 seconds at RT at the same time. Photos of the foams were taken every 30 seconds with a webcam (Logitech C310, Lausanne, Switzerland) until complete foam had collapse. With these images the foam half-life $\left(t_{1 / 2}\right)$ was calculated by the time for foam height decreased to half of the initial foam height.

\section{Sparging}

A FoamScan (Teclis IT-Concept, Longessaigne, France) was used to assess the stability of the CMD/CMAD foams prepared by sparging according to [8]. The corresponding time foam half-life $\left(t_{1 / 2}\right)$ was used as a measure for foam stability. All experiments were carried out at $20^{\circ} \mathrm{C}$ and all samples were stirred for 30 minutes prior to foaming.

\subsubsection{Light microscopy of foam}

For all samples, an Axioskop 50 (Carl Zeiss, Oberkochen, Germany) was used with an Axiocam HRc (Carl Zeiss, Oberkochen, Germany) to investigate and quantify the presence of aggregated particles in the lamellae of the foam. Axiovision SE64 software was used for image analysis (Carl Zeiss, Oberkochen, Germany). Foam samples were prepared by manually shaking $5 \mathrm{~mL}$ of samples in a test tube for 30s. A small part of the foam was transferred to a concave glass slide (with depth of 1.20-1.50 mm, Thermo Fisher Scientific Gerhard Menzel B.V. \& Co., Braunschweig, Germany) and covered with a cover glass for further observation. 20 images from 20 different bubbles with a magnification of 100x were taken to quantify the number of aggregated particles in the foam lamellae for all samples. The number of particles per image was counted manually. The size of each image represented an area of $\mathrm{A}=889 \mu \mathrm{m} \times 660 \mu \mathrm{m}$.

\subsubsection{Film stability}

The thin film stability was measured by micro-interferometry using a microscope (Axio plan 01, Zeiss, Jena, Germany) according to [35], with some modifications. Thin liquid films $($ diameter $=200 \mu \mathrm{m})$ were made in a Scheludko cell $($ diameter $=0.3 \mathrm{~cm})$ closed with a glass cover. The casing had a reservoir of milk permeate at the bottom to ensure a relative 


\section{Chapter 4}

humidity of $100 \%$ in the cell during measurements. CMD and CMAD with an initial protein concentration of $2.20 \%$ and $2.18 \%(\mathrm{w} / \mathrm{w})$ respectively were diluted by a factor of 2000 and mixed in different ratios prior to measurement. Liquid was drawn into the capillary with a syringe $(500 \mu \mathrm{L}$, Hamilton, Reno, NV, USA) and the whole setup was left to equilibrate for $5 \mathrm{~min}$ before a thin film was made by drawing sample solution into the capillary. The microscope was in reflected light mode, equipped with a five mega pixel CCD camera (Mightex Systems, Pleasanton, CA, USA). The rupture time was the time from reaching a diameter of $200 \mu \mathrm{m}$ to the time of rupture. If a film did not break after 60 min, it was considered stable. In this case, the lifetime was expressed as $3600 \mathrm{~s}$. In case of stable films, samples were measured for 6 times. In the case of rupturing films, experiments were repeated 10 times to calculate the average and standard deviation of the rupture time.

\subsubsection{Statistical analysis}

All tests were conducted at least in triplicate. The results obtained were subjected to a oneway analysis of variance (ANOVA). Duncan's new multiple range test was performed using SPSS 22.0 software (SPSS Inc., Chicago, IL, USA) to determine the significance of difference between samples using a significance level of $p<0.05$.

\subsection{Results and discussion}

\subsubsection{Particle size of CMD and CMAD}

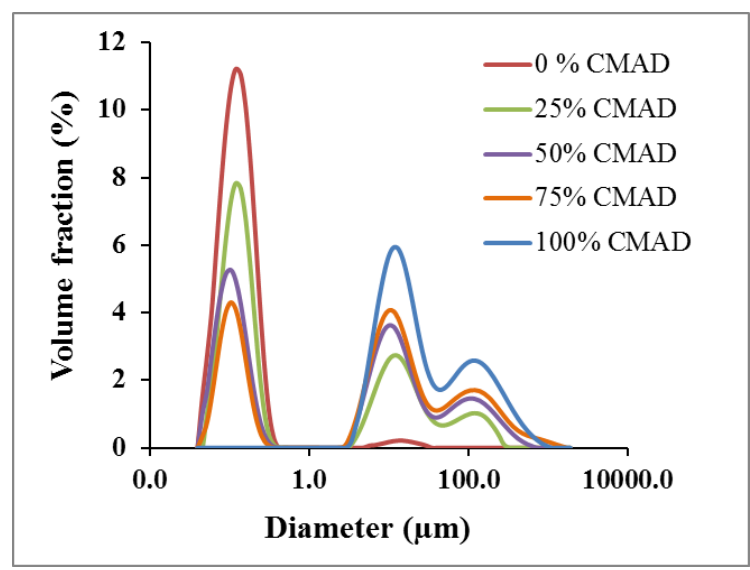

Figure 4-1. Particle size distribution of the mixtures of casein micelle dispersion (CMD) and casein micelle aggregates dispersion (CMAD) with different ratios.

Figure 4-1 shows the particle size distribution of a casein micelle dispersion (CMD), a dispersion of casein micelle aggregates, (CMAD) and of their mixtures containing 25\%, $50 \%, 75 \%$ and $100 \%$ CMAD. The size of colloidal particles present in the CMD ranged 
from 30 to $300 \mathrm{~nm}$ which was the same as research by Saint-Jalmes, et al. (2005), with an average of $0.13 \pm 0.02 \mu \mathrm{m}$, which was a bit smaller compared to the average particle size of casein micelles in skim milk $(200 \mathrm{~nm})[8,36]$. The average particle size of CMAD was $6.7 \pm 0.5 \mu \mathrm{m}$ with a volume percentage of $80 \%>10 \mu \mathrm{m}$ and $98 \%>5 \mu \mathrm{m}$. As expected, when more CMAD was present in the mixture, the peak of the smaller particles decreased and the peak of the large aggregates increased. The measurement of the particle size distribution by dynamic light scattering is based on a mathematical model that assumes the particles to be spherical. SEM and light microscopy images were taken to further investigate the size and shape of the aggregates present in the dispersions (Figure 4-2). It was confirmed that the homogenization of CMD did not affect the morphology of the micelles, as shown in Figure 4-2A. The morphology of the casein micelles before (data not shown) and after homogenization was comparable, and similar to that reported in previous studies on the structure of casein micelles [37, 38]. For CMAD, circular shaped flat particles were observed using optical microscopy (Figure 4-2B). Interesting to note is that all these particles had a very similar shape (Figure 4-2C and 2D). No spherical-shaped CMAs were found in the SEM images, only collapsed ones. Based on the SEM image of the paste that was used to make the CMAD (Supplementary materials), these collapsed shell particles might originate from air-filled casein micelle stabilized microbubbles formed during milling. Although the mechanism responsible for the formation of these particles is certainly very interesting, it is outside the scope of this research and was therefore not further investigated.
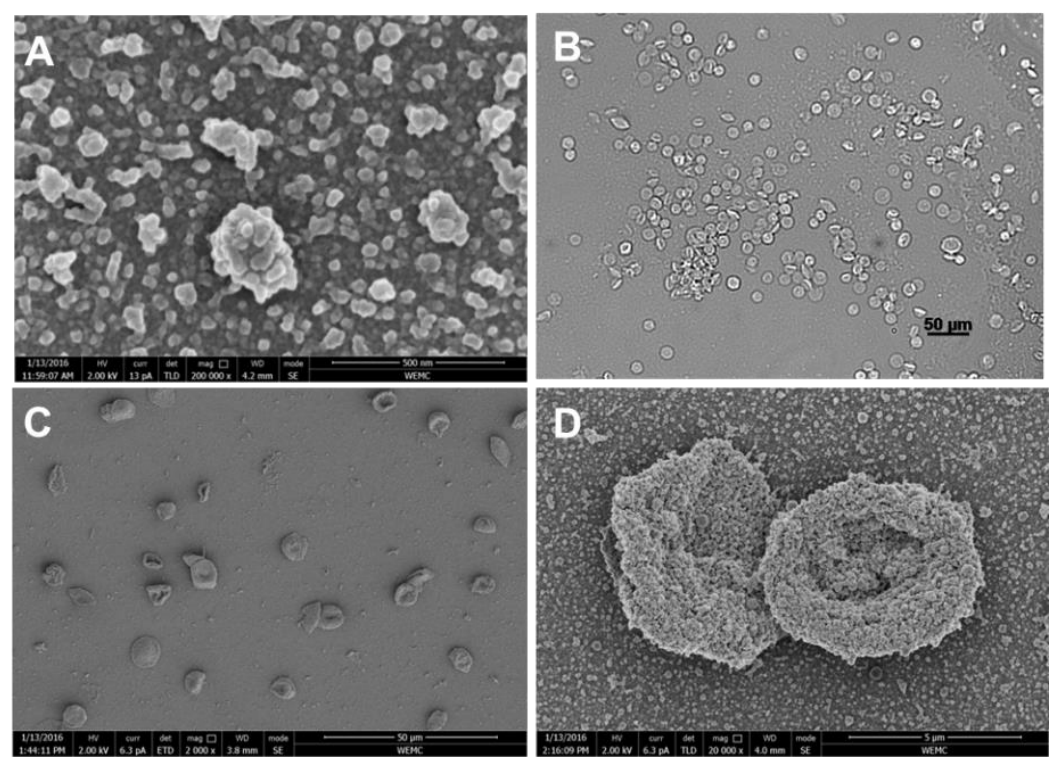


\section{Chapter 4}

Figure 4-2. (A) SEM image of CMD with a magnification of 200000x. (B) The optical microscopy image of CMAD with a magnification of 100x. (C) and (D) SEM image of CMAD with a magnification of 2000x and 20000x, respectively.

\subsubsection{Foam stability}

To study the effect of the concentration of CMAs on the stability of foam, foams were made by both manual shaking and sparging. In Figure 4-3, foam stability, expressed as halflife $t_{1 / 2}$, is plotted versus the volume fraction of CMAD in the mixture. It was observed that foam half-life increased with CMAD volume fraction both for foams made by shaking and by sparging. It increased from about $3 \mathrm{~h}$ for CMD to $24 \mathrm{~h}$ for CMAD in the case of shaking and from about $9 \mathrm{~h}$ to $27 \mathrm{~h}$ in the case of sparging.

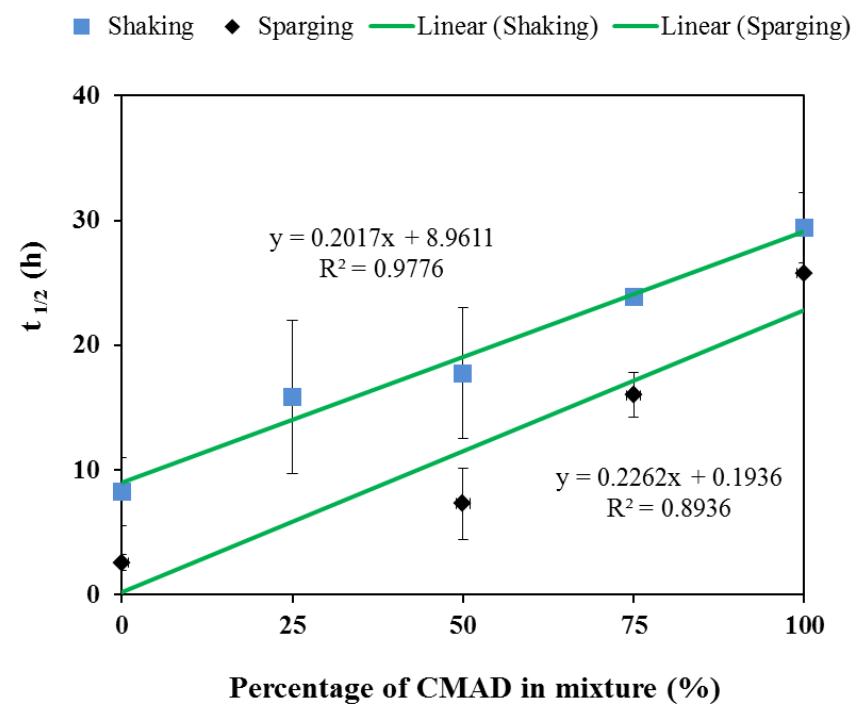

Figure 4-3. Foam half-life $\left(t_{1 / 2}\right)$ as a function of volume percentage of CMAD in CMDCMAD mixtures.

\subsubsection{Foam visualization and film stability}




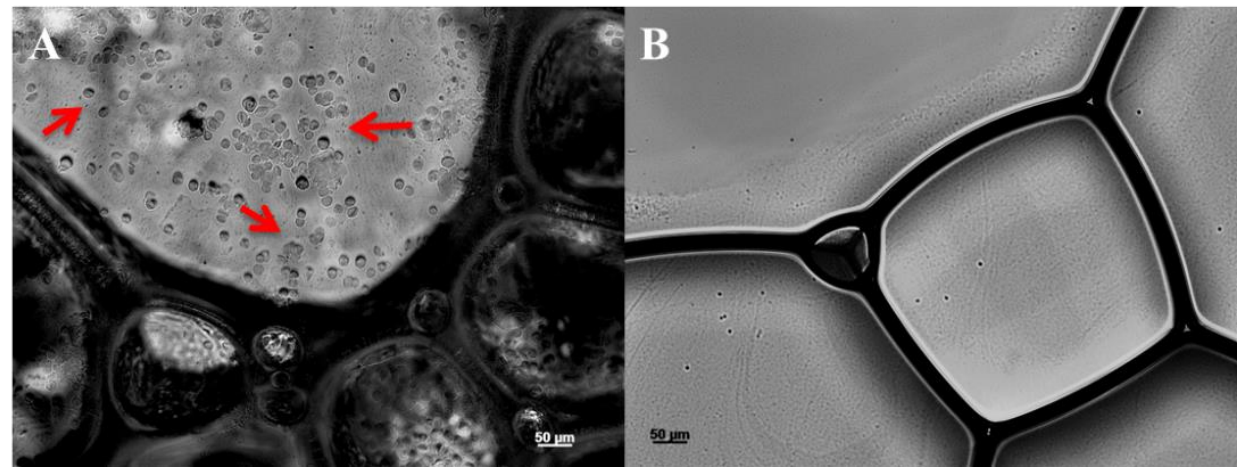

Figure 4-4. Bubbles visualized with optical microscopy at a magnification of 100x (A) Casein micelle aggregates visualized in foam of CMAD. (B) Foam of CMD.

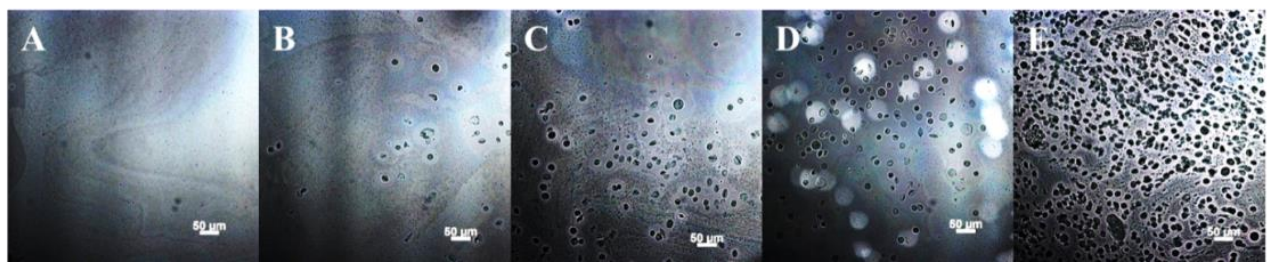

Figure 4-5. Lamellae in foam of CMD-CMAD mixtures with different ratios visualized with optical microscopy at a magnification of 100x. (A) $0 \%$ CMAD (B) 25\% CMAD (C) $50 \%$ CMAD (D) $75 \%$ CMAD (E) 100\% CMAD.

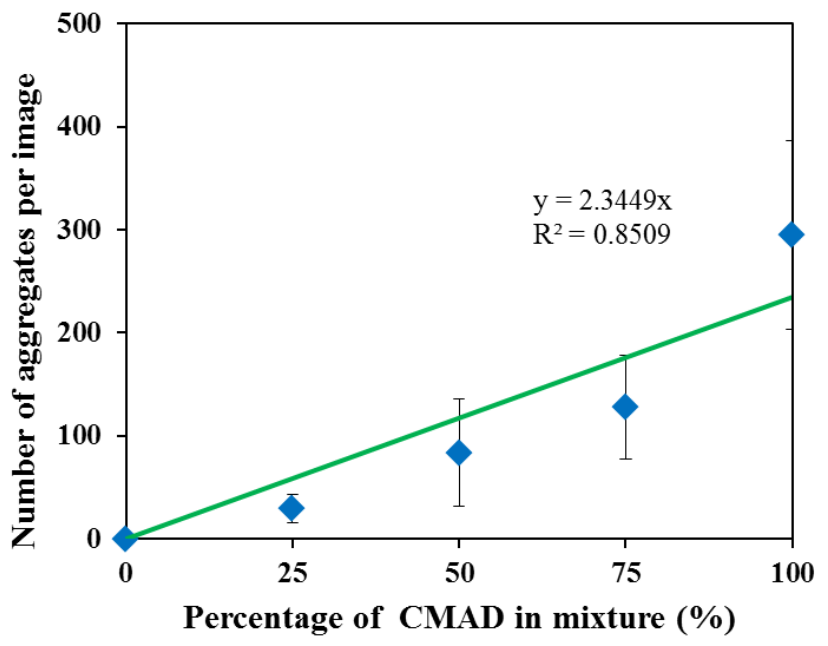




\section{Chapter 4}

Figure 4-6. Number of casein micelle aggregates (CMAs) present in the lamellas observed by optical microscopy as a function of volume percentage of CMAD in CMD-CMAD mixtures. The green line is the linear trend line.

Microscopy was performed to visualize the aggregates in the different structural elements of the foam. As shown in Figure 4-4A, spherical particles of around $10 \mu \mathrm{m}$ were clearly visualized in the lamellae of a foam made with CMAD. As expected, no large particles were observed for foams prepared with CMD (Figure 4-4B). For foams prepared with mixtures of CMD and CMAD, the presence of $10 \mu \mathrm{m}$ particles increased with increasing the CMAD volume fraction (Figure 4-5). A roughly linear correlation was observed between the number of aggregates in the lamellae per image and the volume fraction of CMA in the mixtures (Figure 4-6). The combination of these findings with the results depicted in Figure 4-3 suggests a strong correlation between the number of aggregates present in lamella and the stability of foams. In order to further check this fact, we also measured the stability of thin films prepared with mixtures of CMD and CMAD in a dilute regime with a microscope in reflected light mode and equipped with a Scheludko cell. Thin film images of CMD-CMAD mixtures (2000 times diluted) with increasing volume fraction of CMAD are shown in Figure 4-7. As can be seen, with increasing CMA concentration, the films became more heterogeneous, indicating the presence of larger aggregates. The stability of these thin films is shown in Figure 4-8. The rupture time of the film was less than $100 \mathrm{~s}$ for CMD, but more than one hour for CMAD. A clear trend was observed for the mixtures: thin film stability improved as the CMAD volume fraction in the mixtures increased. This is in line with our findings reported above.
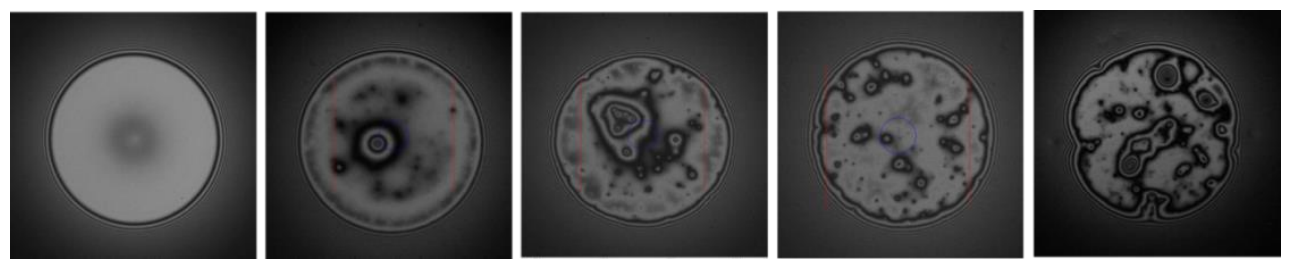

Figure 4-7. Thin film images of CMD-CMAD mixtures containing different amounts of CMAD (from left to right: $0 \%, 25 \%, 50 \%, 75 \%$ and $100 \%$ ). The size of the film was monitored by the distance between two red lines which is $200 \mu \mathrm{m}$. 


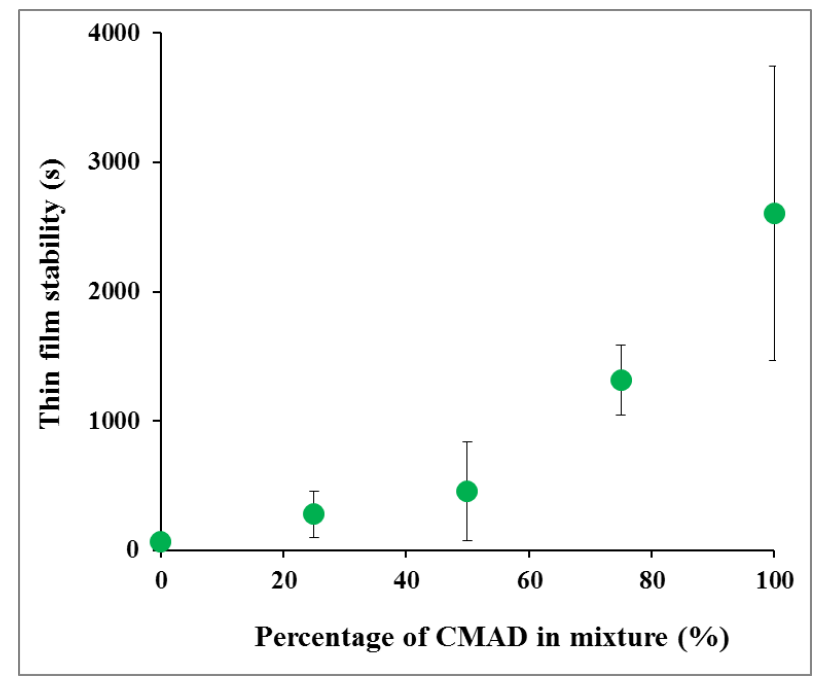

Figure 4-8. Thin film stability as a function of volume percentage of CMAD in CMDCMAD mixtures.

The mechanism responsible for the increased foam stability upon addition of aggregates is not yet clear. Our previous research indicated that the thin film stability in a diluted regime corresponds well with the foam stability of CMDs, both for the systems with and without aggregates. The current study confirms the strong correlation between foam stability and thin film stability, at dilution. Furthermore, we found that the thin film stability increased with an increased number of aggregates in the film. For highly stable foams, the bulk concentration of aggregates was in line with the corresponding number of CMAs in the foam lamellae. This makes the correlation between lamella stability and foam stability even stronger. As far as we know, this direct relation between number of aggregates present in the foam lamella and foam stability is discovered for the first time for foams made with protein particles or aggregates. It was hypothesized by [29] that a good foam stability with presence of aggregates was due to a higher film stability caused by a slower film drainage and a gel network formation in the thin liquid films. However, there was no direct proof of this gel network formation in the thin film. It was inferred from an apparent immobility of aggregates on the film surface [28-30]. In our microscopic visualization of the foam, separated individual aggregate particles were observed and there were no signs that these particles aggregated in the lamellae. Therefore, we conclude that the improved foam stability is not due to the formation of a gel network in the foam lamella. Most probably the observed aggregates are effectively entrapped within the lamellae by interaction with the immobile interfacial layer with adsorbed caseins with attached casein micelles in the sub phase. These entrapped particles are well wetted because of hydrophilicity and will keep the two air/water interfaces better apart, thereby slowing down film drainage and film rupture. Furthermore, the particles divide the whole lamella into smaller thin film regions 


\section{Chapter 4}

that contain no aggregates. These regions may eventually rupture by thinning. The more aggregates are present in the lamella, the smaller these regions will be. According to Vrij [39], the critical film thickness below rupture of the film can occur is inversely proportional to the film area. This effect may also add to the relation that more aggregates in the film lead to higher film stability. The driving force for the drainage of the film is the difference between the Laplace pressure in the Plateau border and the disjoining pressure in the film. The wettability of the particles in the thin film will result in an additional force that effectively reduces this drainage driving force, thereby slowing down the drainage. We hypothesize that the pinning of the aggregate particles to the interface is the main factor leading to the delay of film rupture. 


\subsection{Conclusions}

In this study we investigated the mechanism of ultra-stabilization of foams by large casein micelle aggregates with a size of about 5-10 $\mu \mathrm{m}$. Directly visualization of these aggregates indicated that these particles are more or less randomly distributed in the thin films and not moved to the outer periphery, most probably due to the immobile character of the adsorbed casein interfaces with casein micelles attached in the sub phase. Furthermore, quantification of the number of aggregates in the foam lamella showed that it increased with increasing concentration of aggregates in the bulk. A clear relation between the number of aggregates effectively entrapped in the foam lamella and foam stability was established: more aggregates lead to a more stable foam. With a protein concentration of $2 \%(\mathrm{w} / \mathrm{w})$, we found no evidence that the improved foam stability was due to the formation of a gel network. The picture arising from the foam stability data was further strengthened by thin film stability studies on diluted systems. 


\section{Chapter 4}

\section{References}

1. Schmitt, C., et al., Whey protein soluble aggregates from heating with NaCl: Physicochemical, interfacial, and foaming properties. Langmuir, 2007. 23(8): p. 4155-4166.

2. Rullier, B., Novales, B. and Axelos, M.A.V., Effect of protein aggregates on foaming properties of $\beta$ lactoglobulin. Colloids and Surfaces A: Physicochemical and Engineering Aspects, 2008. 330(2): p. 96-102.

3. Oboroceanu, D., et al., Fibrillization of whey proteins improves foaming capacity and foam stability at low protein concentrations. Journal of Food Engineering, 2014. 121: p. 102-111.

4. Schmidt, I., et al., Foaming properties of protein/pectin electrostatic complexes and foam structure at nanoscale. Journal of Colloid and Interface Science, 2010. 345(2): p. 316-324.

5. Fameau, A.L. and Salonen, A., Effect of particles and aggregated structures on the foam stability and aging. Comptes Rendus Physique, 2014. 15(8): p. 748-760.

6. Oboroceanu, D., et al., Fibrillization of whey proteins improves foaming capacity and foam stability at low protein concentrations. Journal of Food Engineering, 2014. 121: p. 102-111.

7. Schmitt, C., Bovay, C. and Rouvet, M., Bulk self-aggregation drives foam stabilization properties of whey protein microgels. Food Hydrocolloids, 2014. 42: p. 139-148.

8. Chen, M., et al., Particle size determines foam stability of casein micelle dispersions. International Dairy Journal, 2016. 56: p. 151-158.

9. $\quad$ Lazidis, A., et al., Whey protein fluid gels for the stabilisation of foams. Food Hydrocolloids, 2016. 53: p. 209-217.

10. Wan, Z., Yang, X. and Sagis, L.M., Nonlinear Surface Dilatational Rheology and Foaming Behavior of Protein and Protein Fibrillar Aggregates in the Presence of Natural Surfactant. Langmuir, 2016. 32(15): p. 3679-3690.

11. Horozov, T.S., Foams and foam films stabilised by solid particles. Current Opinion in Colloid \& Interface Science, 2008. 13(3): p. 134-140.

12. Ata, S., Ahmed, N. and Jameson, G.J., Collection of hydrophobic particles in the froth phase. International Journal of Mineral Processing, 2002. 64(2): p. 101-122.

13. Ata, S., Ahmed, N. and Jameson, G., The effect of hydrophobicity on the drainage of gangue minerals in flotation froths. Minerals engineering, 2004. 17(7): p. 897-901.

14. Schwarz, S. and Grano, S., Effect of particle hydrophobicity on particle and water transport across a flotation froth. Colloids and Surfaces A: Physicochemical and Engineering Aspects, 2005. 256(2): p. 157-164.

15. Subramanian, R.S., Larsen, R.J. and Stone, H.A., Stability of a Flat Gas-Liquid Interface Containing Nonidentical Spheres to Gas Transport: Toward an Explanation of Particle Stabilization of Gas Bubbles. Langmuir, 2005. 21(10): p. 4526-4531.

16. Stocco, A., et al., Aqueous foams stabilized solely by particles. Soft Matter, 2011. 7(4): p. 1260-1267.

17. Kaptay, G., Interfacial criteria for stabilization of liquid foams by solid particles. Colloids and Surfaces A: Physicochemical and Engineering Aspects, 2003. 230(1): p. 67-80.

18. Murray, B.S. and Ettelaie, R., Foam stability: proteins and nanoparticles. Current Opinion in Colloid \& Interface Science, 2004. 9(5): p. 314-320.

19. Guignot, S., et al., Liquid and particles retention in foamed suspensions. Chemical Engineering Science, 2010. 65(8): p. 2579-2585.

20. Carl, A., Bannuscher, A. and von Klitzing, R., Particle stabilized aqueous foams at different length scales: synergy between silica particles and alkylamines. Langmuir, 2015. 31(5): p. 1615-1622.

21. Carn, F., et al., Foam Drainage in the Presence of Nanoparticle-Surfactant Mixtures. Langmuir, 2009. 25(14): p. 7847-7856.

22. Brooker, B., Observations on the air-serum interface of milk foams. Food microstructure (USA), 1985.

23. Zhang, Z., Dalgleish, D.G. and Goff, H.D., Effect of pH and ionic strength on competitive protein adsorption to air/water interfaces in aqueous foams made with mixed milk proteins. Colloids and Surfaces B: Biointerfaces, 2004. 34(2): p. 113-121. 


\section{Quantification of aggregates in foam lamellae and foam stability}

24. Borcherding, K., et al., Effect of foaming temperature and varying time/temperature-conditions of preheating on the foaming properties of skimmed milk. International Dairy Journal, 2008. 18(4): p. 349358.

25. Bals, A. and Kulozik, U., Effect of pre-heating on the foaming properties of whey protein isolate using a membrane foaming apparatus. International Dairy Journal, 2003. 13(11): p. 903-908.

26. Davis, J.P. and Foegeding, E.A., Foaming and Interfacial Properties of Polymerized Whey Protein Isolate. Journal of Food Science, 2004. 69(5): p. C404-C410.

27. Wierenga, P.A., van Norél, L. and Basheva, E.S., Reconsidering the importance of interfacial properties in foam stability. Colloids and Surfaces A: Physicochemical and Engineering Aspects, 2009. 344(1-3): p. 72-78.

28. Rullier, B., et al., $\beta$-Lactoglobulin aggregates in foam films: Correlation between foam films and foaming properties. Journal of Colloid and Interface Science, 2009. 336(2): p. 750-755.

29. Rullier, B., et al., $\beta$-Lactoglobulin aggregates in foam films: Effect of the concentration and size of the protein aggregates. Journal of colloid and interface science, 2010. 343(1): p. 330-337.

30. Saint-Jalmes, A., et al., Differences between protein and surfactant foams: microscopic properties, stability and coarsening. Colloids and Surfaces A: Physicochemical and Engineering Aspects, 2005. 263(1): p. 219-225.

31. Rio, E., et al., Unusually stable liquid foams. Advances in Colloid and Interface Science, 2014. 205: p. 74-86.

32. Huppertz, T. and de Kruif, C.G., Rennet-induced coagulation of enzymatically cross-linked casein micelles. International dairy journal, 2007. 17(5): p. 442-447.

33. Beliciu, C.M. and Moraru, C.I., Effect of solvent and temperature on the size distribution of casein micelles measured by dynamic light scattering. Journal of Dairy Science, 2009. 92(5): p. 1829-1839.

34. Ambrose Griffin, M.C. and Griffin, W.G., A simple turbidimetric method for the determination of the refractive index of large colloidal particles applied to casein micelles. Journal of Colloid and Interface Science, 1985. 104(2): p. 409-415.

35. Lech, F.J., et al., Stability Properties of Surfactant-Free Thin Films at Different Ionic Strengths: Measurements and Modeling. Langmuir, 2015. 31(9): p. 2777-2782.

36. Glantz, M., et al., Importance of casein micelle size and milk composition for milk gelation. Journal of Dairy Science, 2010. 93(4): p. 1444-1451.

37. McMahon, D.J. and McManus, W.R., Rethinking Casein Micelle Structure Using Electron Microscopy1. Journal of Dairy Science, 1998. 81(11): p. 2985-2993.

38. Dalgleish, D.G., Spagnuolo, P.A. and Douglas Goff, H., A possible structure of the casein micelle based on high-resolution field-emission scanning electron microscopy. International Dairy Journal, 2004. 14(12): p. 1025-1031.

39. Vrij, A., Possible mechanism for the spontaneous rupture of thin, free liquid films. Discussions of the Faraday Society, 1966. 42: p. 23-33. 


\section{Chapter 4}

\section{Supplementary information}

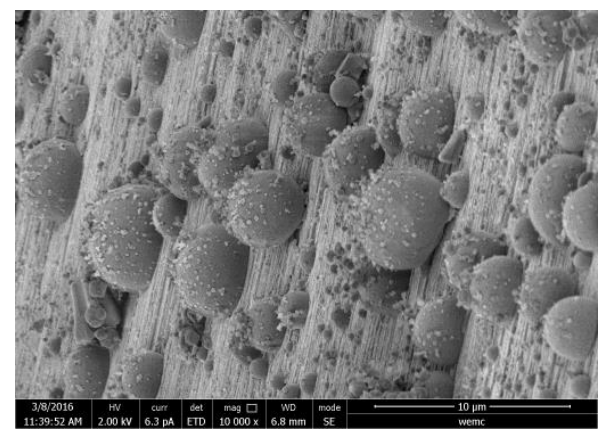

Supplementary Figure 4.1 SEM image of the paste of casein micelle pellets made by milling 


\title{
Chapter 5
}

\section{Foam properties of $\beta$-casein and silica particle mixtures: the influence of particle size and concentration}

\begin{abstract}
In this research the effect of the addition of hydrophilic silica particles to $\beta$-casein $(\beta-\mathrm{CN})$ solutions was investigated and the role of silica particle size and concentration. Diameter of the particles used were $0.2 \mu \mathrm{m}, 1 \mu \mathrm{m}$, and $3 \mu \mathrm{m}$ ), and $\beta$-CN/silica weight ratios varied between $1: 10$ and 1:100. Particles were added to $\beta$-CN solutions with concentration of $0.15 \%$ and $0.015 \%(\mathrm{w} / \mathrm{w})$. Samples were characterized for particles size, morphology, and contact angle and related to foaming, interfacial, and thin film properties. A clear negative relationship between particle size and foam stability as well as between particle concentration and foam stability was observed. At fixed silica concentration, larger silica particles decreased foam stability. At fixed silica particle size, larger particle concentration decreased both foamability and foam stability. This could be ascribed to the depletion of free $\beta$-CN in the bulk due to the adsorption to the silica particles. Surface rheological measurement show no effect of the particles up to a strain of 0.3. The study of the thin film properties of the dispersions showed that the particles are at the interface and that a central film was surrounded by particles at the outer periphery. This is contrary to what is observed for the casein micelle aggregate dispersions where the aggregates are in the film, keeping the interface apart and stabilize the film. Both the rupture time and thickness of thin films decreased with increasing concentration of silica particles in the mixture. This would be most probably ascribed to a decrease in $\beta$-casein bulk concentration due to the adsorption to the silica interface.
\end{abstract}

Submitted as:

M. Chen, G. Sala, M.B.J. Meinders, H.J.F. van Valenberg, A.C.M. van Hooijdonk, E. van der Linden. Foam properties of $\beta$-casein and silica particle mixtures: the influence of particle size and concentration. 


\section{Chapter 5}

\subsection{Introduction}

In food science, foams stabilized by particles, like protein particles, aggregates, fluid gel particles, and modified starch particles have received lots of attention [1-8]. Casein micelles, the natural food nano-gel particle present in milk, function as the main emulsion stabilizing component of homogenized milk and exhibit good foaming properties [9]. In previous research we studied the foaming properties of casein micelle dispersions (CMDs) and found that the foam stability of CMDs that contained casein micelle aggregates (CMAs) significantly improved [10]. The size of CMAs in our studies ranged from $0.5 \mu \mathrm{m}$ till a few $\mu \mathrm{m}$. This study indicated that the type of protein as well as particle size, shape and concentration play an important role in the stabilization of foams made by CMDs. We found that aggregates of casein micelles were entrapped in the lamellae between bubbles without forming a gel. These entrapped particles keep the two interfaces apart. This entrapment was suggested to be the main factor leading to the delay of film rupture and stabilization of the foams made from CMA's.

The location of particles in a foam structure is influenced by the wetting properties of particles [11-13], which also will determine whether particles stabilize or destabilize foam $[14,15]$. The wettability of particles depends on their hydrophobicity. In general, completely hydrophilic particles do not adsorb onto the air/water interface [16]. Partially hydrophobic particles with contact angle $\theta$ close to $90^{\circ}$ can act as a foam stabiliser, whereas hydrophobic particles $\left(\theta>90^{\circ}\right)$ destabilize a foam and are often used as antifoaming agents [17]. The particle hydrophobicity could be modified by appropriate chemical reaction [18, 19], by adjusting the salt concentration [20], or through the adsorption of amphiphiles to the particle surface [7]. For foams made of particles, partially hydrophobic particles were found to be optimum for foam stabilization [21-23]. Foaming behaviour becomes more complicated for mixed systems of particles and amphiphiles.

Silica $\left(\mathrm{SiO}_{2}\right)$ is one of the widely chosen spherical inorganic particles for foam studies due to their well characterized physicochemical properties [18] [24]. Previous studies have investigated foaming properties of silica particles hydrophobized by SDS [25] or hexylamine [26]. The former had a contact angle of $66^{\circ}$ and the latter ranged between 26 to $56^{\circ}$. In the study of Karakashev et al. (2011) [25], silica particles were segregated and trapped in both foam lamellas and Plateau borders. Foams with silica particles get less stable than foams without. According to Kruglyakov et al. (2011) [26], aggregation of particles and formation of the thixotropic gels in the dispersion medium of the foam enabled a ultra-stable foam. Thus, modification of silica particles by coverage with of amphiphiles on the particle surface may lead to stable foams depending on the type and concentration of amphiphiles used.

$\beta$-casein $(\beta-\mathrm{CN})$ is an abundant and surface active amphiphilic protein in milk. Above the critical micellization concentration it forms micelles, which at $25^{\circ} \mathrm{C}$ is about $24 \mu \mathrm{mol} / \mathrm{L}$ 
[27]. $\beta$-CN adopts flexible disordered configurations with little ordered secondary structure in aqueous phase because of the preponderance of proline residues and the lack of cysteine residues in protein primary structure [28]. As far as we know, $\beta-\mathrm{CN}$ could attach to the surface of silica [29], which could possibly modify the surface charge, roughness and hydrophobicity of the particles. It may be expected that after adsorption of casein to the particle surface, silica could have a similar surface charge and hydrophobicity as casein micelles. This would make $\beta$-CN/silica a simplified model system for casein micelle dispersions where the model systems allows for testing the effect of particle size and thereby mimic the casein micelle aggregates.

To be able to control foam stabilization using hydrophilic particles, more insight in the stabilization mechanism is needed. Therefore, we investigated the effect of silica particle size and concentration on foaming behaviour of $\beta$-CN/silica mixed systems. Hydrophilic silica particles with different sizes (Small: $0.2 \mu \mathrm{m}$; Medium: $1 \mu \mathrm{m}$ and Large: $3 \mu \mathrm{m}$ ) were added to $\beta-\mathrm{CN}$ solutions at varying ratios. Samples were characterized for particle size and morphology. The contact angle of silica particles was estimated by measuring an air-liquid contact angle of $\beta-\mathrm{CN}$ on smooth hydrophilic glass surface. The foaming properties were measured using a FoamScan. Linear and non-linear surface rheology was applied to study the interfacial properties. Thin film stability was measured with thin film balance technique. These physical properties were related to the foaming and interfacial properties of the mixtures, as well as to their thin film properties.

\subsection{Materials and methods}

\subsubsection{Materials}

$\beta$-casein was generously provided by NIZO food research BV (Ede, Netherlands). The silica particles (sicastar) were purchased from Micromod Partikeltechnologie $\mathrm{GmbH}$ (Rostock, Germany), and were received as $50 \mathrm{mg} / \mathrm{mL}(5.0 \%, \mathrm{w} / \mathrm{w})$ aqueous dispersions. The surface of silica particles presented hydrophilic $\mathrm{Si}-\mathrm{OH}$ groups, without any modification. In this work, three particular silica samples were used: one with an average diameter of $0.2 \mu \mathrm{m}$ (Small), one with an average diameter of $1 \mu \mathrm{m}$ (Medium) and one with an average diameter of $3 \mu \mathrm{m}$ (Large). The water used in all the experiments was first passed through a PURELAB Ultra Milli-Q (Elga, Darmstadt, Germany) water system. Its surface tension at $25^{\circ} \mathrm{C}$ was $71.99 \mathrm{mN} / \mathrm{m}$. All measurements were repeated at least twice and the average values were used.

\subsubsection{Preparation of $\beta$-casein/silica particles mixtures}

All $\beta$-casein/silica particles mixtures ( $\beta$-CN/silica) were prepared at room temperature in a phosphate buffer (PB). PB was prepared by first mixing appropriate stock solutions of 0.1 $\mathrm{M} \mathrm{Na}_{2} \mathrm{HPO}_{4}$ and $0.1 \mathrm{M} \mathrm{NaH}_{2} \mathrm{PO}_{4}$ with a further dilution to $10 \mathrm{mM}$. The buffer solution had a final $\mathrm{pH}$ of 7.0 and an ionic strength of $21.5 \mathrm{mM}$. Fresh PB was prepared before each 


\section{Chapter 5}

measurement. $0.02 \%(\mathrm{w} / \mathrm{w})$ sodium azide was added to prevent bacterial contamination. A $0.015 \%(\mathrm{w} / \mathrm{w}) \beta$-casein solution was mixed with silica particles $(5.0 \%, \mathrm{w} / \mathrm{w})$ at varying ratios $(1: 5,1: 10,1: 50,1: 100$, weight of $\beta-\mathrm{CN}$ : weight of particles) and stirred overnight. Correspondingly, the concentrations of silica particles in $\beta-\mathrm{CN} /$ silica mixtures were $0.075 \%$, $0.15 \%, 0.75 \%$ and $1.5 \%(\mathrm{w} / \mathrm{w}) . \beta-\mathrm{CN} /$ silica mixtures were defined as: $\beta-\mathrm{CN} / \mathrm{S}-\mathrm{L}$ for large silica $(3 \mu \mathrm{m}), \beta-\mathrm{CN} / \mathrm{S}-\mathrm{M}$ for medium silica $(1 \mu \mathrm{m})$ and $\beta$-CN/S-S for small size silica $(0.2$ $\mu \mathrm{m})$ For the ratio $1: 10$, the $\beta$-CN/silica mixtures were ultracentrifuged at $100,000 \mathrm{~g}$ for 90 min at $20^{\circ} \mathrm{C}$ to remove the particles. The supernatants were collected for further research.

\subsubsection{Particle size distribution}

The size distribution of silica particles was determined with multi angle light scattering [30] (Mastersizer 2000 Malvern Instruments, Worcestershire, U.K.). The refractive index used for silica was 1.54 [31]. The particle size distribution was also checked using Malvern Zetasizer Nano-ZS (Malvern, Worcestershire, UK) by dynamic light scattering [32] with the same refractive index mentioned above.

\subsubsection{Scanning electron microscope (SEM)}

$150 \mu \mathrm{L}$ of silica particle dispersions were carefully dripped on poly-L-lysine coated glasses. Excess of the sample was removed by dipping in MilliQ-water. The glass with sample attached was immersed in 3\% (v/v) glutaraldehyde for fixation and MilliQ-water was used to wash the excess of glutaraldehyde. After that, the MilliQ-water was subsequently replaced by ethanol $(10 \%, 30 \%, 50 \%, 70 \%, 90 \%$, and 100\%) for dehydration. Samples in ethanol attached on sample holders with CCC Carbon Adhesive (Electron Microscopy Sciences, Washington, USA) were further dried by critical point drying (CPD). After that, the samples were sputter coated with a layer of tungsten in SCD 500 (Leica EM VCT 100, Leica, Vienna, Austria) before imaging. All samples were analysed with a scanning electron microscope (Magellan XHR 400L FE-SEM, FEI, Eindhoven, the Netherlands) at a working distance of $4 \mathrm{~mm}$ with SE detection at $2.00 \mathrm{kV}$.

\subsubsection{Static contact angle measurement}

The contact angle of $\beta-\mathrm{CN}$ on glass (hydrophilic silica) surface was measured with VCA 2500XE Video contact angle system (Advanced Surface Technology Inc., Billerica, MA). The samples analysed in this study were MilliQ water, phosphate buffer $(\mathrm{pH}=7.0,10 \mathrm{mM})$ and $\beta$-casein $(0.015 \%, w / w)$ in the phosphate buffer. A droplet of the mentioned liquids was dispensed manually at the tip of a micropipette to a smooth glass plate $(7 \mathrm{~cm} \times 2 \mathrm{~cm})$, as the stage raised the sample surface into contact with the liquid. Upon creating the droplet on the surface of the sample, the VCA software program captured the image on a CCD camera. The contact angle was calculated manually with the VCA Optima XE. At least 6 measurements were conducted for each sample. Two numbers were displayed: the left and right contact angles with variance within $1-2^{\circ}$. The mean contact angle was selected. 


\subsubsection{Foaming properties}

Foaming properties of $\beta-\mathrm{CN}$ solution, $\beta-\mathrm{CN} /$ silica mixtures and supernatants of $\mathrm{CN} / \mathrm{S}-\mathrm{L}$ 1:10 were assessed with a FoamScan (Teclis IT-Concept, Longessaigne, France) according to Chen et al. (2016) [10]. Foam was produced using sparging air through a frit for $40 \mathrm{~s}$, corresponding to a total air volume of $120 \mathrm{~mL}$. The foam volume after sparging for $40 \mathrm{~s}$ was used to assess the foamability of the samples. The foam half-life, the time when the foam reached half of its initial height $\left(t_{1} / 2\right)$, was used as a measure for foam stability. Two dimensional images of the foam at the wall of the tube were recorded using a chargecoupled device (CCD) camera. The image covered an area of $1.0 \mathrm{~cm}^{2}$.

\subsubsection{Interfacial properties measured with Profile Analysis Tensiometer (PAT)}

The interfacial properties of $\beta-\mathrm{CN}$ solution, silica in $\mathrm{PB}$ and $\beta-\mathrm{CN}$-/silica mixtures were measured using a SINTERFACE PAT 1-M (SINTERFACE Technologies, Berlin, Germany) according to Chen et al. (2016). Data were analysed using SINTERFACE Profile Analysis Tensiometer PAT 1-M version 1.4.0.685 software according to van Kempen et al. [33] with some modifications. The surface tension was $72.2 \pm 0.7 \mathrm{mN} / \mathrm{m}$ for MilliQ-water and $70.1 \pm 0.3 \mathrm{mN} / \mathrm{m}$ for PB. First, the surface tension was measured for $1000 \mathrm{~s}$ with the area (A) of the droplet kept constant at $25 \mathrm{~mm}^{2}$. A sinusoidal oscillation was applied after reaching equilibrium ( $\mathrm{t}=1000 \mathrm{~s})$ to obtain the dilatational modulus with a deformation of $7 \%$ and $30 \%$ at $0.02 \mathrm{~Hz}$. Results of non-linear dilatational rheology were analysed by Lissajous plots of surface pressure $(\Pi)$ versus strain $(\Delta \mathrm{A} / \mathrm{A})$.

\subsubsection{Thin film stability}

The thin film stability of $\beta-\mathrm{CN}$ solution, silica in PB and $\beta-\mathrm{CN} / \mathrm{S}-\mathrm{L}(3 \mu \mathrm{m})$ mixtures was measured by micro interferometry using a microscope (Axio plan 01, Zeiss, Jena, Germany) according to Chen et al. (2016) with some modifications. The studied samples were silica in PB (Large: $3 \mu \mathrm{m})$ with a concentration from $0.00015 \%$ to $0.15 \%(\mathrm{w} / \mathrm{w}), \beta-\mathrm{CN}(0.015 \%$, $\mathrm{w} / \mathrm{w})$ and $\beta-\mathrm{CN} / \mathrm{silica}$ mixtures with varying ratios $(1: 10,1: 20,1: 30,1: 50,1: 100, \mathrm{w} / \mathrm{w})$. Thin liquid films (diameter $=200 \mu \mathrm{m})$ were made in a Scheludko cell $($ diameter $=0.3 \mathrm{~cm})$ covered with a glass cover. The casing had a reservoir of PB (10 mM, pH 7.0) at the bottom to ensure a relative humidity of $100 \%$ in the cell during measurements. Liquid was drawn into the capillary with a syringe $(500 \mu \mathrm{L}$, Hamilton, Reno, NV, USA) and the whole setup was left to equilibrate for 5 min before a thin film was made by drawing sample solution into the capillary. If a film did not break after $30 \mathrm{~min}$, it was considered stable. In this case, the lifetime was expressed as $1800 \mathrm{~s}$. In case of stable films, samples were measured for 5 times. In the case of rupturing films, experiments were repeated 10 times to calculate the average and standard deviation of the rupture time and film thickness (h). Images of the thin films were collected with a software script (developed at the Laboratory of Food Chemistry, Wageningen University) for Matlab (Software version 2013b, MathWorks, Natick). The magnification was $\times 100$. The equilibrium film thickness (h) was calculated using the intensity of the reflected monochromatic light $(\lambda=546 \mathrm{~nm})$. The average intensity 


\section{Chapter 5}

of light (pixels) was recorded in the centre of the film in a circle of radius of around $25 \mu \mathrm{m}$. The thickness of the film was calculated as described in reference [34] using:

$$
h=\frac{\lambda}{2 \pi n} \sin ^{-1}\left(\sqrt{\frac{I-I_{\min }}{I_{\max }-I_{\min }}}\right)
$$

Where $\lambda$ is the wavelength of the light $(\lambda=546 \mathrm{~nm}), \mathrm{n}$ is the refractive index of the film, $I$ is the intensity of the reflected light, and $I_{\min }$ and $I_{\max }$ are the minimum and maximum intensities, respectively.

\subsection{Results and discussion}

\subsubsection{Sample characterization}

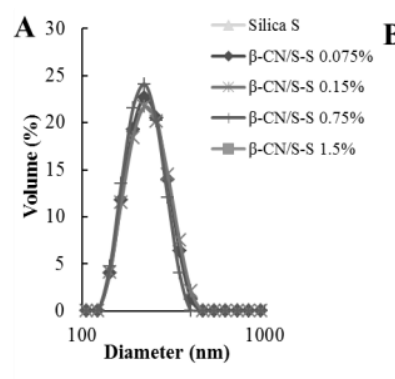

D

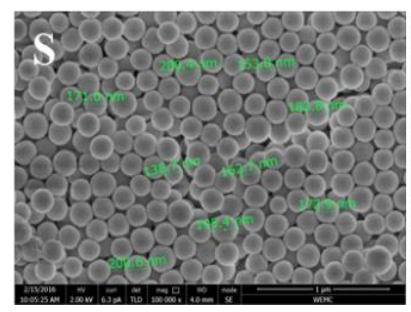

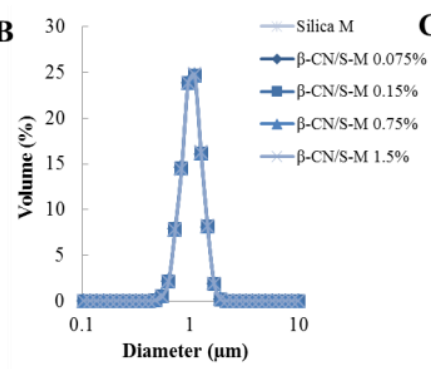
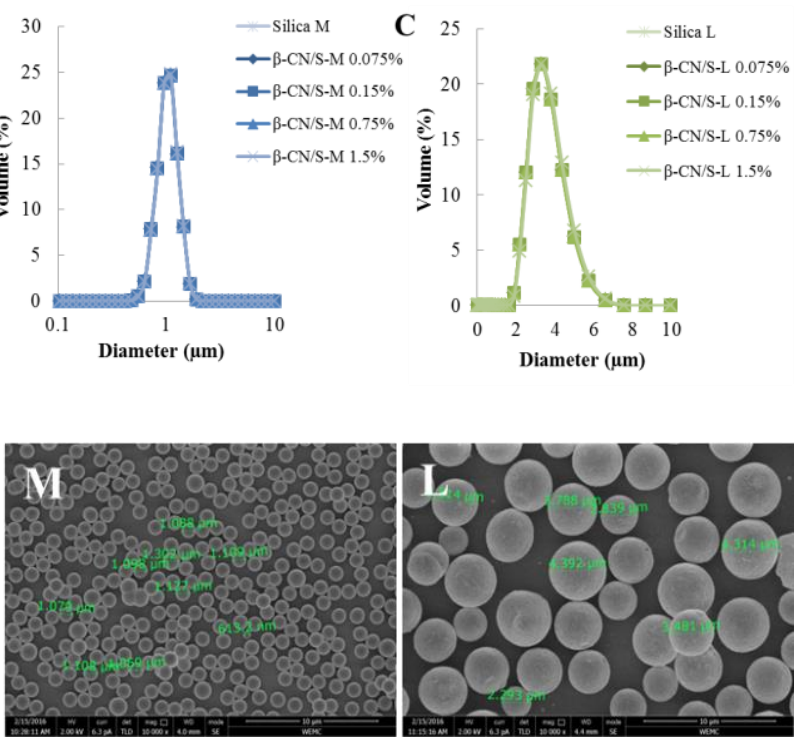

Figure 5-1. Particle size distribution of silica dispersed in buffer and $\beta$-CN/silica mixtures in volume fraction (\%).The $\beta-\mathrm{CN} /$ silica mixtures contained $0.075 \%, 0.15 \%, 0.75 \%$ and $1.5 \%$ $(\mathrm{w} / \mathrm{w})$ silica particles and $0.015 \%(\mathrm{w} / \mathrm{w}) \beta-\mathrm{CN}$. Silica particles with different sizes were used. (A): $200 \mathrm{~nm}$; (B) $1 \mu \mathrm{m}$; (C) $3 \mu \mathrm{m}$. (D) Morphology of silica particles with different sizes: (S) $200 \mathrm{~nm}$; (M) $1 \mu \mathrm{m}$; (L) $3 \mu \mathrm{m}$.

The silica particles and the $\beta$-CN/silica mixtures were characterized for size distribution and particle morphology. According to the supplier, the particle size distribution of socalled small silica is $0.2 \mu \mathrm{m}$, so-called medium silica is $1 \mu \mathrm{m}$ and so-called large silica is 3 $\mu \mathrm{m}$. Particle size was checked with mastersizer, nanosizer and SEM. Results indicated that nanosizer was more accurate for size measurement of small particles while the mastersizer was more accurate for size measurement of large particles. All methods worked well for medium size particles. Thus, the average particle size of $\beta-\mathrm{CN} / \mathrm{S}-\mathrm{S}$ mixtures containing 
small silica was taken from nanosizer results (Figure 5-1A). The particle size of $\beta-\mathrm{CN} / \mathrm{S}-\mathrm{M}$ and $\beta$-CN/S-L mixtures containing medium and large silica respectively was taken from the mastersizer results (Figure 5-1 B and C). The average particle size was $0.2 \mu \mathrm{m}$ for (S), 1.05 $\mu \mathrm{m}$ for $(\mathrm{M})$ and $3.59 \mu \mathrm{m}$ for $(\mathrm{L})$. These data are in line with the specifications provided by the supplier. The particle size determined in $\beta-\mathrm{CN} /$ silica mixtures was similar to that found for the bare silica particles, indicating that the particles did not aggregate in the $\beta$-CN solution. Samples with the large silica particles were more polydisperse than the samples of the other two sizes.

To check the morphology of the particles, SEM was conducted. The obtained images are shown in Figure 5-1D. The small and medium sized silica particles were well spherical and monodisperse with a smooth surface. However, the large size silica particles showed a higher polydispersity, confirming the findings of the Mastersizer determination, and a rougher surface. The higher surface roughness is because the large silica particles were porous. The medium and small silica were both nonporous. As expected, no differences were observed between the morphology of the silica particles dispersed in water or dispersed in $\beta-\mathrm{CN}$ (data not shown).

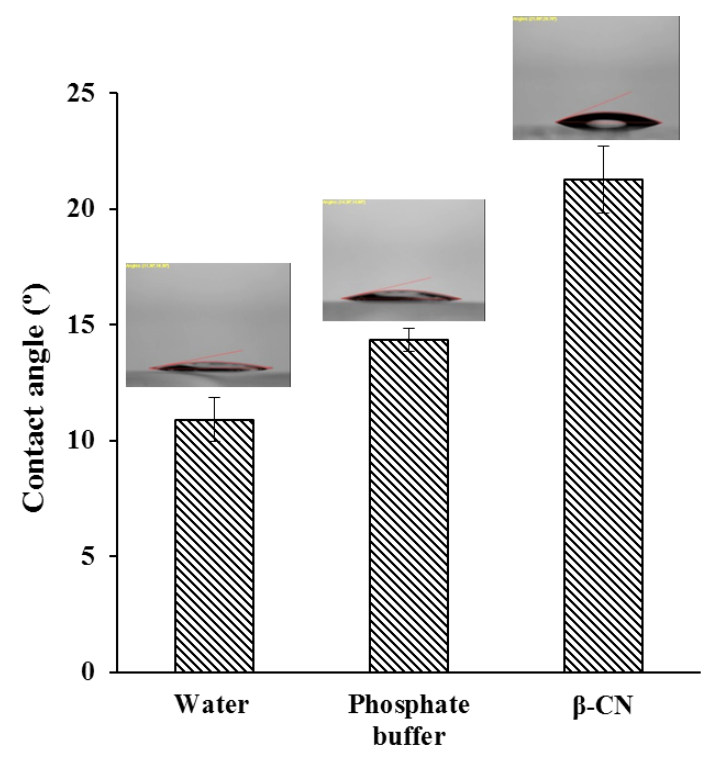

Figure 5-2. Contact angle of water, phosphate buffer $(\mathrm{pH}=7.0,10 \mathrm{mM})$ and $\beta-\mathrm{CN}(0.015 \%$, $\mathrm{w} / \mathrm{w}$ in phosphate buffer) on a glass plate.

The size distribution values measured by SEM were in line with those obtained with Mastersizer. Also here, no sign of aggregation of the particles in the $\beta-\mathrm{CN} / \mathrm{silica}$ mixtures used in this study was observed. According to F. Tiberg et al.(2001), $\beta-\mathrm{CN}$ forms an asymmetric-bilayer when adsorbed to hydrophilic silica [35], which indicated that the 


\section{Chapter 5}

surface of hydrophilic silica with adsorbed $\beta-\mathrm{CN}$ becomes more hydrophobic. To check this we estimated the contact angle of the particles after attachment of $\beta$-CN. Therefore, we used a hydrophilic glass surface to mimic the surface of hydrophilic silica particles. Results are shown in Figure 5-2. The hydrophilic glass surface had a water contact angle of $11 \pm 1^{\circ}$ which increased to $21 \pm 2^{\circ}$ when water was replaced by $\beta$-CN solution. This indicates that the adsorption of $\beta-\mathrm{CN}$ at the surface of silica indeed makes the glass surface more hydrophobic. For the contact angle of silica particles with adsorbed $\beta-\mathrm{CN}$, we expect that it will be close to $21 \pm 2^{\circ}$. Other research also reported an hydrophobicity of particle changed by binding of amphiphilic molecules to the surface of hydrophilic inorganic particles [36, 37]. However, besides material, the surface roughness of the particle could also influence the contact angle since it could lead to a 'non-equilibrium' wetting characteristic of the particles.

\subsubsection{Foam properties}

\section{Foamability}

No foam could be formed with silica particles dispersed in buffer solution only, i.e. without $\beta-\mathrm{CN}$. This is the case for all particle sizes. This is in line with previous results of Binks et al. [18] who found that hydrophilic silica particles with a surface coverage of Si-OH larger than $70 \%\left(\theta<13^{\circ}\right)$ does not foam. The silica particles used in this work were hydrophilic with a $\mathrm{Si}-\mathrm{OH}$ surface coverage of about $100 \%$. The isoelectric point of silica is between 2-3 [24] so that the silica particles are negatively charged at $\mathrm{pH}=7.0$.

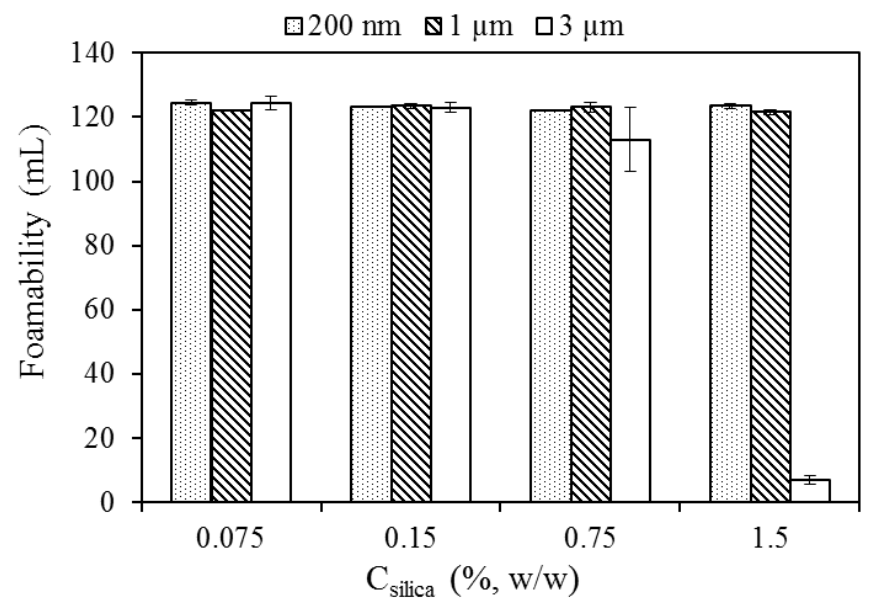

Figure 5-3. Foamability of $\beta-\mathrm{CN} /$ silica mixtures with different size and concentration of silica particles. The concentration of $\beta-\mathrm{CN}$ in all samples was kept at $0.015 \%(\mathrm{w} / \mathrm{w})$.

Aqueous foams were prepared with $\beta$-CN/silica mixtures at varying ratios (1:0, 1:5, 1:10, 1:50, 1:100, w/w). As shown in Figure 5-3, samples could reach a final foam volume of 120 
$\mathrm{mL}$ after $40 \mathrm{~s}$ of sparging, except $\beta$-CN/S-L 1:50 and $\beta$-CN/S-L 1:100. As the concentration of large silica particles increased, a dramatic decrease in foam height was observed: $\beta$ CN/S-L 1:100 hardly foamed.

\section{Foam stability}

For all investigated $\beta-\mathrm{CN} / \mathrm{silica}$ mixtures, the results of samples containing $0.015 \%(\mathrm{w} / \mathrm{w})$ $\beta-\mathrm{CN}$ are shown in Figure 5-4A and those containing the ten times higher concentration of $0.15 \%(w / w)$ are shown in Figure 5-4B. The $t_{1 / 2}$ of the $0.015 \%(w / w) \beta-C N$ solution was $260 \pm 20 \mathrm{~min}$ while that of the $0.15 \%$ (w/w) solution was $455 \pm 7 \mathrm{~min}$, being significantly higher than that of any other $\beta$-CN/silica mixtures. For mixtures with the same silica particle size but different amounts of silica particles, foam stability decreased with increasing concentration of silica particles at two $\beta-\mathrm{CN}$ concentrations. It is noted that, compared to $\beta-\mathrm{CN}$ without any particles, foam stability decreased to $0 \mathrm{~min}$ at $0.015 \%(\mathrm{w} / \mathrm{w})$ upon addition of $1.5 \%$ large silica particles, while it decreased by factor of 6 at $0.15 \%(w / w)$ upon addition of the same amount of large silica particles. This indicates that the decrease in foam stability upon addition of particles is relatively stronger at lower $\beta$-CN concentrations.
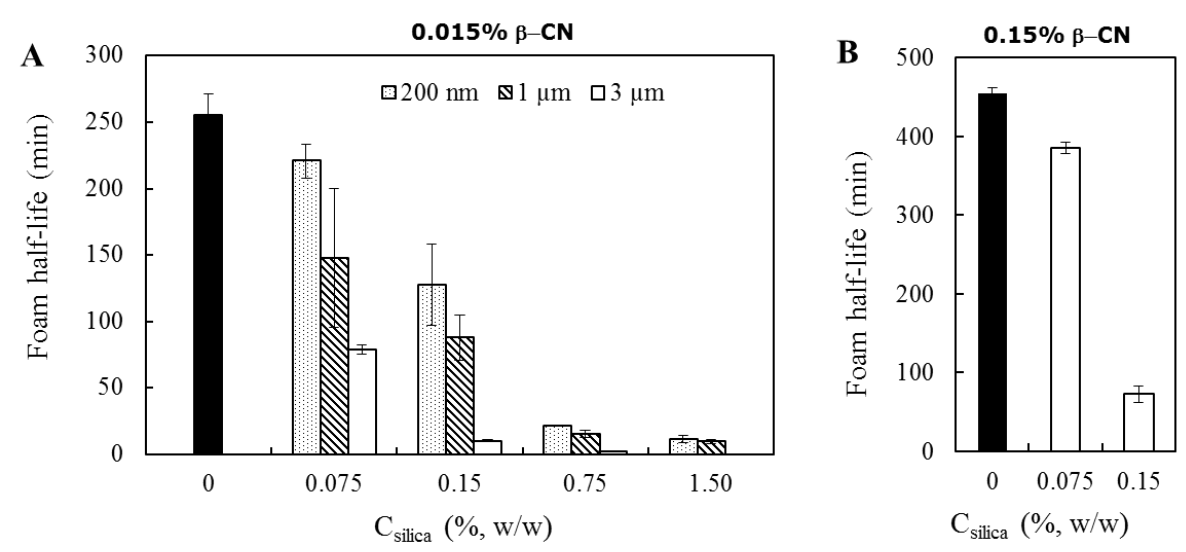

Figure 5-4. Foam half-life $\left(t_{1 / 2}\right)$ of $\beta$-CN/silica mixtures with different size and concentration of silica particles. $\mathrm{C}_{\text {silica }}=0 \%$ represents a $\beta-\mathrm{CN}$ solution with a protein concentration of $0.015 \%(\mathrm{w} / \mathrm{w})$ in $(\mathrm{A})$ and $0.15 \%(\mathrm{w} / \mathrm{w})$ in $(\mathrm{B})$. Black bar: $\beta-\mathrm{CN}$.

The role of particle size in this decrease in foam stability by adding particles was also checked, at the lower $\beta$-CN concentration of $0.015 \%(w / w)$. For equal weight ratio in $\beta$ $\mathrm{CN} /$ silica, mixtures show a clear negative relation between particle size and foam stability.

We also measured the foam properties of the supernatant of the $\beta$-CN/silica 1:10 solution for all three particle sizes and results are shown in Figure 5-5. It was found that foams of the supernatants (containing no silica particles) were markedly lower in height than those of 


\section{Chapter 5}

the initial $0.015 \%, \mathrm{w} / \mathrm{w} \beta-\mathrm{CN}$ solution. This effect was more pronounced for the larger silica particle samples and their supernatants. The supernatant of $\beta-C N / S-S$ 1:10, which had the most stable foam among supernatants, showed a decrease in foam height of almost a factor of two compared to that of initial $\beta-\mathrm{CN}$ solution. One possible explanation for the above behaviour could be the decrease of $\beta-\mathrm{CN}$ in solution due to its adsorption to the silica particles, i.e. the silica depriving the solution from its $\beta-\mathrm{CN}$. Based on this assumption, the reason why foam stability of $\beta-\mathrm{CN} /$ silica decreased less at the higher $\beta-\mathrm{CN}$ concentration of $0.15 \%$ is most probably due to the fact that there is more $\beta-\mathrm{CN}$ left free in the bulk and the effect therefore is relatively smaller because there is still enough $\beta-\mathrm{CN}$ left in solution to sufficiently stabilise the foam. The adsorbed amount $(\Gamma)$ of $\beta$-casein on hydrophilic silica surface was reported to be $0.26 \mu \mathrm{g} / \mathrm{cm}^{2}$ for a bulk concentration of $27 \mu \mathrm{M}$ [29]. From this, the according estimated amount of $\beta-\mathrm{CN}$ adsorbed to the particle surface on basis of the total area of the silica spheres in solution was calculated to be $100 \%$ for $200 \mathrm{~nm}, 25.3 \%$ for $1 \mu \mathrm{m}$ and $6.5 \%$ for $3 \mu \mathrm{m}$ sized silica particles in a $0.015 \%(\mathrm{w} / \mathrm{w}) \beta-\mathrm{CN}$ solution that contains $1.5 \%(\mathrm{w} / \mathrm{w})$ silica particles. For the $0.15 \%$ solution, approximately $10 \%, 3 \%$, and $1 \%$ of the $\beta-\mathrm{CN}$ is estimated to adsorb to the silica particles. This estimate also implies that a considerable amount of $\beta-\mathrm{CN}$ could indeed be adsorbed at the silica particle surface and be deprived from the solution. The high porosity and surface roughness of large silica $(3 \mu \mathrm{m})$ probably resulted in more adsorption of $\beta-\mathrm{CN}$ to the particle surfaces compared to smaller particles. To get more insights in the possible mechanisms of foam destabilization of $\beta-\mathrm{CN}$ solutions by these silica particles, the properties of the air/water interfaces and the thin film stability were studied as below.

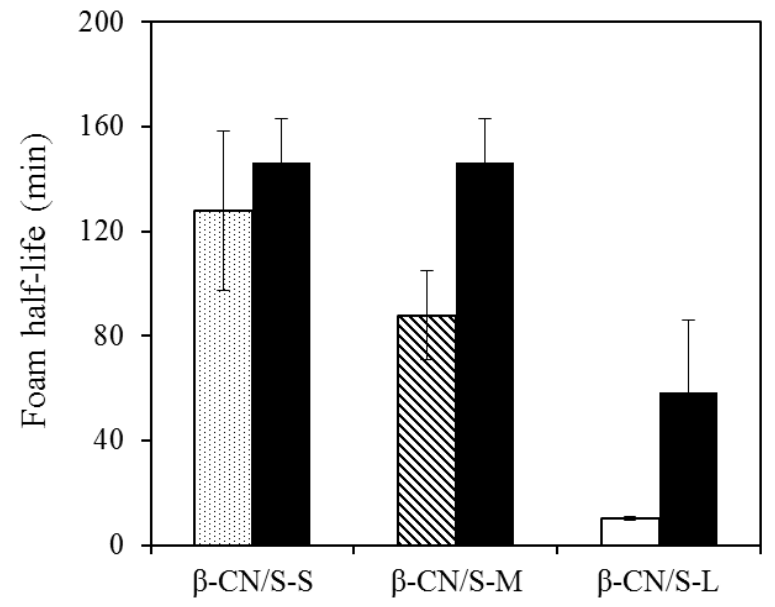

Figure 5-5. Foam half-life $\left(\mathrm{t}_{1 / 2}\right)$ of $\beta$-CN/Silica (L: $3 \mu \mathrm{m}$; M: $1 \mu \mathrm{m}$; $\mathrm{S}: 200 \mathrm{~nm}$ ) mixtures with a ratio of $1: 10(\mathrm{w} / \mathrm{w})$ and their supernatants. Dark bars represent corresponding supernatant of the $\beta-\mathrm{CN} /$ silica mixture. 


\subsubsection{Interfacial properties}

\section{Dynamical surface pressure}

The surface pressure $(\Pi)$ at $\mathrm{t}=100 \mathrm{~s}$ as a function of foam stability of $\beta$-CN/silica mixtures containing different amount of particles $(0,0.075 \%, 0.15 \%, 0.75 \%$ and $1.5 \%, \mathrm{w} / \mathrm{w})$ is shown in Figure 5-6. The surface pressure for silica in PB was almost zero, which confirmed that the silica particles were initially hydrophilic and do not go to the air/water interface. For most $\beta$-CN/silica mixtures, $\Pi$ reached about $15.0 \mathrm{mN} / \mathrm{m}$ after $100 \mathrm{~s}$, except for the $\beta-\mathrm{CN} /$ silica mixtures containing the large silica particles. For $\beta-\mathrm{CN} / \mathrm{S}-\mathrm{L} 1: 50$, the $\Pi$ was 0 at $\mathrm{t}=100 \mathrm{~s}$ and for $\beta-\mathrm{CN} / \mathrm{S}-\mathrm{L} 1: 20$, $\Pi$ was only $11.8 \mathrm{mN} / \mathrm{m}$. According to Churaev et al. (1995), the value of the surface pressure was linked with the ability to incorporate air: the higher the surface pressure, the more air will be incorporated [39]. This can explain the poor foamability of $\beta$-CN/S-L 1:50 and $\beta$-CN/S-L 1:20 (Figure 5-3).

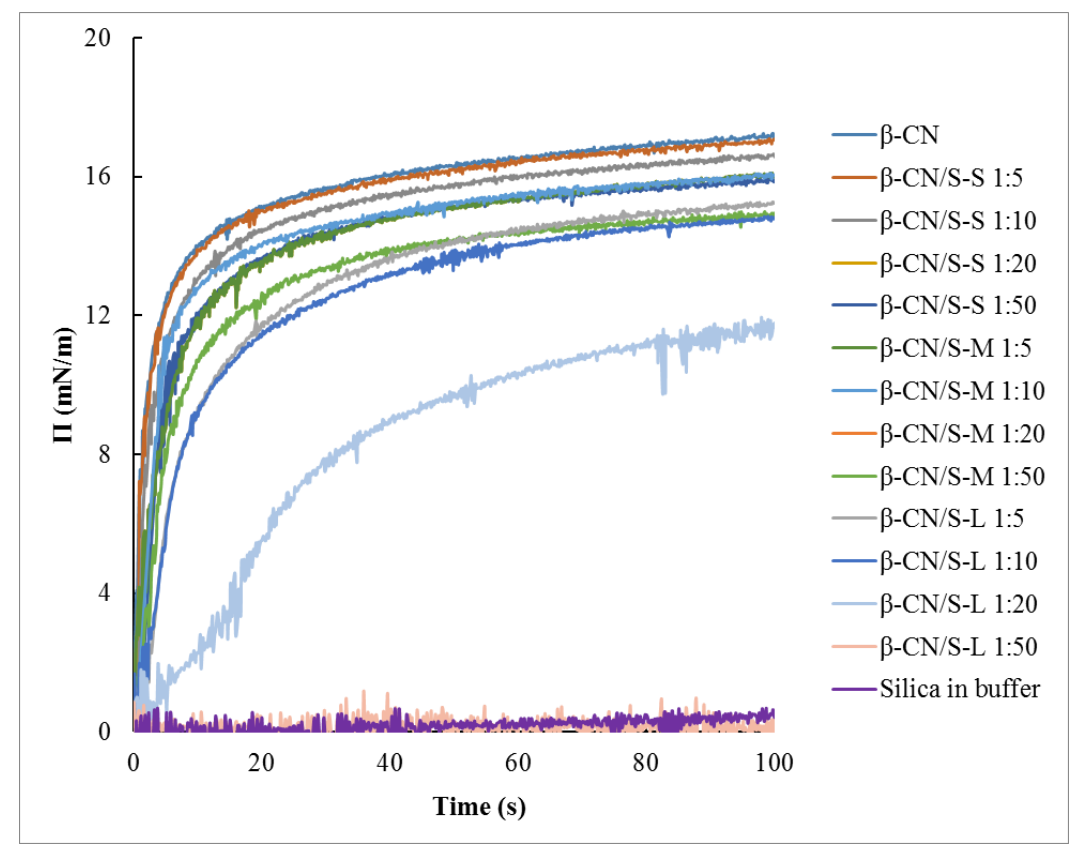

Figure 5-6. Surface pressure $(\Pi, \mathrm{mN} / \mathrm{m})$ of $\beta-\mathrm{CN}(0.015 \%, \mathrm{w} / \mathrm{w})$ silica in buffer $(3 \mu \mathrm{m})$ and $\beta-\mathrm{CN} /$ silica mixtures with varying ratios $(1: 5,1: 10,1: 20$ and 1:50) with different sized silica particles (L: $3 \mu \mathrm{m}, \mathrm{M}: 1 \mu \mathrm{m}$ and $\mathrm{S}: 200 \mathrm{~nm}$ ).

\section{Surface dilatational modulus}

Nonlinear surface rheology of the air/water interface stabilized by $\beta-\mathrm{CN}(0.015 \%, \mathrm{w} / \mathrm{w})$ and $\beta-\mathrm{CN} /$ silica 1:10 (w/w) with three particle sizes was performed and the according Lissajous plots (30\% deformation) are shown in Figure 5-7. No differences in patterns could be 


\section{Chapter 5}

observed between the $\beta-\mathrm{CN}$ and $\beta-\mathrm{CN} /$ silica mixtures containing small and medium sized particles. Their air/water interfaces showed a strong increase in cohesion in the end of compression, which was probably caused by the entanglement of $\beta$-CN. However the air/water interface stabilized by $\beta-C N / S-L$ appeared like that of a diluted surfactant layer without cohesion in the end of compression. This may be simply due to the fact that there is a lower bulk concentration of free $\beta-\mathrm{CN}$ in $\beta$-CN/S-L. From these experiments, no conclusions can be drawn whether the particles adsorb at the air/water interface or not. However, we can conclude that if the particles adsorb, they do not significantly change the interfacial properties indicating that they are diluted and do not interact up to a strain of 0.3 .

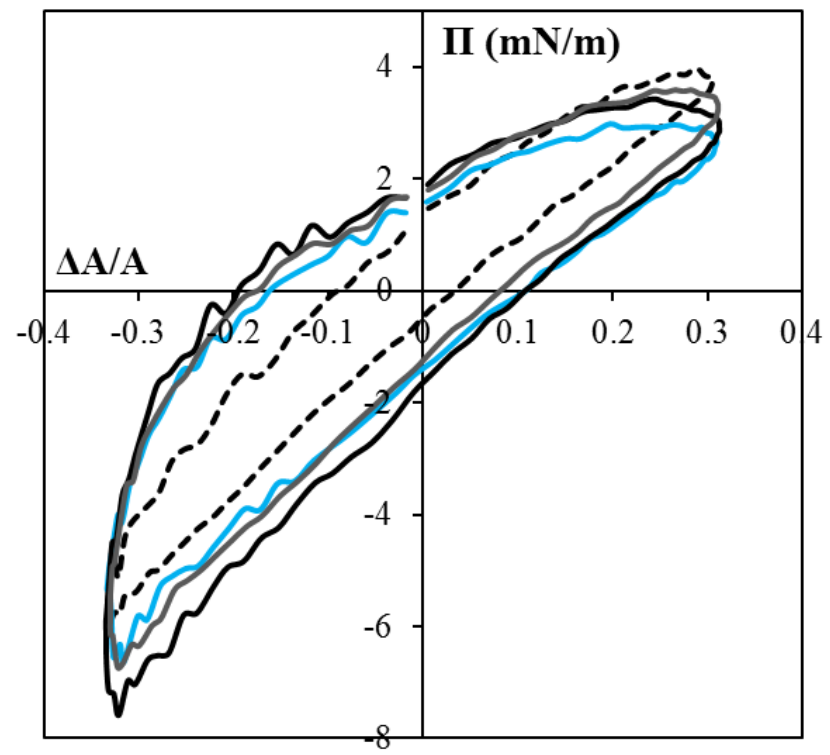

Figure 5-7. Nonlinear surface rheology (30\% deformation) of $\beta-\mathrm{CN}$ and $\beta-\mathrm{CN} / \mathrm{silica}$ mixtures with ratio of 1:10 (w/w). Blue line: $\beta-\mathrm{CN}$; dash line: $\beta-\mathrm{CN} / \mathrm{S}-\mathrm{L}$; solid black line: $\beta-\mathrm{CN} / \mathrm{S}-\mathrm{M}$; solid grey line: $\beta-\mathrm{CN} / \mathrm{S}-\mathrm{S}$.

\subsubsection{Thin film properties}

The morphology and stability of thin liquid films made from $\beta$-CN solutions containing silica particles of $3 \mu \mathrm{m}$ with varying $\beta-\mathrm{CN}$ concentration (ranging from $0.00015 \%$ to $0.15 \%$, $\mathrm{w} / \mathrm{w})$ as well as varying $\beta-\mathrm{CN} /$ silica weight ratios $(1: 10,1: 20,1: 30,1: 50,1: 100, \mathrm{w} / \mathrm{w})$ were studied with the thin film balance technique. Figure 5-8 shows thin films of silica (L) in PB for $\beta$-CN/S-L 1:10. For films of a solution of only silica particles in PB, the morphology and stability were both similar to that of films made with only PB. Their rupture times were around $20 \mathrm{~s}$. This is in line with the observation that PB solutions containing only hydrophilic silica do not foam. We note that in films made from $\beta-\mathrm{CN} /$ silica mixtures, the silica particles seem located at the interface and are depleted from the film centre and are 
more concentrated around the periphery of the film in a band of about ten times the silica particle diameter. This concentrated band of particles seemingly touching or even bridging the film surfaces at the outer periphery is depicted in Fig. 5-8B and 8C. The depletion of particles from the centre of the film observed in our experiments is in line with the work of Horozov (2008) [17] and of Narsimhan (2016) [15], who report that particles in dilute monolayers in the film cannot resist the hydrodynamic flow inside the film and will be dragged away from the film centre into its periphery.

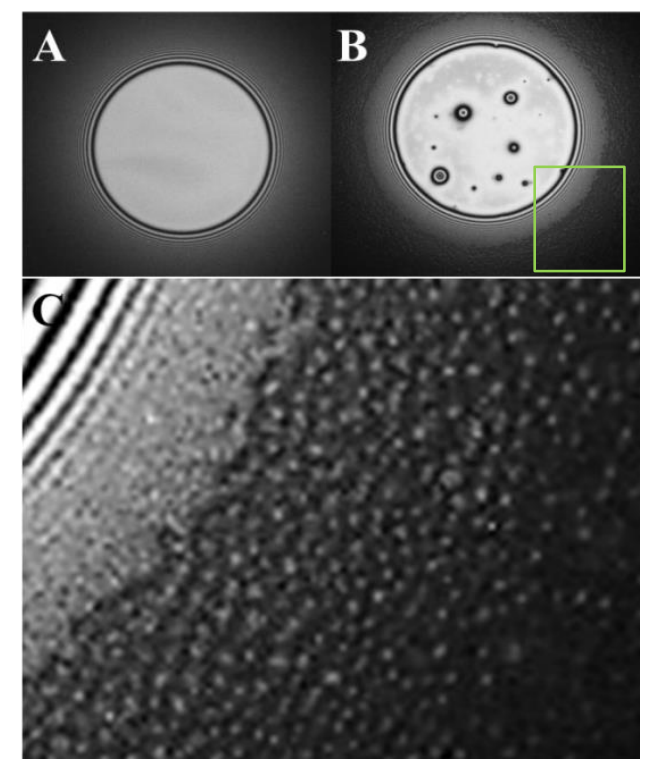

Figure 5-8. Images of thin films of silica (L: $3 \mu \mathrm{m})$ in PB (A), $\beta-C N / S-L ~ 1: 10(B)$ and (C) Zoomed in image of the area within green cube in image $(B)$.

Figure 5-9 shows the evolution of the morphology of films of $\beta-\mathrm{CN} /$ silica mixtures in time. For all films of $\beta-\mathrm{CN} /$ silica mixtures, the thicker central part of the films gradually flattened, thinned and eventually ruptured. Only for $\beta$-CN/S-L 1:10, the thinning rate of the film (data not shown), did not change much compared to that of $\beta-\mathrm{CN}$ without silica particles. From $\beta$-CN/S-L 1:20 to $\beta$-CN/S-L 1:100, the films exhibited a faster thinning process compared to the $\beta$-CN solution without particles. With increasing particle concentration, the gradually decreasing light intensity at equilibrium also indicated a lower final inner film thickness shortly before rupture. 


\section{Chapter 5}

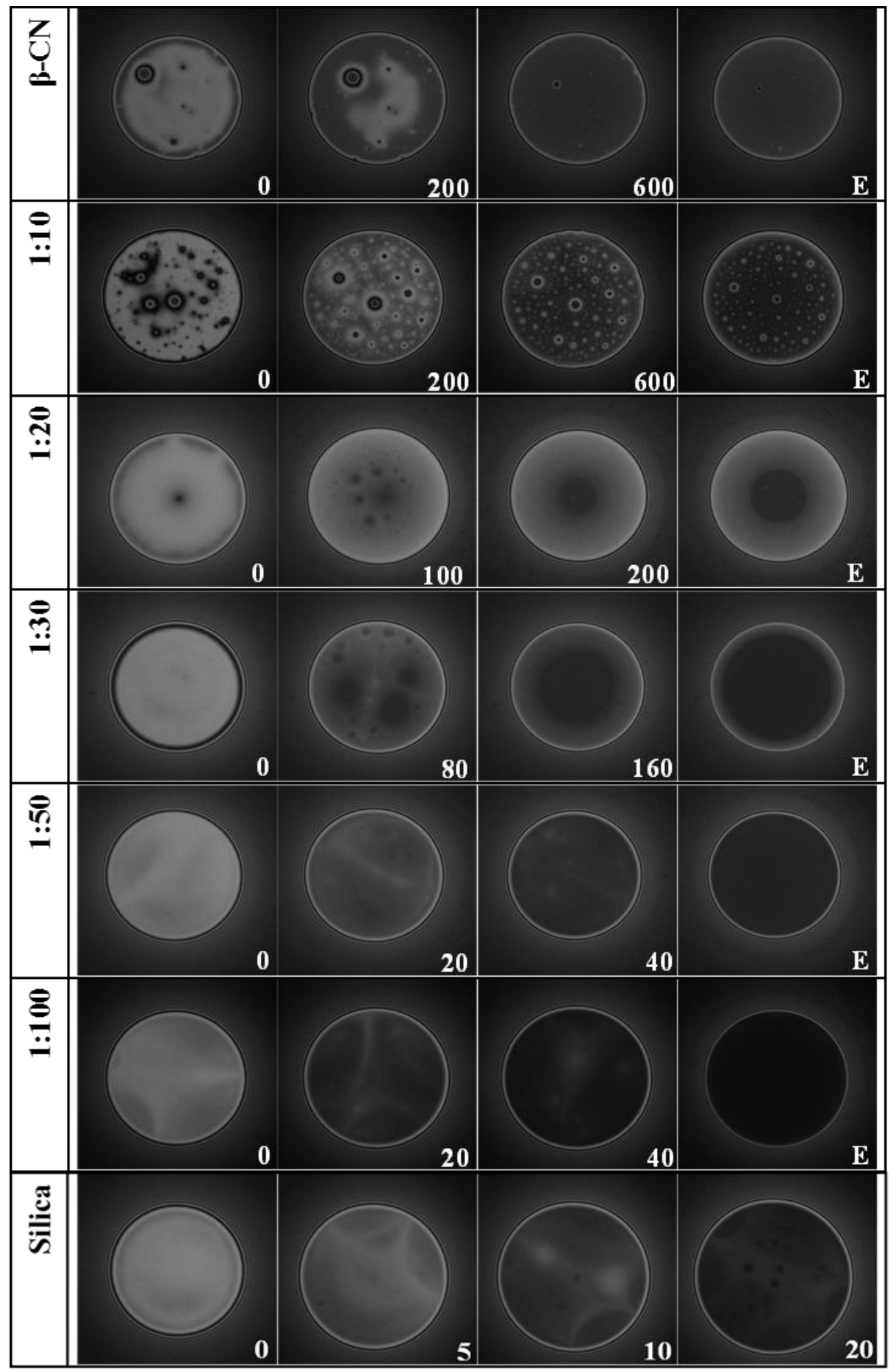


Figure 5-9. Thin liquid film images of silica, $\beta-\mathrm{CN}$ and $\beta-\mathrm{CN} /$ silica mixtures with varying ratios (from 1:10 to $1: 100, w / w$ ). The size of silica particle for thin film study was $3 \mu \mathrm{m}$. The number on the images is the different time points (s) and " $E$ " represent equilibrium.
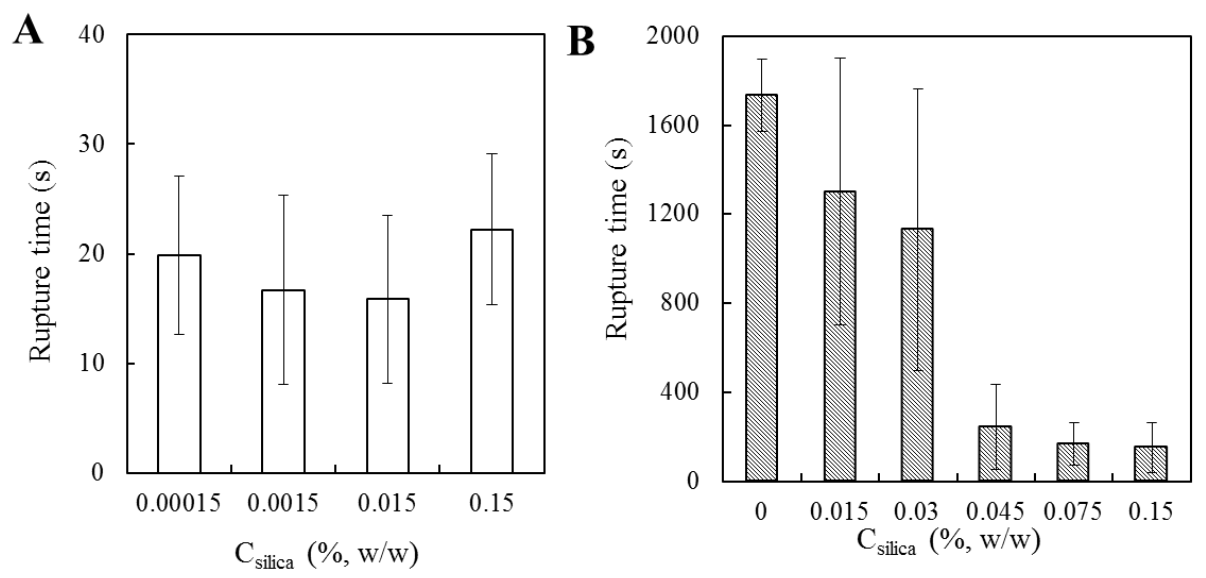

Figure 5-10. Rupture time of thin liquid films of (A) Large silica particles (from $0.00015 \%$ to $0.15 \%, \mathrm{w} / \mathrm{w}$ ) in buffer and (B) $\beta-\mathrm{CN} /$ silica mixtures containing $0 \%$ to $0.15 \%$ silica particles. The concentration of $\beta-\mathrm{CN}$ was kept constant at $0.0015 \%(\mathrm{w} / \mathrm{w})$.

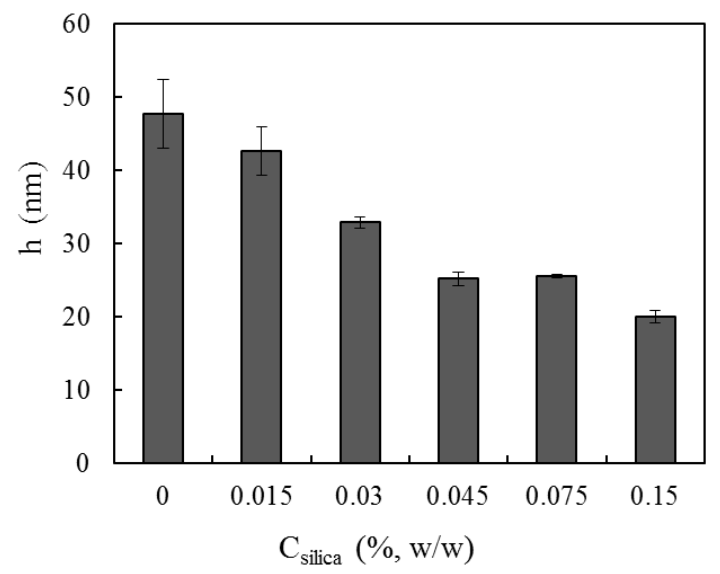

Figure 5-11. Thickness just before rupture (h) of liquid films of $\beta-\mathrm{CN} /$ silica mixtures containing from $0 \%$ to $0.15 \%$ silica particles with a size of $3 \mu \mathrm{m}$.

According to Figure 5-10A, for silica in PB (10 mM, pH 7.0), the thin film stability was similar to that of only $\mathrm{PB}$, with an average rupture time of around $20 \mathrm{~s}$. Figure 5-10B shows the stability of $\beta-\mathrm{CN}$ solution and of $\beta-\mathrm{CN} /$ silica mixtures containing from $0.0 \%-0.15 \%$ 


\section{Chapter 5}

silica with silica particle size of $3 \mu \mathrm{m}$. The concentration of $\beta-\mathrm{CN}$ in the samples used for the study of the thin film properties was kept constant at $0.0015 \%(w / w)$. Note that this is 10 times lower than that used for foam experiments). The film of the $\beta-\mathrm{CN}$ solution was relatively stable (rupture time: $1800 \mathrm{~s}$ ). After adding silica particles to the $\beta$-CN solution, the rupture time decreased. The more particles added to the mixture, the smaller the rupture time and the lower the stability of the liquid film. For instance, with $0.045 \%(\mathrm{w} / \mathrm{w})$ or more silica particles in the mixtures, the thin film stability of $\beta-\mathrm{CN} / \mathrm{S}-\mathrm{L}$ dramatically decreased to less than $400 \mathrm{~s}$. Besides the rupture time, the thickness $h$ of the central part of films of $\beta$ $\mathrm{CN} /$ silica mixtures at the equilibrium before rupture was estimated and is shown in Figure 5-11. Interestingly, this thickness decreased gradually with increasing particle concentration in the $\beta$-CN/silica mixtures, from $47.7 \pm 4.6 \mathrm{~nm}$ for the $\beta$-CN solution $(0.0015 \%, \mathrm{w} / \mathrm{w})$ to $20.0 \pm 0.9 \mathrm{~nm}$ for $\beta$-CN/S-L 1:100.

Research on mixtures of protein aggregates and proteins showed foam stabilization improved with the presence of protein aggregate particles that range in size between tens of nanometers to a few microns [10, 41-45]. We hypothesized that adding hydrophilic silica to $\beta-\mathrm{CN}$ solution would lead to $\beta-\mathrm{CN}$ coated particles that could mimic, depending on the size, casein micelles and their aggregates. In the previous chapter it was shown that these aggregates increased foam stability (Chapter 4). In contrast to this hypothesis our results presented in this chapter show the opposite; a clear destabilization effect when adding hydrophilic silica particles. Based on the results above, it is most likely that the silica particles deplete the solution from its $\beta-\mathrm{CN}$ molecules. In line with our research, Karakashev et al. (2011) [25] found that addition of silica particles to SDS solutions increased the rate of foam decay. The mechanism behind their results was not worked out in detail. Our suggested mechanism of $\beta-\mathrm{CN}$ depletion from the solution could be proven by chemical analysis of the silica particles centrifuged from the $\beta$-CN solution and is also supported by a theoretical estimation of the amount of $\beta-\mathrm{CN}$ adsorbed at the particles interface. In addition we observed that the silica particles are at the air/water interface and located in the outer film region, most probably transported their due to the drag of the liquid during film drainage. This is (also) contrary to what is observed in the case of casein micelle aggregates, which are more or less randomly distributed over the film. 


\subsection{Conclusion}

In this research the effect of size and concentration of hydrophilic silica particles on the properties of foams from solutions containing $\beta$-casein $(\beta-\mathrm{CN})$ and silica particles was investigated. Foam stability of the $\beta-\mathrm{CN} /$ silica mixture decreased with increasing size and concentration of the silica particles. This destabilizing effect is suggested to be caused the depletion of $\beta-\mathrm{CN}$ from solution by means of its adsorption to the silica particles. Thin film study shows that the $\beta$-CN/silica particles are at the interface. The thin foam films arising from $\beta-\mathrm{CN}$ silica dispersions exhibit a central region without silica particles and a band of more concentrated solution of silica particles. Both the rupture time and thickness of the thin films just before rupture (inner region) decreased with increasing particle concentration in the mixtures. The presence of the particles at the outer side of the lamellae would add to the stability of the film because of a reduced pressure difference across the film. However, the decrease in foam and film stability would be ascribed to a decrease in $\beta$-casein bulk concentration due to the adsorption to the silica interface. 


\section{Chapter 5}

\section{References}

1. Murray, B.S., et al., Stabilization of foams and emulsions by mixtures of surface active food-grade particles and proteins. Food Hydrocolloids, 2011. 25(4): p. 627-638.

2. Schmidt, I., et al., Foaming properties of protein/pectin electrostatic complexes and foam structure at nanoscale. Journal of Colloid and Interface Science, 2010. 345(2): p. 316-324.

3. Nicolai, T., Britten, M. and Schmitt, C., $\beta$-Lactoglobulin and WPI aggregates: Formation, structure and applications. Food Hydrocolloids, 2011. 25(8): p. 1945-1962.

4. Fameau, A.L. and Salonen, A., Effect of particles and aggregated structures on the foam stability and aging. Comptes Rendus Physique, 2014. 15(8): p. 748-760.

5. Lazidis, A., et al., Whey protein fluid gels for the stabilisation of foams. Food Hydrocolloids, 2016. 53: p. 209-217.

6. Oboroceanu, D., et al., Fibrillization of whey proteins improves foaming capacity and foam stability at low protein concentrations. Journal of Food Engineering, 2014. 121: p. 102-111.

7. Binks, B.P., et al., Dispersion Behavior and Aqueous Foams in Mixtures of a Vesicle-Forming Surfactant and Edible Nanoparticles. Langmuir, 2015. 31(10): p. 2967-2978.

8. Asghari, A.K., et al., Interfacial and foaming characterisation of mixed protein-starch particle systems for food-foam applications. Food Hydrocolloids, 2016. 53: p. 311-319.

9. De Kruif, C. and Holt, C., Casein micelle structure, functions and interactions. Advanced Dairy Chemistry-1 Proteins. 2003, p. 233-276. Springer US.

10. Chen, M., et al., Particle size determines foam stability of casein micelle dispersions. International Dairy Journal, 2016. 56: p. 151-158.

11. Stamou, D., Duschl, C. and Johannsmann, D., Long-range attraction between colloidal spheres at the air-water interface: The consequence of an irregular meniscus. Physical Review E, 2000. 62(4): p. 5263.

12. Kralchevsky, P.A., Denkov, N.D. and Danov, K.D., Particles with an undulated contact line at a fluid interface: interaction between capillary quadrupoles and rheology of particulate monolayers. Langmuir, 2001. 17(24): p. 7694-7705.

13. Ghezzi, F., et al., Pattern formation in colloidal monolayers at the air-water interface. Journal of colloid and interface science, 2001. 238(2): p. 433-446.

14. Hunter, T.N., et al., The role of particles in stabilising foams and emulsions. Advances in Colloid and Interface Science, 2008. 137(2): p. 57-81.

15. Narsimhan, G., Drainage of particle stabilized foam film. Colloids and Surfaces A: Physicochemical and Engineering Aspects, 2016. 495: p. 20-29.

16. Vivaldini, D.O., et al., Why foams containing colloidal hydrophilic particles are unstable? Ceramics International, 2013. 39(5): p. 6005-6008.

17. Horozov, T.S., Foams and foam films stabilised by solid particles. Current Opinion in Colloid \& Interface Science, 2008. 13(3): p. 134-140.

18. Binks, B.P. and Horozov, T.S., Aqueous Foams Stabilized Solely by Silica Nanoparticles. Angewandte Chemie, 2005. 117(24): p. 3788-3791.

19. Safouane, M., Langevin, D. and Binks, B., Effect of particle hydrophobicity on the properties of silica particle layers at the air-water interface. Langmuir, 2007. 23(23): p. 11546-11553.

20. Dickinson, E., et al., Factors controlling the formation and stability of air bubbles stabilized by partially hydrophobic silica nanoparticles. Langmuir, 2004. 20(20): p. 8517-8525.

21. Ata, S., Ahmed, N. and Jameson, G.J., Collection of hydrophobic particles in the froth phase. International Journal of Mineral Processing, 2002. 64(2): p. 101-122.

22. Ata, S., Ahmed, N. and Jameson, G., The effect of hydrophobicity on the drainage of gangue minerals in flotation froths. Minerals engineering, 2004. 17(7): p. 897-901.

23. Schwarz, S. and Grano, S., Effect of particle hydrophobicity on particle and water transport across a flotation froth. Colloids and Surfaces A: Physicochemical and Engineering Aspects, 2005. 256(2): p. 157-164. 
24. Binks, B.P., Kirkland, M. and Rodrigues, J.A., Origin of stabilisation of aqueous foams in nanoparticle-surfactant mixtures. Soft Matter, 2008. 4(12): p. 2373.

25. Karakashev, S.I., et al., Formation and stability of foams stabilized by fine particles with similar size, contact angle and different shapes. Colloids and Surfaces A: Physicochemical and Engineering Aspects, 2011. 382(1): p. 132-138.

26. Kruglyakov, P.M., Elaneva, S.I. and Vilkova, N.G., About mechanism of foam stabilization by solid particles. Advances in colloid and interface science, 2011. 165(2): p. 108-116.

27. Esmaili, M., et al., Beta casein-micelle as a nano vehicle for solubility enhancement of curcumin; food industry application. LWT - Food Science and Technology, 2011. 44(10): p. 2166-2172.

28. Dickinson, E., Caseins in emulsions: interfacial properties and interactions. International Dairy Journal, 1999. 9(3): p. 305-312.

29. Krisdhasima, V., Vinaraphong, P. and McGuire, J., Adsorption Kinetics and Elutability of $\alpha$ Lactalbumin, $\beta$-Casein, $\beta$-Lactoglobulin, and Bovine Serum Albumin at Hydrophobic and Hydrophilic Interfaces. Journal of Colloid and Interface Science, 1993. 161(2): p. 325-334.

30. Ince Coskun, A.E., et al., Preparation, structure and stability of sodium caseinate and gelatin microparticles. Food Hydrocolloids, 2015. 45: p. 291-300.

31. Ghosh, G., Dispersion-equation coefficients for the refractive index and birefringence of calcite and quartz crystals. Optics Communications, 1999. 163(1): p. 95-102.

32. Berghout, J.A.M., et al., Comparing functional properties of concentrated protein isolates with freezedried protein isolates from lupin seeds. Food Hydrocolloids, 2015. 51: p. 346-354.

33. van Kempen, S.E., et al., Non-linear surface dilatational rheology as a tool for understanding microstructures of air/water interfaces stabilized by oligofructose fatty acid esters. Soft Matter, 2013. 9(40): p. 9579-9592.

34. Scheludko, A. and Platikanowa, D., Untersuchung dunner flussiger schichten auf quecksiber.Kolloid-zertschrift and zeitschrift fur polymere, 1961. 175(2): p. 150.

35. Tiberg, F., et al., $\beta$-Casein Adsorption at the Silicon Oxide-Aqueous Solution Interface. Biomacromolecules, 2001. 2(3): p. 844-850.

36. Gonzenbach, U.T., et al., Stabilization of Foams with Inorganic Colloidal Particles. Langmuir, 2006. 22(26): p. 10983-10988.

37. Kostakis, T., Ettelaie, R. and Murray, B.S., Enhancement of stability of bubbles to disproportionation using hydrophilic silica particles mixed with surfactants or proteins. Food Colloids, 2007. p. 357-368.

38. van Kempen, S.E.H.J., et al., Effect of Variations in the Fatty Acid Chain of Oligofructose Fatty Acid Esters on Their Foaming Functionality. Food Biophysics, 2013. 9(2), p. 114-124.

39. Churaev, N.V., Contact angles and surface forces. Advances in Colloid and Interface Science, 1995. 58(2): p. 87-118.

40. Gergely, V., Jones, R. and Clyne, T., The effect of capillarity-driven melt flow and size of particles in cell faces on metal foam structure evolution. Transactions-JWRI, 2001. 30(SPI): p. 371-376.

41. Schmitt, C., et al., Whey protein soluble aggregates from heating with NaCl: Physicochemical, interfacial, and foaming properties. Langmuir, 2007. 23(8): p. 4155-4166.

42. Rullier, B., et al., $\beta$-Lactoglobulin aggregates in foam films: Effect of the concentration and size of the protein aggregates. Journal of Colloid and Interface Science, 2010. 343(1): p. 330-337.

43. Lech, F., et al., Role of complex formation on foam stability of protein surfactant mixtures. 2014.

44. Morales, R., et al., Modification of foaming properties of soy protein isolate by high ultrasound intensity: particle size effect. Ultrasonics sonochemistry, 2015. 26: p. 48-55.

45. Wan, Z., Yang, X. and Sagis, L.M., Nonlinear Surface Dilatational Rheology and Foaming Behavior of Protein and Protein Fibrillar Aggregates in the Presence of Natural Surfactant. Langmuir, 2016. 32(15): p. 3679-3690. 


\section{Chapter 6}

General discussion 


\section{Chapter 6}

\subsection{Introduction}

The aim of the research described in this thesis is to better understand the role of milk proteins on milk foam behaviour. Milk is composed of different protein fractions and the main focus in this thesis is on casein micelles. The influence of composition, particle size (size of aggregates of the casein micelles) and concentration on the foaming behaviour of dispersions of casein micelles (i.e. casein micelle dispersions or, in short, CMDs) is described in Chapter 2-4. In order to compare the findings on the behaviour of foams stabilised by CMDs to that of other particle stabilised foams, the $\beta$-casein/silica system is investigated (Chapter 5). In the current chapter, we discuss how the results described in the different chapters can be combined to lead to a more refined overall emerging picture of the importance of casein micelle particles and their aggregation for milk foam behaviour and discuss implications for applications and future work. In the next section we first describe the physico-chemical properties of the various systems studied in this thesis. 


\subsection{Physicochemical properties of the systems studied in this thesis}

Chapters 2-4 of this thesis are focused on the foam, thin film and air/water interface stabilized by casein micelle dispersions (CMDs) that vary in the number of aggregates of casein micelles (CMAs). The CMDs that practically do not contain any aggregated casein micelles, i.e. as in the case in regular milk, mainly contain single casein micelles with a small amount of casein molecules and casein-derived peptides. The CMDs that contain aggregates of casein micelles are referred to as CMADs. Chapter 5 describes a foam study of a mixture of $\beta$-casein and hydrophilic silica ( $\beta$-CN/silica). The initial idea of the work in Chapter 5 was to build a model system to check the role of particles in foam stabilization and the role of $\beta$-casein as a possible adsorbent on the surface of the silica particles, thereby possibly modifying the contact angle between the silica particles and air/water interface [1].

For both the casein dispersion systems and the silica system we have considered concentration, size, contact angle, surface charge, shape and surface roughness and density of the dispersed casein micelles and its aggregates, and silica particles, respectively. These properties can be summarized as follows.

The concentration of particles in the two systems investigated (CMDs/CMADs and $\beta$ $\mathrm{CN} /$ silica) is in the range of 0\%-5.0 \% (w/w). The average particle size of CMDs without aggregates (i.e. casein micelles) ranges between 130 and $200 \mathrm{~nm}$. The average particle size for the CMADs containing aggregates ranges between $500 \mathrm{~nm}$ and $10 \mu \mathrm{m}$. The contact angle of hydrophilic silica particles with adsorbed $\beta$-casein was estimated from our experiments to be around $20^{\circ}$, which is comparable to that of hydrated casein micelles at neutral $\mathrm{pH}[2,3]$. The zeta potential of casein micelles measured in milk permeate is around $-20 \mathrm{mV}$ [4]. The bare silica particles used in this study have a surface charge density according to the supplier of $30 \mathrm{mM} / \mathrm{g}$ for $200 \mathrm{~nm}, 7 \mathrm{mM} / \mathrm{g}$ for $1.0 \mu \mathrm{m}$ and $1.2 \mathrm{mM} / \mathrm{g}$ for 3 $\mu \mathrm{m}$. The zeta potential with adsorbed $\beta$-casein is between -20 and $-30 \mathrm{mV}$, similar to that of casein micelles. The $\mathrm{pH}$ of the two particle systems was comparable, i.e. 6.7-7.0. The ionic strength is $125.4 \mathrm{mM}$ for CMDs, which is calculated according to [5] based on the recipe of SMUF in [6] whereas it is $21.5 \mathrm{mM}$ for the $\beta-\mathrm{CN} /$ silica dispersions. The shape of casein micelles is roughly spherical, however, that of the CMAs is either irregular-shaped or flatspherical. As derived from Figure 6-1, the surface roughness of casein micelles is around 15-20 nm. Because CMAs are composed of casein micelles, the large scale apparent surface roughness of the casein micelle aggregates is of the order of the length scale of size of casein micelles while at the shorter length scale the apparent roughness is given by that of a single casein micelle. In $\beta-\mathrm{CN} /$ silica systems, the shape and surface roughness depends on the size of particles (Figure 6-2). Silica particles of $200 \mathrm{~nm}$ and $1 \mu \mathrm{m}$ are non-porous, well spherical and have very smooth surface. Silica particles of $3 \mu \mathrm{m}$ are roughly spherical with some irregularities. Their surface is rougher than that of smaller silica. In general, the morphology of silica particles is not affected by adsorption of $\beta$-casein. Casein micelles have a density of $1.0632 \mathrm{~g} / \mathrm{cm}^{3}$ and a voluminosity of $4.4 \mathrm{~cm}^{3} / \mathrm{g}$, they are porous and highly 


\section{Chapter 6}

hydrated [4]. Silica particles of $200 \mathrm{~nm}$ and $1 \mu \mathrm{m}$ have a density of $2.0 \mathrm{~g} / \mathrm{cm}^{3}$ and particles of $3 \mu \mathrm{m}$ have a density of $1.8 \mathrm{~g} / \mathrm{cm}^{3}$.

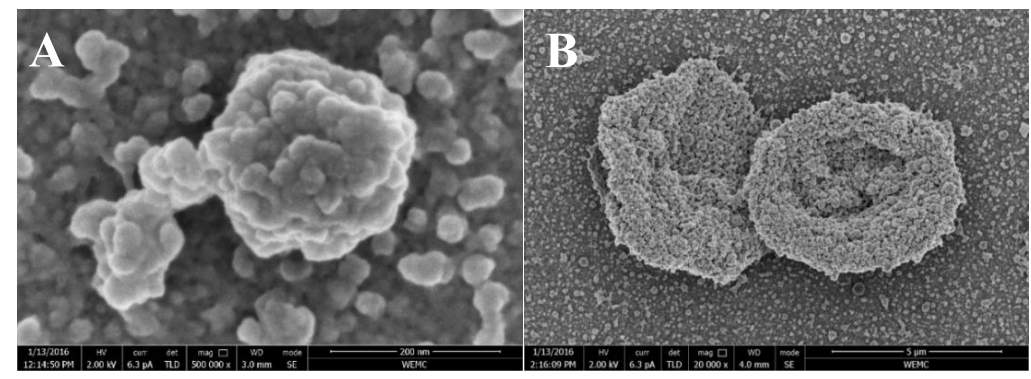

Figure 6-1. SEM image of (A) casein micelles (scale bar: $200 \mathrm{~nm}$ ) and (B) casein micelle aggregates (scale bar: $5 \mu \mathrm{m}$ ).

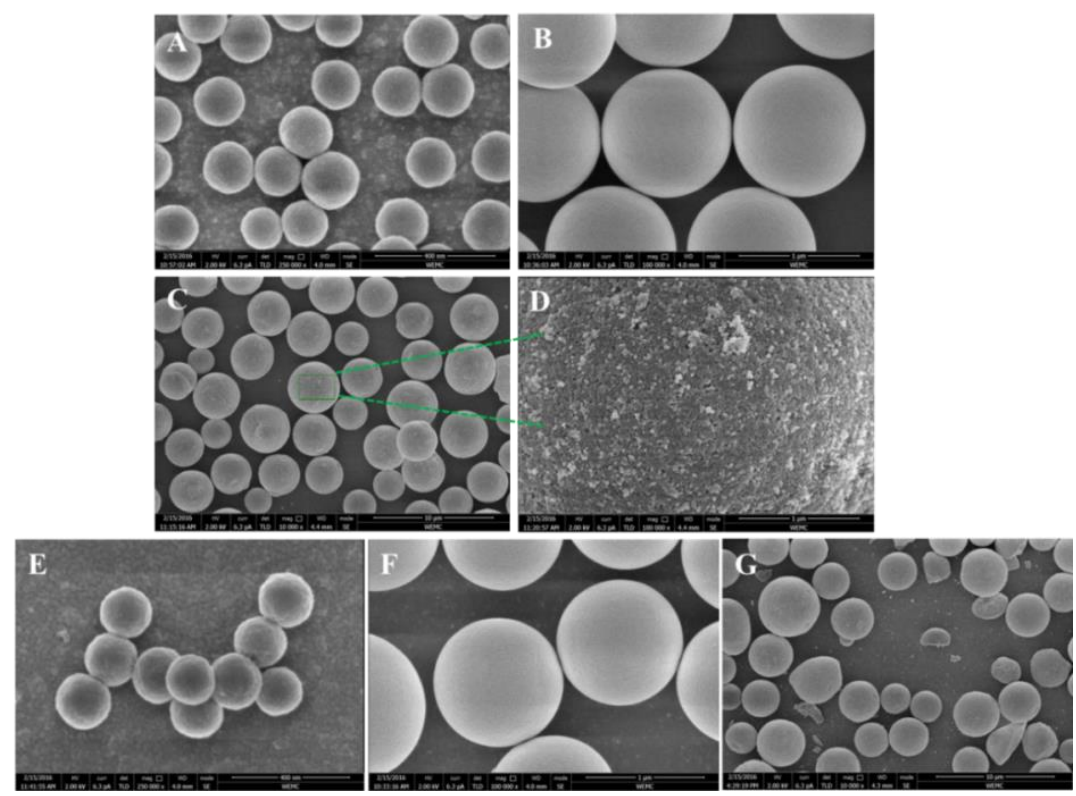

Figure 6-2. SEM image of (A) Hydrophilic silica $200 \mathrm{~nm}$ (scale bar: $400 \mathrm{~nm}$ ); (B) Hydrophilic silica $1 \mu \mathrm{m}$ (scale bar: $1 \mu \mathrm{m}$ ); (C) Hydrophilic silica $3 \mu \mathrm{m}$ (scale bar: $10 \mu \mathrm{m}$ ); (D) Surface of hydrophilic silica $3 \mu \mathrm{m}$ (scale bar: $1 \mu \mathrm{m}$ ); (E) Silica $200 \mathrm{~nm}$ with adsorbed $\beta$-CN (scale bar: $400 \mathrm{~nm}$ ); (F) Silica $1 \mu \mathrm{m}$ with adsorbed $\beta-\mathrm{CN}$ (scale bar: $1 \mu \mathrm{m}$ ) and $(\mathrm{G})$ Silica $3 \mu \mathrm{m}$ with adsorbed $\beta$-CN (scale bar: $10 \mu \mathrm{m}$ ). 


\subsection{Structures and properties at different length scales}

In this study, system structures and properties at different length scales are characterized. A typical example of the different structures and corresponding length scales that exist in foams stabilized by CMDs is given in Figure 6-3.

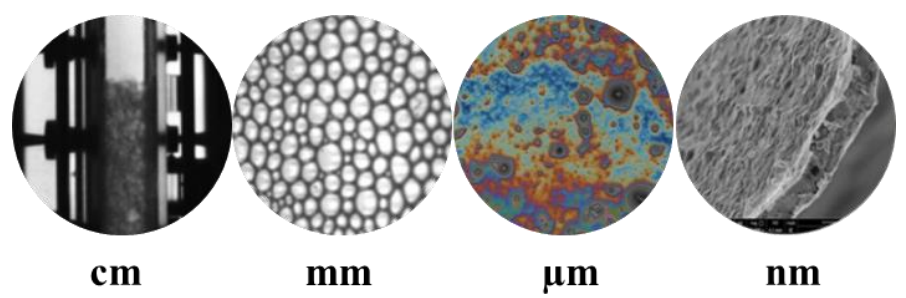

Figure 6-3. Structures at different length scales in foams of casein micelle dispersions

\subsubsection{Interfaces}

To create a foam, newly formed bubbles need to be covered with foaming agents as quickly as possible, which require sufficient amounts of the surface active agents to rapidly adsorb to the air/water interface. To get insight in foaming behavior, we therefore, studied the dynamics of adsorption of CMDs and $\beta$-CN/silica systems, which is described in Chapter 2-3 and Chapter 5, respectively. The dynamics of adsorption is relevant for the initial stages of foam formation [7]. It is usually assessed by measuring, the surface pressure (П) as a function of time [8] and its dependence on the surfactant concentration in the bulk, C, and at the surface, $\Gamma[9,10]$. In this study, the rheological properties of interfaces are investigated to obtain the mechanical properties of the interfacial film [11] [12, 13] (Chapter 2, 3 \& 5). Surface dilatation is conducted which measures surface pressure (П) as a function of the change in area $(\Delta \mathrm{A})$ of the droplet while maintaining a constant shape of the air/water interface. The surface dilatational modulus consists of an elastic part E' that presents the recoverable energy stored in the interface and a viscous part E' that presents the loss of energy through relaxation processes [14]. Both linear and nonlinear surface rheology [15] is conducted. The amplitude of deformation ranges from $6 \%$ to $30 \%$ in this study. Frequency sweeps, where the speed of interfacial deformation will relate to the time scale of the transport of molecules from bulk to interface and vice versa, are also conducted and used to deduce insights of the interfacial properties on the microstructural scale.

\subsubsection{Thin liquid film}

At the scale of thin liquid films, direct observation of morphology of the lamella is conducted with optical microscopy. CMAs are directly visualized in the foam lamella under transmission light mode (Chapter 4). This enables a better quantification of the concentration of particles in foam lamella. In the thin film balance technique, a horizontal 


\section{Chapter 6}

thin liquid film is generated with a Scheludko cell to mimic the foam lamella. Under a reflected light mode, the stability of thin films including film thinning rate, rupture time and film thickness h [16-18] is evaluated through light interference (Chapter 3 \& 5). The thin film stability measured with this technique is found to be more stable compared to that of a thin film in a real foam, implying this parameter will only serve as an indication of stability of foam lamellae.

\subsubsection{Bubble and macroscopic foam}

At the scale of a single bubble, the bubble size distribution is observed by microscopic imaging in 2D linked with image analysis technique (Chapter 2 \& 5). The bubble size shortly after foam formation is measured as an indication of foam stability against early stage coalescence, which is closely related to the adsorption kinetics and concentration of foaming agents in bulk. At the macroscopic level, foam is generated mainly by sparging. Shaking is performed in Chapter $\mathbf{4}$ for CMDAs with large CMAs as well. Foam decay is evaluated by foam half-life $\left(t_{1 / 2}\right)$, which is the time required for the foam to reach half of its initial volume [19]. Drainage of liquid is assessed by the liquid volume accumulated at the bottom of the foam [20] and the liquid fraction in foam measured by electric conductivity. The pattern of foam collapse is different for CMDs and $\beta-\mathrm{CN} /$ silica system. 


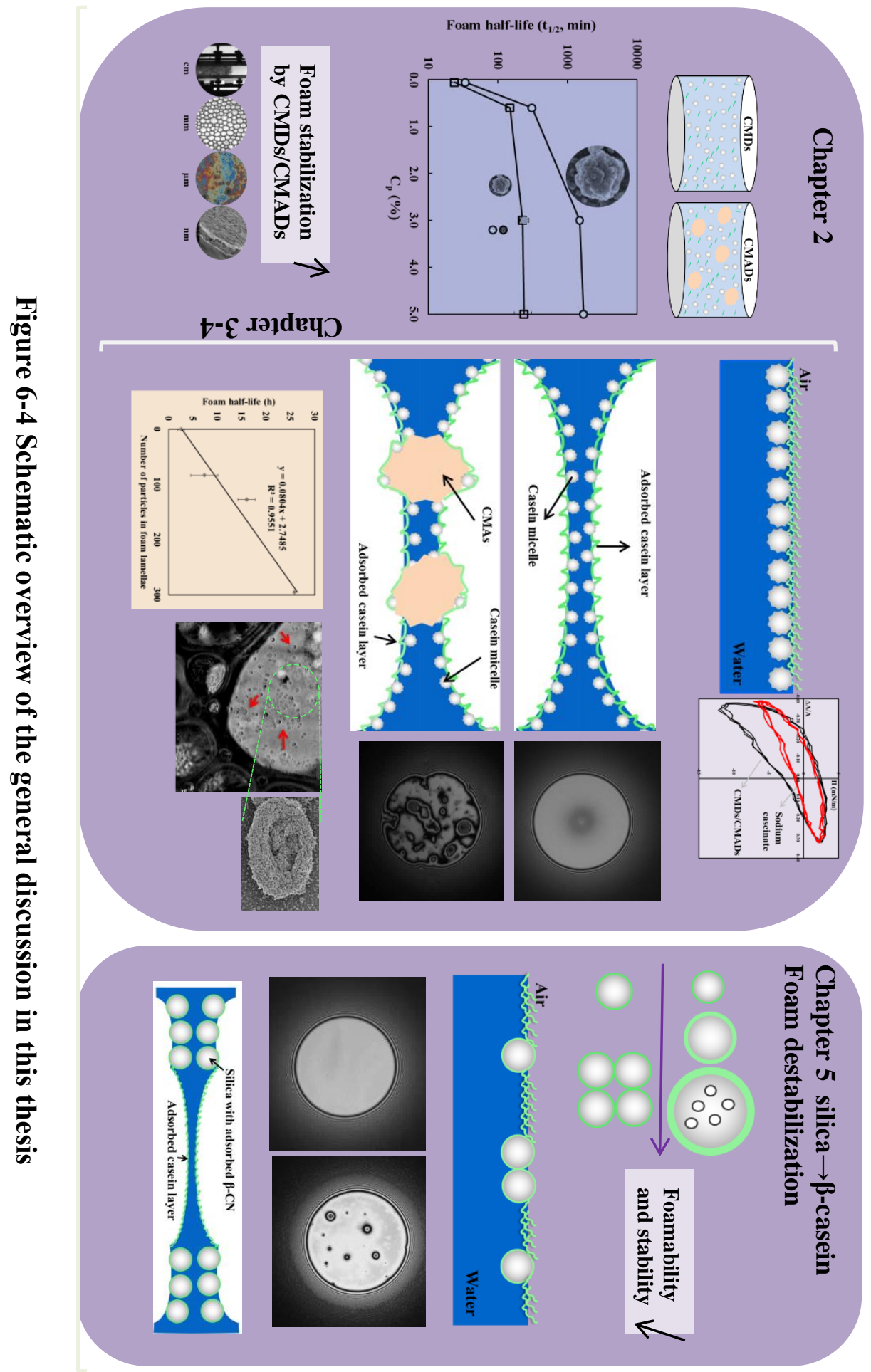




\section{Chapter 6}

\subsection{Main results and discussion}

Figure 6-4 depicts a schematic overview of the general discussion in this thesis. As introduced above, several particle systems are studied, of which the results are described in this thesis: casein micelle dispersions without aggregates (CMDs) and with aggregates (CMADs) (Chapter 2-4), and $\beta$-CN/silica systems (Chapter 5). CMDs and CMADs exhibited foam stabilization whereas addition of silica particles into $\beta-\mathrm{CN}$ solution results in foam destabilization. A comparison is made on the bulk properties, interfacial structure and thin film morphology of the systems and how these properties relate to differences in foaming behaviour.

\subsubsection{Bulk rheology and drainage}

Colloidal properties of casein micelles dispersions depend on the concentration and polydispersity of particles [21, 22]. According to [21], at concentrations below $100 \mathrm{~g} / \mathrm{L}$, CMDs behaved as Newtonian hard-sphere fluids. In our study, the bulk concentration of CMDs and sodium caseinate is smaller than $50 \mathrm{~g} / \mathrm{L}$, the shear viscosity is smaller than 10 mPa.s (Chapter 2-4), and the behaviour is Newtonian. The bulk rheological properties and flow behaviour of silica particles is mainly dependent on the volume fraction of particles in dispersions [23]. In diluted dispersions [24], a solution of silica particles behaves as a Newtonian hard sphere fluid. The maximum concentration in this thesis study used for silica and $\beta-\mathrm{CN}$ (Chapter 5) is $1.5 \%(\mathrm{w} / \mathrm{w})$ and $0.015 \%(\mathrm{w} / \mathrm{w})$, respectively. The shear viscosity of $\beta-\mathrm{CN} / \mathrm{silica}$ systems is measured to be close to the viscosity of water confirming the diluted regime. While Kruglyakov et al. reported [25] that amphiphiles could induce aggregation of particles, resulting in a marked increase in bulk viscosity, this is apparently not the case for our system. High viscosity of the continuous phase could slow down liquid drainage [26]. However, the shear viscosity of two studied systems in this thesis is below $10 \mathrm{mPa} . \mathrm{s}$, and therefore we assume that for our systems there is no large influence of bulk viscosity on foam drainage.

\subsubsection{Influence of physicochemical properties on interfacial structure and thin film morphology}

6.4.2.1 Contact angle \& location of particles

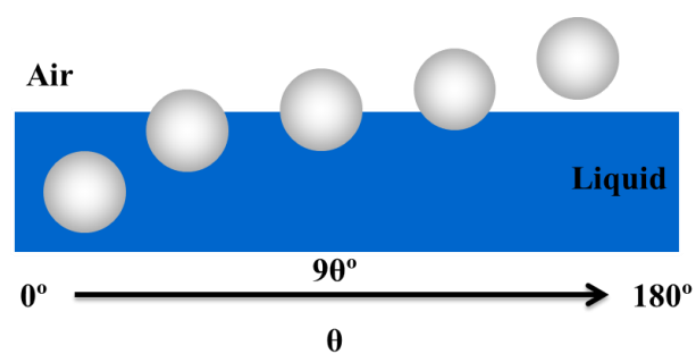


Figure 6-5. Location of particles with increasing contact angle at the air/water interface redrawn after [27]

The contact angle of particles determines the location of particles in foam. As illustrated in Figure 6-5, completely hydrophilic particles do not adsorb at the air/water interface, which is also reported by [28], whereas partially hydrophobic particles can [29]. With increase in particle contact angle, more particle area will be exposed in the air. The particle hydrophobicity could be modified by means of appropriate modification [30-33]. Large CMAs are most probably completely wetted and present in the film. The bare silica particles used in this study are completely hydrophilic with a measured contact angle between particle and water-air interface of about $10^{\circ}$. In a $\beta-\mathrm{CN}$ solution of $0.015 \mathrm{wt} \%$ the contact angle between particle and liquid-air interface is measured to be close to $21^{\circ}$ (Chapter 5) and partially more hydrophobic due to the adsorption of $\beta-\mathrm{CN}$ onto the particle surface.

\subsubsection{Structure of the air/water interface in various systems studied in this thesis}

In this study, interfacial properties are thoroughly investigated for CMDs/CMADs and sodium caseinate (Chapter 3) and the $\beta-\mathrm{CN} /$ silica system (Chapter 5). The main aspects to quantify are the surface composition and mechanical properties of the air/water interface. CMDs mainly contain individual caseins, casein micelles, and possibly a small fraction of casein-derived peptides. The difference in composition of CMDs and CMADs is that CMADs contains CMAs (aggregates of casein micelles). Small surface-active agents diffuse significantly faster than large particles [34]. From the surface rheology results we conclude that a possible structure for the CMDs-stabilized interface could be a heterogeneous structure consisting of patches of peptides and individual caseins. Casein micelles could either be randomly incorporated in this structure or attached to a primary adsorbed layer which contains peptides, caseins and small micelles. The observed strain hardening is due to jamming of these larger structures, which explains the increased cohesion after full compression. Sodium caseinate-stabilized interfaces do not show this strong increase in cohesion upon compression and exhibit a significantly lower resistance against dilation, which indicates a microstructure of the interface quite different from that of an interface stabilized by CMDs. No difference is found between the surface structure of CMDs and CMADs regarding the presence of aggregates, indicating the aggregates are completely wetted and stay in the film and therefore they do not show influence on the interfacial properties, which is in line with other studies [35-37].

For interfaces stabilized by $\beta-\mathrm{CN} /$ silica system, $\beta-\mathrm{CN}$ will be adsorbed at the interface much faster than the silica particles. We showed that $\beta-\mathrm{CN}$ covered silica particles are at the interface, but do hardly interact up to an interfacial strain of 0.3 , so their concentration at the interface is low. Furthermore, the particles at the air/water interface are mobile, and seem to have been transported to the outer region of the thin film due to the film drainage 


\section{Chapter 6}

flow that dragged the particles along. Most probably this results in an inhomogeneous interfacial structure. A slightly increased cohesion after full compression is found for only $\beta-\mathrm{CN}$ solution and the mixture of $\beta-\mathrm{CN}$ with the smaller silica particles. That is probably due to the association and entanglement of $\beta-\mathrm{CN}$ with a sufficient high surface coverage under full compression.

\subsubsection{Morphology of thin liquid films of the systems studied}

The morphology of foam lamellae and thin liquid films of CMDs/CMADs (Chapter 3-4) and of the $\beta-\mathrm{CN} /$ silica system (Chapter 5) is investigated using light interference and transmission. As shown in Figure 6-6, films of CMDs without aggregates are very homogeneous. Local thinning of the film due to drainage is observed in this study, in line with the stepwise stratification of casein submicelles film reported by Koczo et al. (1995) [38]. Films of CMADs appear more heterogeneous, with large CMAs entrapped in the thin film, supporting the result of Rullier et al. [39] and Saint-Jalmes et al. [40]. Only a minor degree of thinning in regions between these aggregates is observed. After homogenization of the samples, aggregates are no longer present in this sample and drainage of casein micelles is observed again. It was found that the individual large CMAs (5-10 $\mu \mathrm{m})$ are evenly distributed in the foam lamellae, and not connected with each other (Chapter 4). The whole film may be seen as effectively divided into many small film elements by these aggregates. As for silica dispersions, particles are completely wetted in the buffer and the whole film is like a water film with salts.
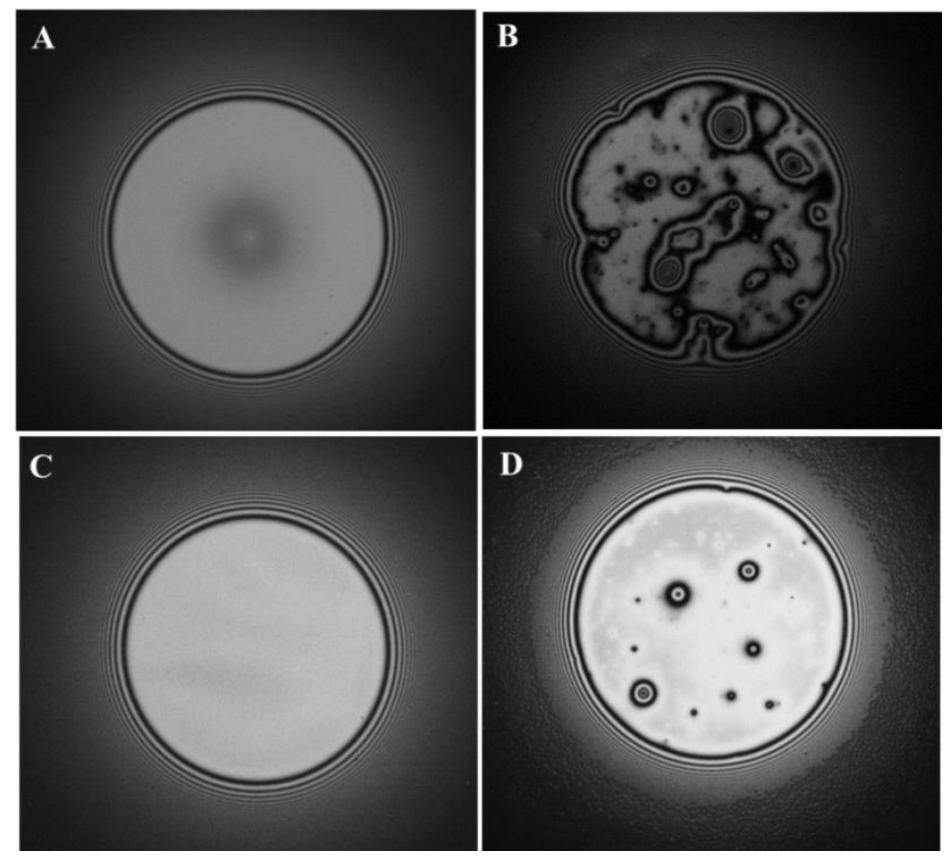
Figure 6-6. Morphology of thin liquid films of (A) CMDs without aggregates (B) CMADs with aggregates (C) Silica in buffer (D) $\beta$-CN/silica (Large: $3 \mu \mathrm{m}$ ). The magnification is 100x with film diameter of $200 \mu \mathrm{m}$.

Thin liquid films of $\beta$-CN/silica system with large silica particles $(3 \mu \mathrm{m})$ exhibit a very different morphology. The silica particles are expelled from the film centre toward its periphery, giving a thin film in the centre that is surrounded by a thick film with a high interfacial concentration of particles, similar as described by Narsimhan et al. (2016) [41]. A schematic drawing is shown in Figure 6-7.

\subsubsection{Comparing foam stabilisation by different particles}

\subsubsection{CMDs with/without CMAs}

A positive relation is found between thin film stability and number of aggregates in the film and foam lamellae (Chapter 4): film stability is proportional to the number of aggregates in the film. As far as we know, this direct relation between number of aggregates present in the foam lamellae and foam stability is discovered for the first time for foams made with protein particles or aggregates. Previously, [40, 42, 43], the presence of aggregates was also ascribed to a high foam stability by means of a slower film drainage, and a gel network formation in the thin liquid films. We note that these conclusions were inferred from an apparent immobility of aggregates on the film surface. In this study, individual aggregate particles are still found to exist separately and we found no evidence for formation a gel network in the lamellae (Chapter 4). Therefore, we think that the improved foam stability in our study (protein concentration, $\mathrm{C}_{\mathrm{p}}<5 \%$ for casein micelle system) is most probably caused by the fact that the originally present aggregates are effectively entrapped within the lamellae. These entrapped particles keep the two air/water interfaces apart and thus stabilize the film. These particles also divide the whole lamellae into small thin films elements. With more aggregates present in the lamellae, the area of these thin film elements gets smaller. According to Vrij [44], a shorter thin film element will lead to smaller critical film thickness for film rupture. As another contributing factor, the wettability of the particles in the thin film can result in an additional force that effectively reduces drainage. In conclusion, it is hypothesized that the presence itself of aggregates/particles in a thin film already can be facilitating film stability and that a network formation is not a prerequisite sine qua non.

\subsubsection{2 $\beta-\mathrm{CN} /$ silica systems}

Foam stability of $\beta-\mathrm{CN} /$ silica dispersions decreases with increasing concentration of the hydrophilic silica particles, contrary to what we initially expected based on the CMA study. For the concentrations used in our study we could attribute this for a large extent to the adsorption of $\beta-\mathrm{CN}$ to the silica particle surface. This caused a decrease in the bulk 


\section{Chapter 6}

concentration of $\beta-\mathrm{CN} /$ silica accordingly. This decreased $\beta-\mathrm{CN}$ concentration lead to a lack of foaming agent that adsorbs quickly to the air/water interface, lowering the stabilization of the newly formed bubbles. Besides the effect of decreased $\beta-\mathrm{CN}$ concentration on foam stability, we observed that the $\beta-\mathrm{CN} /$ silica particles are mobile at the film surfaces, and are transported to the outer region of the thin film, as described by Horozov (2008) [29] and Narsimhan (2016) [41]. The particles are diluted at the interface in the film and cannot resist the hydrodynamic flow inside the film due to thin film drainage and will be dragged away from the film centre into the periphery, thus leaving the inner part of the film unprotected and vulnerable to rupture. This would also have a stabilizing effect with respect to a film without particles because the wetting properties of the particles in the outer ring causes that the pressure difference across the film due to the difference in curvature will be lower than in the case the thick outer ring would not be there. However, the decrease in bulk- $\beta$-casein concentration is dominant causing a decrease in stability. In addition it is hypothesized here that the movement of particles from the central of film to the periphery might break the structure of initially adsorbed interfacial layers, thereby adding to the destabilization of the thin film.

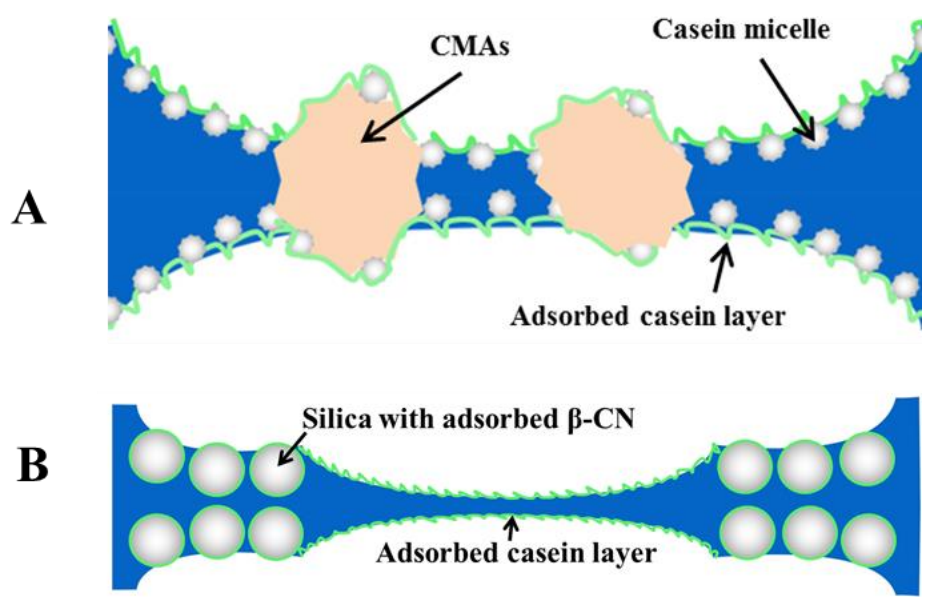

Figure 6-7. Schematic representation of foam film structure for (A) CMADs and (B) $\beta$ $\mathrm{CN} /$ silica 


\subsection{Conclusions and outlook}

Based on the findings reported in this thesis, the role of particles in foams has become clearer. Casein micelle aggregates in model systems of milk seem to be responsible for a stabilisation effect due to their entrapment in foam lamellae, without influencing the interfacial rheological properties of the concomitant air-water interfaces. If only casein micelles are present, this entrapment stabilisation mechanism becomes less important and the stability drops. In $\beta$-casein solutions containing silica particles, which do not form aggregates, the entrapment mechanism for stabilisation does not seem to occur. The particles are attached to or adsorbed at the interface and are dragged toward the outer region of the lamellae due to the drainage flow. The presence of the particles at the outer side of the lamellae would add to the stability of the film because of a reduced pressure difference across the film. In contrast, a decrease in foam stability is observed upon increasing silica concentration, which we however would ascribe to a decrease in $\beta$-casein bulk concentration due to the adsorption to the silica interface.

The findings on the extra stabilisation mechanism by entrapment of larger particles in the case of casein micelle aggregate dispersions can be used by manufacturers while producing foams, mousses, etc.. In particular when these processes take place close to $0^{\circ} \mathrm{C}$, incorporation of casein micelle aggregates as obtained from a separate processing line can lead to high foam stability that will act as long as the product remains at low temperature. Alternatively, when high foam stability is only needed for a couple of hours, one may consider using a micelle aggregate dispersion kept at low temperature to make the aerated product. This product is likely to remain stable for the period of time that the aggregates remain, i.e. a couple of hours. If the product is consumed before that time the advantages of the high stability due to the presence of the micelle aggregates can still be used. This may be mostly applicable to culinary applications.

To better understand the role of particles in foams of complex systems, we recommend that more species of better defined particles with more controlled variables (particularly surface properties and shape) should be applied for further foam study. Complexity of the mixed system could be increased by either a wider concentration regime, or more varying ratio between different components in the system. More insights are needed to better control and apply particles and aggregates in foam stabilisation of complex mixtures. For instance, the incorporation of gas bubbles as a full or partial replacement for dispersed fat particles can be very helpful in the design of healthier food products which is also a matter of great technological and commercial significance. Particles prepared from natural resources are recommended, since they are sustainable and biocompatible. Recently particles including hydrogel protein particle, capsules, protein aggregates and polymer fibres etc. have received considerable attention [45-49], which could be promising in application of foods and drug delivery mediums. These particles would greatly extend the types of particles that 


\section{Chapter 6}

can influence the thin film properties which are so important to the foam stabilisation mechanisms. 


\section{References}

1. Krisdhasima, V., Vinaraphong, P. and McGuire, J., Adsorption Kinetics and Elutability of $\alpha$ Lactalbumin, $\beta$-Casein, $\beta$-Lactoglobulin, and Bovine Serum Albumin at Hydrophobic and Hydrophilic Interfaces. Journal of Colloid and Interface Science, 1993. 161(2): p. 325-334.

2. Kühnl, W., et al., Impact of colloidal interactions on the flux in cross-flow microfiltration of milk at different pH values: a surface energy approach. Journal of Membrane Science, 2010. 352(1): p. $107-$ 115 .

3. Britten, M., Boulet, M. and Paquin, P., Estimation of casein micelles' surface energy by means of contact angle measurements. Journal of Dairy Science, 1989. 56: p. 223-234.

4. De Kruif, C. and Holt, C., Casein micelle structure, functions and interactions. Advanced Dairy Chemistry-1 Proteins. 2003, p. 233-276. Springer US.

5. Ellis, K.J., Morrison, J.F. and Daniel, L.P. [23] Buffers of constant ionic strength for studying pHdependent processes. Methods in Enzymology, 1982p. 405-426.

6. Jenness, R. and Koops, J., Preparation and properties of a salt solution which simulates milk ultrafiltrate. The Netherlands Milt und Dairy Journal, 1962. 16(3): 153-164.

7. Javadi, A., et al., Fast dynamic interfacial tension measurements and dilational rheology of interfacial layers by using the capillary pressure technique. Colloids and Surfaces A: Physicochemical and Engineering Aspects, 2012. 407: p. 159-168.

8. Ganzevles, R.A., Protein/polysaccharide complexes at air/water interfaces. 2007, Wageningen University: Wageningen.

9. Binks, B.P., Particles as surfactants-similarities and differences. Current Opinion in Colloid \& Interface Science, 2002. 7(1): p. 21-41.

10. Chang, C. H. and Franses, E.I., Adsorption dynamics of surfactants at the air/water interface: a critical review of mathematical models, data, and mechanisms. Colloids and Surfaces A: Physicochemical and Engineering Aspects, 1995. 100: p. 1-45.

11. Richards, T., Interfacial rheology: principle, applications, and instrumentation. American laboratory, 33(13), 38-39.

12. Sagis, L.M., Dynamic properties of interfaces in soft matter: Experiments and theory. Reviews of Modern Physics, 2011. 83(4): p. 1367.

13. Sagis, L., Generalized surface momentum balances for the analysis of surface dilatational data. The European Physical Journal Special Topics, 2013. 222(1): p. 31-38.

14. Kazakov, V.N., et al., Dilational rheology of serum albumin and blood serum solutions as studied by oscillating drop tensiometry. Colloids and Surfaces B: Biointerfaces, 2008. 62(1): p. 77-82.

15. Sagis, L., Humblet-Hua, K. and van Kempen, S., Nonlinear stress deformation behavior of interfaces stabilized by food-based ingredients. Journal of Physics: Condensed Matter, 2014. 26(46): p. 464105.

16. Wasan, D. and Nikolov, A., Thin liquid films containing micelles or nanoparticles. Current Opinion in Colloid and Interface Science, 2008. 13(3): p. 128-133.

17. Gochev, G., Thin liquid films stabilized by polymers and polymer/surfactant mixtures. Current Opinion in Colloid and Interface Science, 2015. 20(2): p. 115-123.

18. Morris, G., Hadler, K. and Cilliers, J., Particles in thin liquid films and at interfaces. Current Opinion in Colloid and Interface Science, 2015. 20(2): p. 98-104.

19. Huppertz, T., Foaming Properties of Milk: A Review of the Influence of Composition and Processing. International Journal of Dairy Technology, 2010. 63(4): p. 477-488.

20. Silva, S., et al., Formation and stability of milk foams, Bubbles in food, 2008. 2: p. 153-161.

21. Bouchoux, A., et al., Rheology and phase behavior of dense casein micelle dispersions. The Journal of chemical physics, 2009. 131(16): p. 165106.

22. Krishnankutty Nair, P., et al., Physico-chemical properties of casein micelles in unheated skim milk concentrated by osmotic stressing: Interactions and changes in the composition of the serum phase. Food Hydrocolloids, 2014. 34(0): p. 46-53.

23. de Kruif, C.d., et al., Hard sphere colloidal dispersions: Viscosity as a function of shear rate and volume fraction. The Journal of chemical physics, 1985. 83(9): p. 4717-4725. 


\section{Chapter 6}

24. Lee, J.D., So, J.H. and Yang, S.M., Rheological behavior and stability of concentrated silica suspensions. Journal of Rheology, 1999. 43(5): p. 1117-1140.

25. Kruglyakov, P.M., Elaneva, S.I. and Vilkova, N.G., About mechanism of foam stabilization by solid particles. Advances in colloid and interface science, 2011. 165(2): p. 108-116.

26. Dickinson, E., et al., Adsorption at interfaces in dairy systems*. International Journal of Dairy Technology, 1989. 42(1): p. 18-22.

27. Maestro, A., et al., Contact angle of micro-and nanoparticles at fluid interfaces. Current Opinion in Colloid \& Interface Science, 2014. 19(4): p. 355-367.

28. Vivaldini, D.O., et al., Why foams containing colloidal hydrophilic particles are unstable? Ceramics International, 2013. 39(5): p. 6005-6008.

29. Horozov, T.S., Foams and foam films stabilised by solid particles. Current Opinion in Colloid \& Interface Science, 2008. 13(3): p. 134-140.

30. Binks, B.P. and Horozov, T.S., Aqueous foams stabilized solely by silica nanoparticles. Angewandte Chemie, 2005. 117(24): p. 3788-3791.

31. Safouane, M., Langevin, D. and Binks, B., Effect of particle hydrophobicity on the properties of silica particle layers at the air-water interface. Langmuir, 2007. 23(23): p. 11546-11553.

32. Dickinson, E., et al., Factors controlling the formation and stability of air bubbles stabilized by partially hydrophobic silica nanoparticles. Langmuir, 2004. 20(20): p. 8517-8525.

33. Binks, B.P., et al., Dispersion Behavior and Aqueous Foams in Mixtures of a Vesicle-Forming Surfactant and Edible Nanoparticles. Langmuir, 2015. 31(10): p. 2967-2978.

34. Bos, M.A. and van Vliet, T., Interfacial rheological properties of adsorbed protein layers and surfactants: a review. Advances in Colloid and Interface Science, 2001. 91(3): p. 437-471.

35. Bals, A. and Kulozik, U., Effect of pre-heating on the foaming properties of whey protein isolate using a membrane foaming apparatus. International Dairy Journal, 2003. 13(11): p. 903-908.

36. Davis, J.P. and Foegeding, E.A., Foaming and Interfacial Properties of Polymerized Whey Protein Isolate. Journal of Food Science, 2004. 69(5): p. C404-C410.

37. Wierenga, P.A., van Norél, L. and Basheva, E.S., Reconsidering the importance of interfacial properties in foam stability. Colloids and Surfaces A: Physicochemical and Engineering Aspects, 2009. 344(1-3): p. 72-78.

38. Koczo, K., et al., Layering of Sodium Caseinate Submicelles in Thin Liquid Films - A New Stability Mechanism for Food Dispersions. Journal of Colloid and Interface Science, 1996. 178(2): p. 694-702.

39. Rullier, B., et al., $\beta$-Lactoglobulin aggregates in foam films: Effect of the concentration and size of the protein aggregates. Journal of Colloid and Interface Science, 2010. 343(1): p. 330-337.

40. Saint-Jalmes, A., et al., Differences between protein and surfactant foams: microscopic properties, stability and coarsening. Colloids and Surfaces A: Physicochemical and Engineering Aspects, 2005. 263(1): p. 219-225.

41. Narsimhan, G., Drainage of particle stabilized foam film. Colloids and Surfaces A: Physicochemical and Engineering Aspects, 2016. 495: p. 20-29.

42. Rullier, B., et al., $\beta$-Lactoglobulin aggregates in foam films: Correlation between foam films and foaming properties. Journal of Colloid and Interface Science, 2009. 336(2): p. 750-755.

43. Rullier, B., et al., $\beta$-Lactoglobulin aggregates in foam films: Effect of the concentration and size of the protein aggregates. Journal of colloid and interface science, 2010. 343(1): p. 330-337.

44. Vrij, A., Possible mechanism for the spontaneous rupture of thin, free liquid films. Discussions of the Faraday Society, 1966. 42: p. 23-33.

45. Fameau, A.L. and Salonen, A. Effect of particles and aggregated structures on the foam stability and aging. Comptes Rendus Physique, 2014. 15(8-9): p. 748-760.

46. Lam, S., Velikov, K.P. and Velev, O.D., Pickering stabilization of foams and emulsions with particles of biological origin. Current Opinion in Colloid and Interface Science, 2014. 19(5): p. 490-500.

47. Dickinson, E., Structuring of colloidal particles at interfaces and the relationship to food emulsion and foam stability. Journal of Colloid and Interface Science, 2015. 449: p. 38-45. 
48. Morales, R., et al., Modification of foaming properties of soy protein isolate by high ultrasound intensity: Particle size effect. Ultrasonics Sonochemistry, 2015. 26: p. 48-55.

49. Rodríguez, S.D., von Staszewski, M. and Pilosof, A.M.R., Green tea polyphenols-whey proteins nanoparticles: Bulk, interfacial and foaming behavior. Food Hydrocolloids, 2015. 50: p. 108-115. 
Summary 


\section{Summary}

This thesis describes the foaming behaviour of casein micelle systems (Chapter 2-4) and a $\beta$-casein/silica system (Chapter 5) at different length scales. In the following, the term casein micelle dispersions (CMDs) refer to all dispersions without aggregates of casein micelles. Furthermore, casein micelle aggregates are abbreviated as CMAs. The CMDs that do contain casein micelle aggregates are referred to as CMADs. If we refer to a single dispersion, of any kind, we use the abbreviations CMD or CMAD.

We examined the role of composition and particle size in foaming properties of CMDs compared to that of skim milk. These studies are described in Chapter 2. CMDs with different composition and particle sizes were obtained by dispersing casein pellets at different temperatures in milk permeate. CMDs yielded an average particle size of around $200 \mathrm{~nm}$ and CMADs yielded an average particle size of $500 \mathrm{~nm}$. The foam half-life, $t_{1 / 2}$, was increased from $4 \mathrm{~h}$ for CMDs to $24 \mathrm{~h}$ for CMADs, at the same protein concentration. This difference could be ascribed to the average size of the colloidal particles present in dispersions due to the fact that the foam half-life of CMADs decreased back to that of CMDs when the aggregates were broken down by homogenization. To elucidate the underlying mechanism, the role of interfacial and thin film properties in foam stabilization by CMDs/CMADs were investigated (Chapter 3). The dilatational properties of air/water interfaces stabilized by CMD or CMAD and their supernatants were determined under large amplitude oscillatory dilatation as a function of frequency and deformation amplitude and were compared with that of sodium caseinate. The elastic modulus of the interface stabilized with CMAD was twice that of CMD, at $0.005 \mathrm{~Hz}$, which indicates a difference in interfacial composition. The CMD-stabilized interfaces exhibited an increased cohesion after full compression compared to the sodium caseinate stabilized interfaces. The differences in interfacial properties could not fully explain the differences in foam stability. Also there were differences in thin film behaviour for example. Thin films stabilized with CMDs were more homogeneous and had a much shorter rupture time compared to those of CMADs. After homogenization of CMADs, i.e. breaking down the aggregates, effectively changing the CMADs to CMDs, the resulting thin films became much more homogeneous again, and both the rupture time of thin films and foam stability decreased significantly. A strong relation was found between thin film stability (of diluted CMADs and CMDs), and foam stability (of CMADs and CMDs).

In Chapter 4, the mechanism is addressed of ultra-stabilization of foams containing large CMAs of a size of about 5-10 $\mu \mathrm{m}$. The size of the CMAs was tuned by varying the milling time of casein micelle pellets. Microscopic visualization indicated that the large aggregates were randomly distributed in the thin films and had not moved to the outer periphery of the thin film. This may be due to the immobile character of the adsorbed casein interfaces with casein micelles attached in the sub phase. Nonetheless, the number of aggregates in the 
foam lamella increased with increasing concentration of aggregates in the initial solution before foaming. Most interestingly, the more aggregates in the initial solution (and thus in the lamellae), the longer the foam remained stable. We found no evidence that the improved foam stability was due to the formation of a gel network in the film (at a protein concentration of $2 \%, \mathrm{w} / \mathrm{w}$ ). The relation between foam stability and number of aggregates present in the thin film without forming a gel network is further supported by thin film stability studies on the according diluted systems. We suggest to ascribe the film and foam stabilization by CMAs to the fact that they are effectively entrapped in the film without being part of a gelled network. The aggregates keep the two air/water interfaces well apart and markedly delay film drainage. The mechanism may be related to the fact that CMAs effectively divide the entire film into smaller elements, i.e. effectively decreasing the critical film thickness for rupture.

To better understand the role of particles in foaming behavior, the effect of particle size and concentration on foam properties of $\beta$-casein/silica ( $\beta$-CN/silica) mixtures was investigated, and described in Chapter 5. Hydrophilic Silica particles of different size (Small: $200 \mathrm{~nm}$; Medium: $1 \mu \mathrm{m}$ and Large: $3 \mu \mathrm{m})$ were added to a $\beta$-CN solution $(0.015 \%$, w/w), at varying ratios. Both foamability and foam stability of the $\beta-\mathrm{CN} /$ silica mixtures decreased with increasing size and concentration of the silica particles. The attachment of $\beta-\mathrm{CN}$ to silica affected the contact angle of silica particles. No correlation was found between foam stability and surface dilatational modulus. Foamability could be correlated to the surface pressure. The morphology of films of $\beta-\mathrm{CN} /$ silica dispersions showed that a central dimple was surrounded by particles being pushed to the outer periphery of the film. This resulted in an inner film and an outer film. Both the rupture time and thickness of thin films (inner film) decreased with increasing particle concentration in the mixture. This destabilizing effect was ascribed to the decreased bulk concentration of $\beta-\mathrm{CN}$ in mixed systems and a high mobility of particles. 


\section{Acknowledgments}

Doing a $\mathrm{PhD}$ is far more than only doing research. I could not describe it better than a short bloody unique journey full of different flavours. I tasted it, swallowed it, and digested it. Looking back, I appreciate it, in the meantime, I would like to express my sincere gratitude to all the people involved in this process.

First, I would like to give my most sincere gratitude to all my five supervisors. I would like to thank one of my promoters Prof. Erik van der Linden, the leader of my supervisor-group and the chair of Physics and Physical Chemistry of Foods. As a mentor, he tries to think from my side and guides me be aware of the crucial moments to make critical decisions through my PhD study. Besides, it's so kind of him to offer me an extension contract. Many thanks go to my co-promoter Dr. Marcel. Meinders for his solid expertise and contribution to this thesis. He brought me into foam research, sent me to courses, workshops and conferences. His response to my papers was very efficient and critical with a lot of constructive comments and suggestions. He sometimes also let me survive by myself and be more independent. I could have not finished my thesis in a good quality without his contribution. A lot of thanks go to Dr. Guido Sala, everytime I want to discuss something that I can approach him easily. He was very nice and patient in listening. He understands much better with the practical problems that I had in my research and many times introduced me to the right experts. Besides, my second promoter Prof. Toon C.M. van Hooijdonk, the expert of Dairy Science, has also contributed a lot to my $\mathrm{PhD}$ research. $\mathrm{He}$ tried to provide me feedback on how to improve my papers and thesis. His passion and contribution to the progress of dairy science and technology is greatly admired. The last but not the least, Ir. Hein van Valenberg, he is the first contact person before I came to Wageningen. Thanks for picking me up from the airport right after I arrived in the Netherlands. Special thanks go to Dr. Leonard M.C. Sagis, although officially he is not my supervisor, but I've learnt a lot from him about interfaces studies. Many times when I had a scientific question, he has always been very patient and gave a very clear explanation. My $\mathrm{PhD}$ study was partially founded by a CSC scholarship from China. I would like to sincerely acknowledge the support from Chinese Scholarship Council and China Agriculture University. I would not be granted with a Doctor's title without the evaluation from my thesis committee members. Special thanks go to Prof. Dr. P. Fischer from ETH Zurich and Prof. Dr. A. Kelly from University College Cork, Prof. Dr. J van der Gucht and Dr. P.A. Wierenga from Wageningen University. Thanks a lot for their efforts in reading my thesis and travelling all the way to my defence.

Many thanks go to Els, the secretary of Physics and Physical Chemistry of Foods. Els was so kind and helpful. I would like to thank Harry and Miranda for their great support in the lab of Physics and Physical Chemistry of Foods. Besides, I would like to thank Frans and Xandra who helped me when I worked in the lab of Food Quality and design. Thanks Tiny for

the

SEM experiments. 


\section{Acknowledgments}

I would like to acknowledge all the collaboration involved in the TIFN Foam project. Specially, the laboratory of Food Chemistry where the foamscan and thin film equipment are located. Frederik, I cannot remember how many times that I went to you with questions regarding the equipment. Thank you very much for sharing your knowledge and solving all kinds of problems together with me. Christian, thanks for your openness and nice chats, thanks for giving me a lift to the fantastic foam course in Paris. Hans, Erik, Tijs and Ruud, thank you very much for the lively discussions and the critical suggestions. Kees and Arnoud, thank you for preparing the milk permeate powder for my research. Franklin thanks for the milk powder from NIZO. It's a pleasure to work with all of you.

Part of my thesis was contributed by my students: Cherisa, Rianne, Yuezi, Saskia, Xue and Marit. All their hard work is greatly acknowledged. It was a nice experience to work with them and I wish all of them a bright future.

I would like also to express my sincere amplitude to all colleagues and friends from Food Physics and Physical Chemistry of Foods and Food Quality and Design. There are a lot of unforgettable moments during the past four years. When I arrived in the Netherlands in 2012, I was more associated with the Dairy group. Etske Bijl, Elsa Antunes Fernandes, Jing Lu, Dylan Tzompa Sosa, Fahui Liu, Lina Zhang, Chunyue Zhang, Kasper Hettinga and Ruben de Vires, I really enjoyed the discussion with you during the regular DST meeting. Thanks for all your help. The great hiking weekend in Monschau and visit to the chocolate factory we had together will always stay in my mind. Dylan, the "Wadenlopen" day was tough but also cheerful, we survived together with Lina, Ita and Alfred after walking for 11 km. Liya, Lina, Rian, Jialu and Yuzheng, it was a great time with you in the sports centre. Jing Yan, Ningjing Liu, Marine, Sara, Geraldine, Grace, Mary Luz, Irmela, Radhika and Klementina, I will keep the warm memories of the lab trips and all the hot-pot, Christmas dinners and coffee breaks we had together. It was a great pleasure to have you around.

I feel so lucky to be involved in two groups that I get to know a lot more colleagues. From the second year of my study, most part of my PhD I spent was in Food Physics and Physical Chemistry of Foods group. Of course, there were also many cheerful moments that I shared with my Physics colleagues. I really enjoyed the fantastic $\mathrm{PhD}$ trip in US and Canada with Munialo Claire, Carsten Ersch, Auke de Vires, Tijs Rovers, Vaida Urbonaite Kun Liu, Anika Oppermann and many others. All the nice presentations, discussions and visits to different universities and companies were an incredible precious experience. The Otterlo group meeting was also impressive with lots of discussions, nice food and games. Zhili Wan and Yuan Zou, it was a great pleasure to have you around during the last two years of my PhD. Thanks for your openness in discussions on both science and life. Special thanks go to Zhili, thank you for faithfully listening to me when I need support. Philipp Fuhrmann, Monica Aguaya Mendoza and Auke de Vires, thank you for the nice chats which gave me a lot of inspirations on my propositions. Elke Scholten, it was nice to have you around teasing me once in a while although that was not always funny. However, the "Efteling" day was really great, a lot of fun with many others. Thanks for organizing it. 
Belinda Dewi, thank you for your nice words and support during my intensive thesis writing. Leen Sturtewagen and Claudine Diedericks, it was a very nice evening with you in Amsterdam during the light festival. Vaida Urbonaite, Maria Tzoumaki, Laura Oliver Hernandez, Jissy Jose and Anja Oechsle, it was very nice to have you in the group, thank you for your openness and friendliness, also for sharing your learning and working experience. Elisabete Silva, Yuan Zou, Alve Ince, Pauline van Leusden and Jacob Bouman, I am very happy to share the office with you. Besides, I would like to thank also many other colleagues, Paul Venema, Lenka Tonneijck-Srpova, Marco Santagiuliana and Arianne van Eck, May, Pouvreau Laurice, Harmen de Jongh and Anneke Martin. It was very nice to work with you.

Many thanks go to my paranymphs: Philipp Fuhrmann and Chunyue Zhang. Philipp, it was such a pleasure to have you around, thanks a lot for your kindness and help, all the best with your research and you are very welcome to visit me in China. Chunyue, it has been very nice to have you as both a colleague and friend, especially sitting by my side in the final defence. I will always keep the beautiful memories we had together, all kinds of dinners, Karaoke party, Walibi-day and the Waltz dancing course...... Special thanks go to Fahui Liu, for designing thesis cover for me.

Thanks many other nice friends and colleagues in food science being around, Lingmin, Fangjie, Bin, Yongfu, Ya, Yuxi, Red, Zhaojun, qiu, Qi, thanks for the time we had together.

Dear Yujie (He), it has been always so nice to have you around. Thanks for sharing the vegetables you grow by yourself, celebrating my birthdays, doing sports and travelling together with me, as well as gently offering me your room whenever I want to sing Karaoke, many nice dinners and constant support I cannot list here...... Thank you! Yuanyuan (Zhang), Guiling (Ren), we came to Wageningen together, I feel very lucky to have you in my life.

You, thank you for your deep love and constant support during my study in the Netherlands. Your efforts in keeping our relationship are greatly appreciated! Thank you for bringing me surprises and visiting me abroad with my favourite snacks. It is always fantastic to learn poem from you. It is a great fortune to have you love me.

The last but not the least, I would like to give my greatest amplitude to my dear family: 亲 爱的爸爸妈妈, 谢谢你们用最无私的爱温暖我, 引导我, 鼓励我! 教会我为人真诚善 良, 懂得包容谦让, 慎于言敏于行, 知进退识大体, 倾心付出, 感恩收获, 不争不 妒, 自立自强, 但求问心无愧, 做温暖有用的人。还有我最亲爱的老果, 谢谢来自 你无微不至的疼爱, 永远爱你们! 


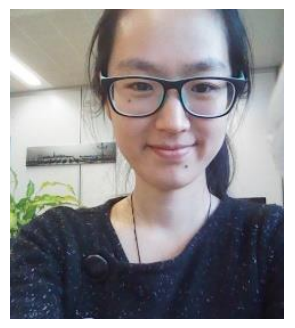

\section{Curriculum Vitae}

Min Chen was born on August $9^{\text {th }}, 1987$ in Shandong in China. In 2005, she started her study in biology in Shandong Normal University. After one year, she moved to specialization of Food Science and acquired a Bachelor degree in Food Science in 2009. In the same year, she started a Master degree program in Food Science in College of Food Science and Nutritional Engineering of China Agricultural University. Her master project was about digestibility of antioxidant peptides. In the meantime, she worked as a master-management assistant in the same group for one year. After obtaining her MSc degree in 2012, she was granted with a CSC scholarship and started to work as a $\mathrm{PhD}$ candidate in Physics and Physical chemistry of Foods (FPH) and Dairy Science and Technology (DST) in Wageningen UR. Her PhD project was "The role of casein micelles and their aggregates in foam stabilization" which was financed by TI Food and Nutrition. She will defend her PhD thesis on December $12^{\text {th }}$ 2016. The results of her research are presented in this thesis. Contact email: minc0715@gmail.com. 


\section{List of publications}

M. Chen, G. Sala, M.B.J. Meinders, H.J.F. van Valenberg, A.C.M. van Hooijdonk, E. van der Linden. (2017). The influence of silica particle size and concentration on foams of betacasein and silica mixtures. (Submitted)

M. Chen, S. Feijen, G. Sala, M.B.J. Meinders, H.J.F. van Valenberg, A.C.M. van Hooijdonk, E. van der Linden. (2017). Mechanism of ultra-stabilization of foam by casein micelle aggregates. (Submitted)

M. Chen, G. Sala, M.B.J. Meinders, H.J.F. van Valenberg, E. van der Linden, L.M.C. Sagis. (2017) Interfacial properties, thin film stability and foam stability of casein micelle dispersions. Colloids and Surfaces B: Biointerfaces 149: 56-63.

Chen, M., Bleeker, R., Sala, G., Meinders, M. B. J., van Valenberg, H. J. F., van Hooijdonk, A. C. M., \& van der Linden, E. (2016). Particle size determines foam stability of casein micelle dispersions. International Dairy Journal, 56, 151-158.

Chen, M., \& Li, B. (2012). The effect of molecular weights on the survivability of caseinderived antioxidant peptides after the simulated gastrointestinal digestion. Innovative Food Science \& Emerging Technologies, 16, 341-348. 


\section{Overview of completed training activities}

\section{Discipline specific activities}

\section{Courses and Workshops}

- $\quad$ Bubbles and Foams joint workshop (FPE-FPH-PCC). Wageningen, NL, 2015

- Soft matter at aqueous interface. Berlin, DE, 2014

- Structure and dynamics of liquid foams and their applications. Paris, FR, 2013

- Workshop on Foam Coarsening. Paris, FR, 2013

\section{Conferences and Symposium}

- (Oral presentation) The $16^{\text {th }}$ Food colloids. Wageningen, NL, 2016

- (Oral presentation) The $7^{\text {th }}$ International Symposium on Food Rheology and Structure - ISFRS. Zurich, CH, 2015

- (Poster) $15^{\text {th }}$ Food Colloids Conference. Karlsruhe, DE, 2014

- $\quad$ Structure design in emulsions and foams. Wageningen, NL, 2012

\section{General courses}

- Career Perspectives (CCP). Wageningen, NL, 2016

- $\quad$ Scientific Writing. Wageningen, NL, 2014

- $\quad$ Applied Statistics. Wageningen, NL, 2014

- Techniques for Writing and Presenting a Scientific Paper. Wageningen, NL, 2013

- Project and Time Management. Wageningen, NL, 2013

- $\quad$ PhD week. Wageningen, NL, 2012

\section{Additional activities}

- $\quad$ Organize and participate in PhD trip in US and Canada, 2014. Oral presentation in University of Massachusetts Amherst, Rutgers University and University of Guelph.

- $\quad$ Science meeting of FPH, weekly

- Dairy science and technology meeting, biweekly

- Foam Project (TIFN FS003) meeting, biweekly

- $\quad$ Annual TIFN meeting 
The research described in this thesis was financially supported by Top Institute Food \& Nutrition and Chinese scholarship council.

Financial support from Wageningen University and Top Institute Food \& Nutrition for printing this thesis is gratefully acknowledged.

Cover design: Fahui Liu, PhD candidate in Wageningen University.

This thesis was printed by GilderPrint, Enschede, The Netherlands.

Min Chen, 2016 


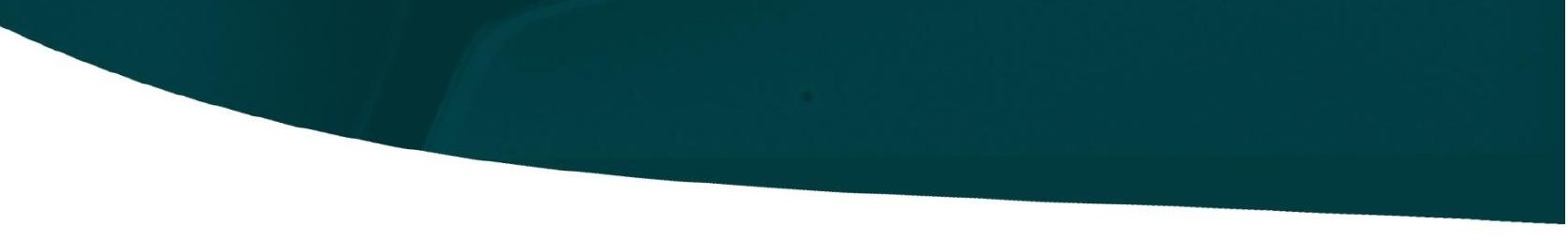

